\title{
New Nitrogenous Spongian Diterpenes from the New Zealand Marine Sponge Darwinella oxeata
}

\author{
by \\ Katie Orlagh Dowle

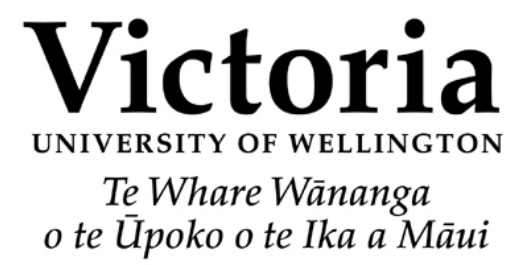

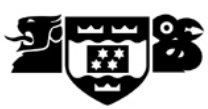

\author{
A thesis \\ submitted to Victoria University of Wellington \\ in fulfilment of the \\ requirements for the degree of \\ Masters by thesis \\ in Chemistry.
}

Victoria University of Wellington

2008 


\section{Dummy Abstract}

This page was not accidentally left blank. 


\section{To my grandpa, Dr Richard McCorry}

"He was a noble man, a treasured companion, and a great role model."*

${ }^{*}$ Trimble, E.; Archbold, P. Br. Med. J. 2007, 335, 405. 


\section{Acknowledgements}

I would firstly like to thank my supervisor Peter Northcote for his support and his invaluable advice (and for taking me on an amazing dive trip). I am in awe of your ability to suggest structures based on the ${ }^{1} \mathrm{H}$ spectrum NMR alone.

I was lucky enough to have shared the lab with Joanna Wojnar and Wendy Popplewell during their time as $\mathrm{PhD}$ students. They have patiently served many different roles: stand in supervisors, colleagues, NMR experts, and lately $\mathrm{LATEX}_{\mathrm{E}}$ tutors, but most importantly they have both been amazing friends. I cannot bare to imagine how hard it would have been without you guys and am going to miss you both dreadfully when you leave.

It has also been a pleasure to work with Jonathan Singh and John Ryan. Jono, you did an awesome-O job of putting up with my occasional foot-stamping in the lab, thanks. John, you have been an immense help during my time at Vic. Thank you for sharing your NMR knowledge (and "your NMR") and for your help with LATEX - I am converted. Thanks also to Mike Page, I really enjoyed working with you, allbeit for such a brief time.

SCPS is a special department full of so many fantastic and incredibly helpful people - I would like to especially acknowledge Darren, Sally, Lisa, Rhys, Alan and Manu as well as Joanne Harvey and Brendan Burkett and the great bunch of grad students. Ariane Chan in SBS also needs to be mentioned for her brilliant job running assays on the oxeatamides. I am very grateful to SCPS for the funding I received in 2007. Thanks for the Curtis-Gordon Research Scholarship and the Marine Natural Products Masters Scholarship, without this assistance this would not have been possible.

Many people have helped me with the editing of this thesis. Thanks must go to Mina, Mum, Rob, Jono, Wendy and especially to Jo. I hope you didn't despair too much.

Thank you to all my "outside" friends who have put up with me during this time. I would not have gotten through this with out the coffees, walks, swims, drinks and dinner. Anna, I could not have asked for a better best friend.

Last but not least, my family (Mum, Dad, Sonja, Claire, Pat and Em) have been wonderful - thanks for the dinners, thanks for listening, thanks for the distractions (and thanks for the financial support) - I hope I can repay you all in kind someday. 
Abstract

Dedication iii

Acknowledgements iv

Table of Contents $\quad$ v

List of Figures viii

$\begin{array}{ll}\text { List of Schemes } & \mathbf{x}\end{array}$

List of Tables $\quad$ xi

Glossary

1 Introduction 1

1.1 Natural Products . . . . . . . . . . . . . . . . . . . . 1

1.2 Marine Natural Products . . . . . . . . . . . . . . . . . . 2

1.3 Marine Sponges . . . . . . . . . . . . . . . . . . . . 3

1.4 Discovery of New Natural Products at VUW . . . . . . . . . . . . 7

1.4.1 Cyclic Loading . . . . . . . . . . . . . . . 7

1.4.2 NMR Based Screening . . . . . . . . . . . . . . 9

1.4.3 Sponges Examined in this Research . . . . . . . . . . . . . 12

2 Sponges Examined by Spectroscopic Screening 13

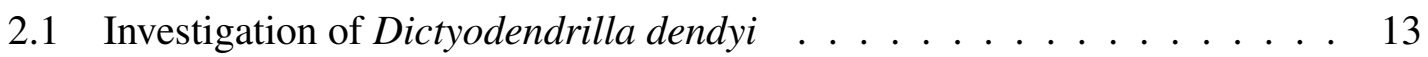

2.2 Investigation of Raspailia topsenti . . . . . . . . . . . . . . . . . 15

2.3 Investigation of Two Unidentified Sponge Species . . . . . . . . . . . . . 17 
$3.1 \quad$ Darwinella oxeata . . . . . . . . . . . . . . . . . . . . 19

3.2 Chemical Ecology of Darwinella oxeata . . . . . . . . . . . . . . . 21

3.2.1 Isolation of New Nitrogenous Aplysulphuranes from Darwinella oxeata . . . . . . . . . . . . . . . 22

3.3 Known Compounds Isolated from Darwinella oxeata . . . . . . . . . . . 26

3.3.1 Oxeatamide A, B and Iso-oxeatamide A . . . . . . . . . 26

3.3.2 Membranolide C and D . . . . . . . . . . . . 26

3.4 New Oxeatamides Isolated . . . . . . . . . . . . . . . . . . . 27

3.4 .1 Oxeatamide D . . . . . . . . . . . . . 28

3.4.2 Relative Configuration of Oxeatamide D . . . . . . . . . . 36

3.4 .3 Oxeatamide E . . . . . . . . . . . . . . . 40

3.4 .4 Oxeatamide F . . . . . . . . . . . . 46

3.4 .5 Oxeatamide $\mathrm{G} \ldots \ldots \ldots \ldots$

3.4.6 Methylation of Oxeatamide $\mathrm{G} \ldots \ldots . \ldots 54$

3.4 .7 Oxeatamide C . . . . . . . . . . . . . . 55

3.4.8 Biological activity of oxeatamides . . . . . . . . . 58

3.4 .9 Summary ......................... 58

3.5 Spongian Diterpenoids $\ldots \ldots \ldots$. . . . . . . . . . . 60

3.6 Nitrogenous Terpenoids . . . . . . . . . . . . . . . . . 61

3.6.1 Nitrogenous Teprpenes of Proposed Amino Acid Origin . . . . . 62

3.6.2 Nitrogenous Spongian Diterpenoids . . . . . . . . . . 63

3.6.3 Proposed Biogenesis of Terpenes with Nitrogens of Proposed Amino Acid Origin . . . . . . . . . . . . . . 63 
5.1 General .............................. 74

5.2 Investigation of Darwinella oxeata . . . . . . . . . . . 75

5.2.1 Initial fractionation of Darwinella oxeata . . . . . . . . . 75

5.2.2 Isolation of oxeatamides A, B and C and iso-oxeatamide A . . . 75

5.2.3 Isolation of oxeatamides $\mathrm{D}, \mathrm{E}, \mathrm{F}$ and $\mathrm{G} \ldots \ldots 78$

5.2.4 Methylation of oxeatamide $\mathrm{G} \quad \ldots . \ldots 81$

5.3 Investigation of Dictyodendrilla dendyi f . . . . . . . . . . . 81

5.4 Investigation of Raspailia topsenti . . . . . . . . . . . . . . . . . 83

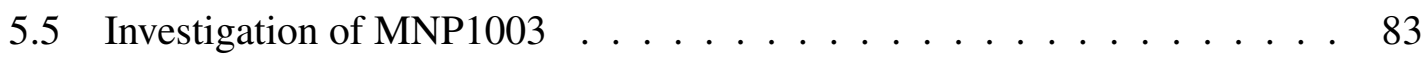

5.6 Investigation of MNP0996 . . . . . . . . . . . . . . . . 84

A Existing Sponge Screening Protocol 85

B Oxeatamide D

$\begin{array}{lll}\text { C Oxeatamide E } & 97\end{array}$

$\begin{array}{lr}\text { D Oxeatamide F } & 102\end{array}$

$\begin{array}{lll}\text { E } & \text { Oxeatamide G } & 107\end{array}$

$\begin{array}{lll}\text { F Oxeatamide C } & 112\end{array}$

$\begin{array}{ll}\text { References } & 117\end{array}$ 


\section{List of Figures}

1.1 New Zealand EEZ . . . . . . . . . . . . . . . . . . . . . . 6

1.2 Computer generated "mask" of HSQC data . . . . . . . . . . . . . 11

1.3 HSQC mask applied to a crude screen of an "uninteresting" extract. . . . 11

1.4 HSQC mask applied to a crude screen of an "interesting" extract. . . . . . 12

2.1 Underwater photo of Dictyodendrilla dendyi. . . . . . . . . . . . . . . . 14

2.2 HSQC mask applied to the crude screen of Dictyodendrilla dendyi. . . . . 14

2.3 Underwater photo of Raspailia topsenti. . . . . . . . . . . . . . . . 16

2.4 HSQC mask applied to the crude screen of Raspailia topsenti. . . . . . . 17

2.5 HSQC mask applied to the crude screen of MNP0996. . . . . . . . . . 18

2.6 HSQC mask applied to the crude screen of MNP1003. . . . . . . . . . 18

3.1 Underwater photo of Darwinella oxeata. . . . . . . . . . . . . . . . . 20

3.2 HSQC mask applied to the crude screen of Darwinella oxeata. . . . . . . 22

3.3 Diode array trace of HPLC separation of membranolides $\mathrm{C}$ and $\mathrm{D}$ and oxeatamides E, F and G. . . . . . . . . . . . . . 27

3.4 Diode array trace of HPLC separation of oxeatamides D to G. . . . . . . 27

3.5 COSY correlations establishing connectivity of C-1 to C-3 of oxeatamide D. 28

3.6 Key HMBC and COSY correlations establishing the connectivity around the quaternray centre $\mathrm{C}-10$ of oxeatamide $\mathrm{D} \ldots \ldots 29$

3.7 Key HMBC correlations establishing the connectivity of the cyclohexane ring, substructure A, of oxeatamide D. . . . . . . . . . . . . . 29

3.8 COSY and HMBC correlations establishing substructure B of oxeatamide D. 30

3.9 COSY and HMBC correlations establishing substructure C of oxeatamide D. 31

3.10 Placement of aromatic substituents of oxeatamide D . . . . . . . . . 31

3.11 HMBC correlations establishing the connectivity of the lactam ring in oxeatamide D. . . . . . . . . . . . . . . . . 32

3.12 COSY and key HMBC correlations establishing the attachment and connectivity of the $\mathrm{C}-22$ to $\mathrm{C}-25$ fragment of oxeatamide D. . . . . . 34 
3.13 Key NOE enhancements of oxeatamide D establishing the relative con-

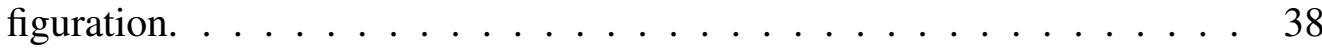

3.14 COSY and key HMBC correlations establishing connectivity of cyclohexane ring of oxeatamide E. . . . . . . . . . . . . . . . . . . 44

3.15 Aromatic ring A of oxeatamide E. . . . . . . . . . . . . . . . 42

3.16 Placement of aromatic substituents of aromatic ring A of oxeatamide E. . 42

3.17 COSY and HMBC correlations establishing the attachment and connectivity of C-22 to C-24 of oxeatamide E. . . . . . . . . . . . . . . . 43

3.18 COSY and key HMBC correlations establishing aromatic ring B of oxeatamide E. . . . . . . . . . . . . . . . . . 44

3.19 COSY and key HMBC correlations establishing connectivity of cyclohexane ring of oxeatamide F . . . . . . . . . . . . . . 46

3.20 Aromatic ring connectivity of oxeatamide F. . . . . . . . . . . . . . . 47

3.21 Connectivity around carbonyl C-6 of oxeatamide F. . . . . . . . . . . . . 47

3.22 Placement of aromatic substituents of oxeatamide F. . . . . . . . . . . . 48

3.23 COSY and key HMBC correlations establishing the attachment and connectivity of C-22 to C-26 fragment of oxeatamide F. . . . . . . . . . . 49

3.24 COSY and key HMBC correlations establishing the attachment and connectivity of $\mathrm{C}-22$ to $\mathrm{C}-26$ fragment of oxeatamide $\mathrm{G}$. . . . . . . 52

3.25 COSY and key HMBC correlations establishing the attachment and connectivity of C-22 to N-24 fragment of oxeatamide $\mathrm{C}$. . . . . . . . . 56 


\section{List of Schemes}

1.1 Cyclic loading. . . . . . . . . . . . . . . . . . . 8

3.1 Isolation of oxeatamides A, B and C, and iso-oxeatamide A . . . . . . 24

3.2 Isolation of oxeatamides D, E, F and G, and membranolides C and D . . . 25

3.3 Proposed biogenesis of thed aplysulphurane backbone from the spongian diterpene backbone. . . . . . . . . . . . . . . . . . 60

3.4 Biogenesis of $N$-substituted lactams from furan precursors, adapted from El Sayed et al. . . . . . . . . . . . . . . . . . . 66

3.5 Alternative biogenesis pathway for $N$-substituted lactams involving singlet oxygen oxidation of furan precursors. . . . . . . . . . . . . . 67

3.6 Proposed biogenesis of the oxeatamides. . . . . . . . . . . . . . 71 


\section{List of Tables}

1.1 Taxonomic classification to order level of phylum Porifera. . . . . . . . . 4

3.1 Taxonomic classification of genus Darwinella from order Dendroceratida. 20

3.2 Comparison of the ${ }^{13} \mathrm{C}$ and ${ }^{1} \mathrm{H}$ NMR chemical shifts $\left(\mathrm{CDCl}_{3}\right)$ for oxeatamide $\mathrm{A}$, iso-oxeatamide $\mathrm{A}$ and oxeatamide $\mathrm{D}$. . . . . . . . . . . 32

$3.3{ }^{13} \mathrm{C}(150 \mathrm{MHz}),{ }^{1} \mathrm{H}(600 \mathrm{MHz}) \mathrm{NMR}$ data $\left(\mathrm{CDCl}_{3}\right)$ for oxeatamide D. . . 35

3.4 NOE enhancements for oxeatamide D. . . . . . . . . . . . . . . 39

3.5 ${ }^{13} \mathrm{C}(150 \mathrm{MHz}),{ }^{1} \mathrm{H}(600 \mathrm{MHz}) \mathrm{NMR}$ data $\left(\mathrm{CDCl}_{3}\right)$ for oxeatamide $\mathrm{E} . \quad . \quad 45$

3.6 ${ }^{13} \mathrm{C}(150 \mathrm{MHz})$ and ${ }^{1} \mathrm{H}(600 \mathrm{MHz}) \mathrm{NMR}$ data $\left(\mathrm{CDCl}_{3}\right)$ for oxeatamide $\mathrm{F} . . \quad 50$

3.7 ${ }^{13} \mathrm{C}(150 \mathrm{MHz})$ and ${ }^{1} \mathrm{H}(600 \mathrm{MHz}) \mathrm{NMR}$ data $\left(\mathrm{CDCl}_{3}\right)$ for oxeatamide $\mathrm{G} . \quad 53$

$3.8{ }^{13} \mathrm{C}(150 \mathrm{MHz})$ and ${ }^{1} \mathrm{H}(600 \mathrm{MHz}) \mathrm{NMR}$ data $\left(d_{6}\right.$-DMSO) for oxeatamide C. 57

3.9 Proposed biogeneic precursors of amino acid derived nitrogenous terpenes. 69 


\section{Glossary}

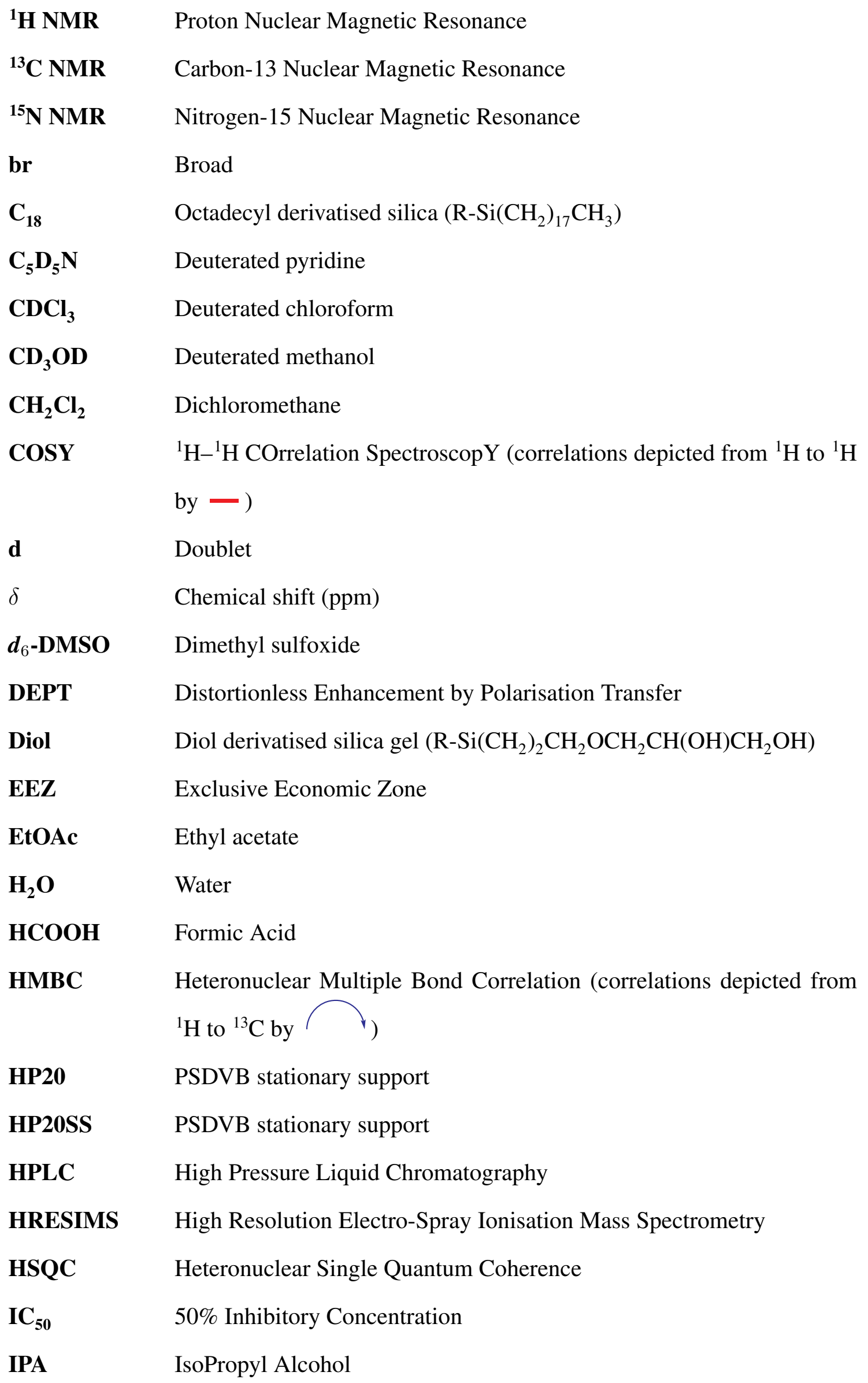


J Scalar coupling constant

LC-NMR Liquid chromatography- Nuclear Magnetic Resonance

m Multiplet

$\mathrm{Me}_{2} \mathrm{CO}$ Acetone (propanone)

MeOH Methanol

MS Mass Spectrometry

MTT 3-(4,5-Dimethylthiazol-2-yl)-2,5-diphenyltetrazolium bromide

mult Mutiplicity

$m / z \quad$ Mass to charge ratio

NIWA National Institute of Water and Atmospheric Research (New Zealand)

NMR Nuclear Magnetic Resonance

NOE Nuclear Overhauser Effect

NOESY Nuclear Overhauser Effect SpectroscopY (enhancements depicted from

${ }^{1} \mathrm{H}$ to ${ }^{1} \mathrm{H}$ by

non Nonet

ppm Parts Per Million

PSDVB Poly(Styrene-Di-VinylBenzene)

q Quartet

quin Quintet

S Singlet

SCUBA Self Contained Underwater Breathing Apparatus

sept Septet

t Triplet

TLC Thin Layer Chromatography

VUW Victoria University of Wellington 


\section{Chapter 1}

\section{Introduction}

\subsection{Natural Products}

The use of natural products for medicinal purposes has a long history. For many thousands of years people have used plant and animal extracts to treat ailments and disease, ${ }^{1}$ for example the Sumerians documented the use of medicinal plants over 5000 years ago. ${ }^{2}$ The medicinal properties of these traditional natural remedies are often due to the biologically active secondary metabolites produced by the organism. Morphine (1), an analgesic and anaesthetic extracted from the opium poppy, Papaver somniferum, was the first ever natural product commercialised for medicinal use in $1826 .{ }^{1}$ Natural products, their derivates and synthetic mimics, have proven to be successful drugs, whereas only $30 \%$ of the new pharmaceuticals introduced between 1981 and 2006 are classified as totally synthetic. ${ }^{3}$

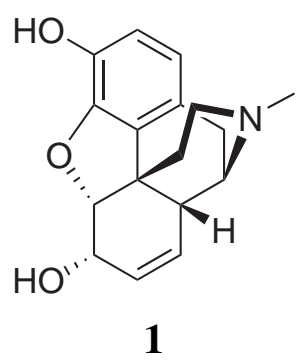

Natural product research has seen cyclical favour from the pharmaceutical industry. Fierce competition from other investigative methods such as combinatorial chemistry has at times led to diminished interest in natural products. ${ }^{4}$ The early 1990s saw the focus shift towards combinatorial chemistry as the next big source of de novo drug candidates. Unfortunately, combinatorial libraries did not live up to this initial hope and no combinatorial derived compounds were approved for use as drugs between 1981 and 2002. ${ }^{5}$ The anticancer agent Sorafenib (marketed as Nexavar by Bayer AG), sanctioned by the U.S. Food and Drug Administration (FDA) in late 2005, was the first and thus far only combinatorial chemistry derived drug to be approved for clinical use. ${ }^{3}$ 
The lack of success in the combinatorial field led to a resurgence in natural products research toward the end of the last millennium. The ascendancy of natural products can at least in part be put down to the structural diversity found amongst them, which far exceeds that found in today's combinatorial or synthetic libraries. ${ }^{6}$ An amalgamation of natural products research with combinatorial chemistry may, in future prove, to be the way forward, with lead compounds found from natural sources optimised for use as drugs by combinatorial methods.

\subsection{Marine Natural Products}

Terrestrial flora and micro-organisms are the traditional source of natural products due to ease of access. The marine environment however, largely unexplored before the development of SCUBA in the $1940 \mathrm{~s},{ }^{7}$ is thought to contain over $80 \%$ of the world's plant and animal species, making it an ideal source of new pharmaceutical leads. ${ }^{8}$ By 2004 more than 13,000 marine natural products had been reported in the literature. ${ }^{9}$ One of the earliest reports which ignited interest in marine natural products was the discovery of the bioactive arabinosyl nucleosides, spongothymidine (2) and spongouridine (3), from the sponge Crypotethia crypta, by Bergmann et al. in the early 1950s. ${ }^{10-12}$ Currently, three derivates of the arabinoysl nucleosides are used clinically: vidarabine (Ara-A, 4), azidothymidine (AZT, 5) and cytarabine (Ara-C, 6). Ara-A and AZT are antiviral agents, while Ara-C is a chemotherapeutic agent. ${ }^{13}$

$\omega$-Conotoxin (7), isolated by Olivera et al. in 1985 from the marine snail Conus magus is a bioactive conopeptide. ${ }^{14}$ Ziconotide (marketed as Prialt by Elan Corporation), the synthetic equivalent of $\mathbf{7}$, is used as an intrathecal analgesic for management of severe chronic pain. ${ }^{15}$ Ziconotide is the only true marine natural product currently approved for drug use. ${ }^{16}$ However, numerous promising drug candidates, including the anticancer agent dolastatin $10(\mathbf{8}),{ }^{17}$ are currently in advanced preclinical and clinical trials. ${ }^{7}$ 


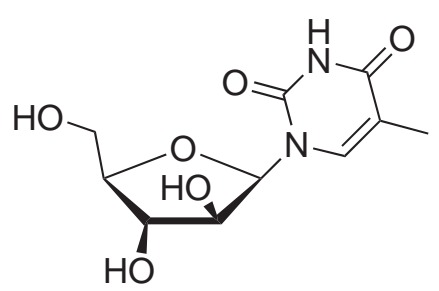

2

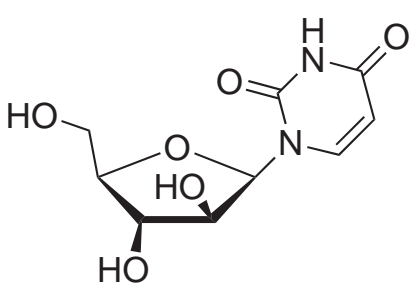

3

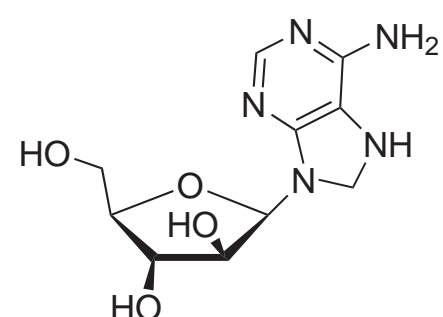

4

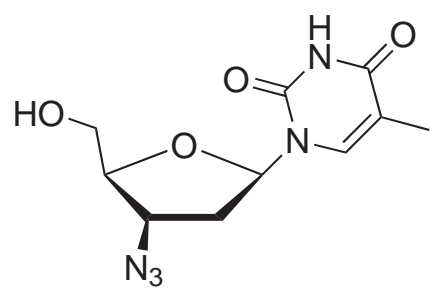

5

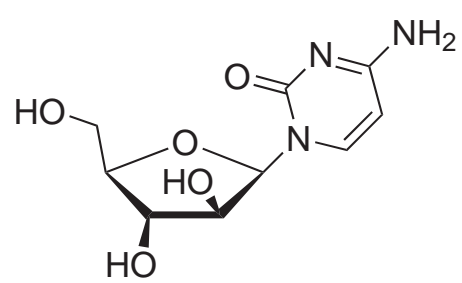

6

Cys-Lys-Gly-Ala-Lys-Cys-Ser-Arg-Leu-Met-Tyr-Asp-Cys-Cys-Thr-Gly-Ser-Cys-Arg-Ser-Gly-Lys-Cys

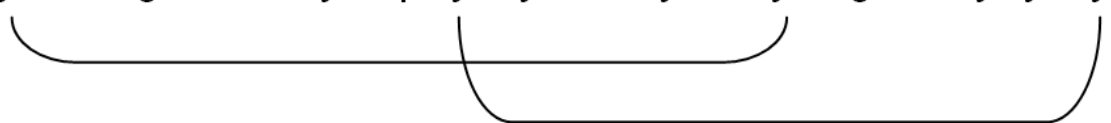

7

\subsection{Marine Sponges}

Sponges (phylum Porifera) are primitive aquatic invertebrate organisms, and whilst multicellular, lack cellular organisation such as tissues or organ systems. They are considered to be the oldest and most primitive phylum of the animal kingdom (Metazoa). ${ }^{18}$ Sponges are characteristically porous as their simple body organisation consists of numerous channels and chambers. ${ }^{19}$ To date around 8000 species of sponge have been described, with perhaps twice that number yet to be characterised. ${ }^{20}$ Marine sponges account for the majority of the described species with only about 150 freshwater species known. ${ }^{19}$

Porifera have long been separated into three classes: Hexactinellida, Demospongiae and Calcarea (see Table 1.1). Within a particular sponge species characteristics such as growth, shape and colour can be greatly affected by location and environmental factors. Because of the plasticity in sponge morphology, sponge classification was traditionally based on the microscopic skeletal components and skeletal architecture. ${ }^{19}$ The microscopic skeletal components of sponges consist of mineral spicules (needlelike structures composed of silica or calcium carbonate) and spongian (collagen) fibres. Hexactinellida have siliceous spicules, Calcarea have calcium carbonate spicules and 
Demospongiae have siliceous spicules and/or collagen fibres. The bulk of living sponge species belong to the latter class. ${ }^{19}$ Recently, chemotaxanomic trends and molecular biology have also been used as tools in sponge taxonomic classification leading to the re-examination of sponge taxonomy. Whilst such new techniques have confirmed the previous classification to the class level, there has been some reassignment at the order level and below. ${ }^{21}$

Table 1.1. Taxonomic classification to order level of phylum Porifera. ${ }^{19}$

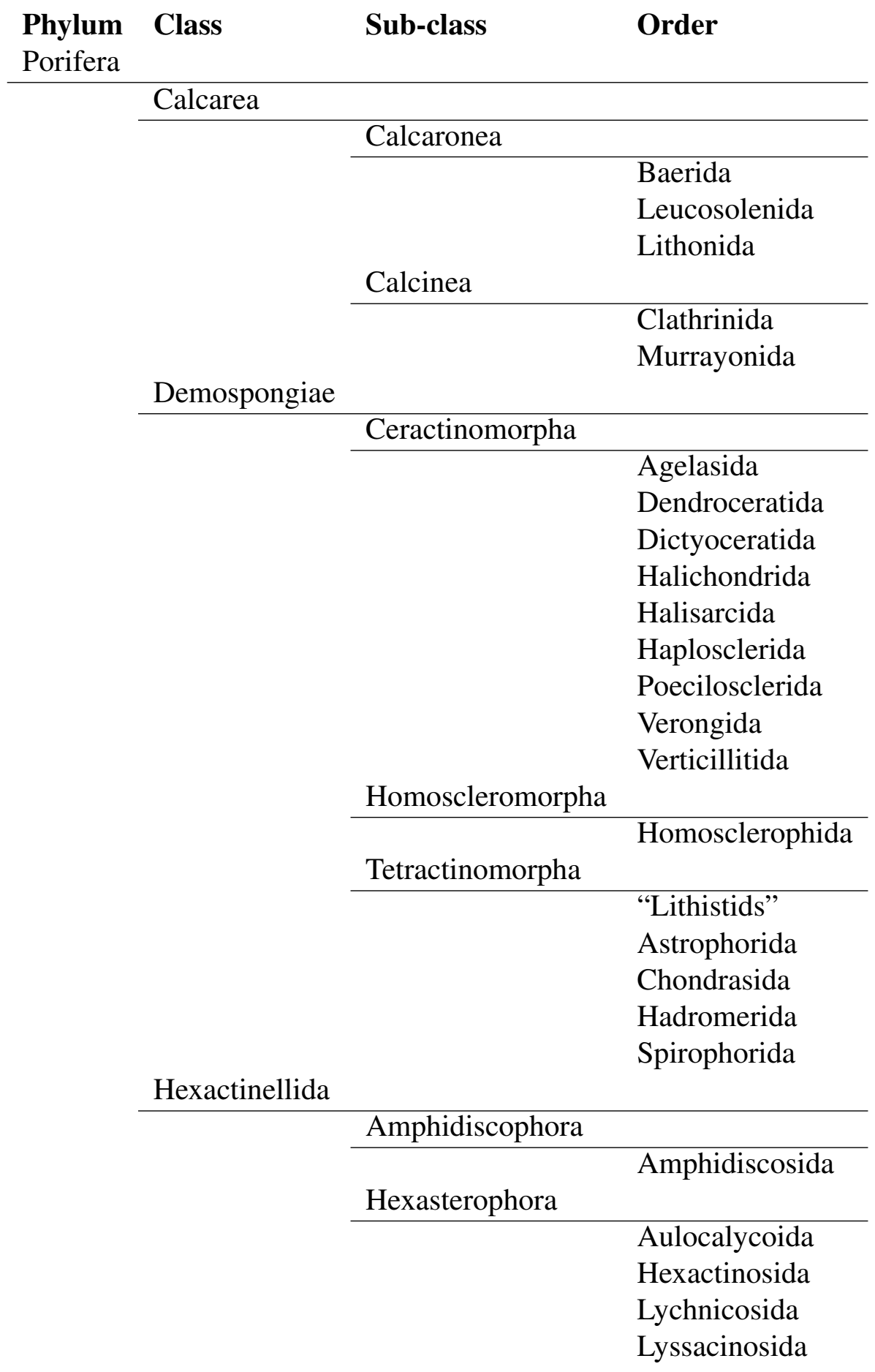


The marine environment's success as a bountiful source of new compounds may in part be due to the sessile nature of many marine algae and invertebrates, including sponges. In order to prevent predation and encroachment many marine organisms have evolved advanced chemical defence mechanisms. Some of these secondary metabolites have promising pharmaceutical activity. Unlike the terrestrial environment where flora surpasses fauna as a source of secondary metabolites, in the marine environment invertebrate animals are a greater source of secondary metabolites than algae. ${ }^{22}$ Research has shown that sponges are a rich source of diverse and often biologically active secondary metabolites such as terpenoids and steroidal compounds. ${ }^{23-29}$ These compounds may be produced by sponges in response to the threat of overgrowth, predation and infection. ${ }^{21}$

Interestingly, a multitude of compounds isolated from sponges are similar to those isolated from marine microbial organisms. As some sponges form symbiotic relationships with micro-organisms, some of the metabolites isolated from sponges may in fact be of microbial origin. ${ }^{30,31}$

Many marine sponge-derived natural products have been found to have useful biological activity. Several compounds with promising anticancer properties are currently in clinical trials, including discodermolide (9), KRN-7000 ( $\alpha$-GalCer, $\alpha$-galactosylceramide) (10), E-7389 (NSC-707389) (11) and HTI-286 (SPA-110) (12). ${ }^{32}$ Peloruside A (13), a tublinstablising agent, with similar activity to the multi-billion dollar chemotherapeutic agent paclitaxel is also about enter clinical trials. ${ }^{33}$ Peloruside A was first isolated from the New Zealand marine sponge Mycale hentscheli by West et al. at Victoria University of Wellington (VUW) in $1999 .{ }^{34}$

New Zealand has a large and diverse marine environment. The New Zealand Exclusive Economic Zone (EEZ), depicted in Figure 1.1, is around 4.2 million $\mathrm{km}^{2}$ (approximately 15 times the land area) and spans over $30^{\circ}$ of latitude. The EEZ encompasses both subantarctic and subtropical waters and has an estimated 23,000 species inhabiting it. ${ }^{35}$ 


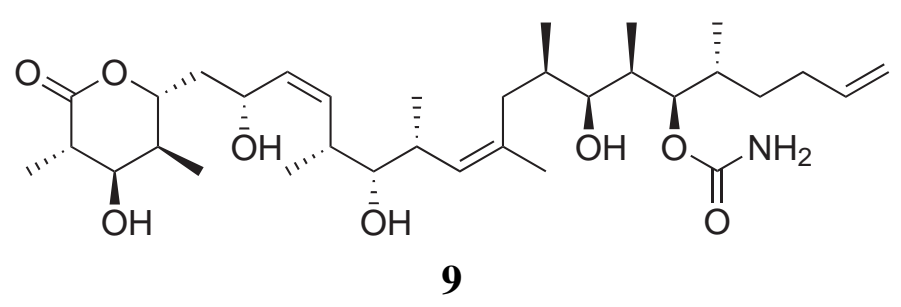

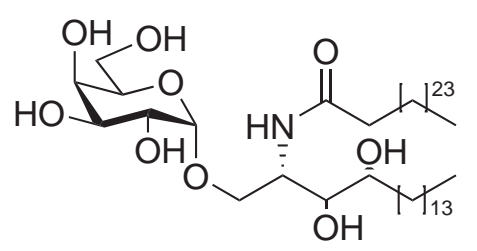<smiles>CN[C@H](C(=O)N[C@H](C(=O)N(C)[C@H](/C=C(\C)C(=O)O)C(C)C)C(C)(C)C)C(C)(C)c1ccccc1</smiles>

12

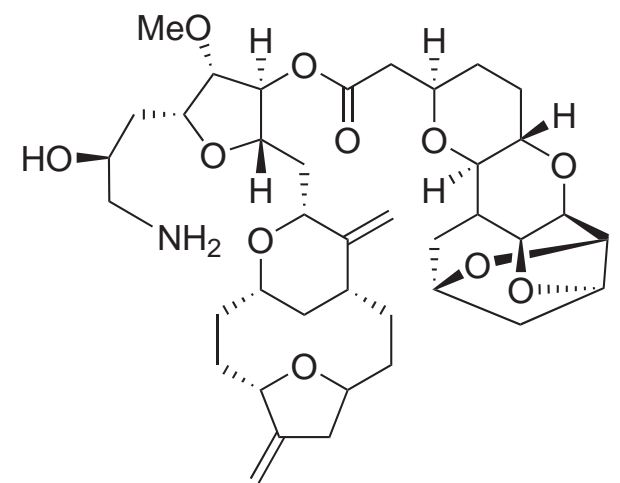

11

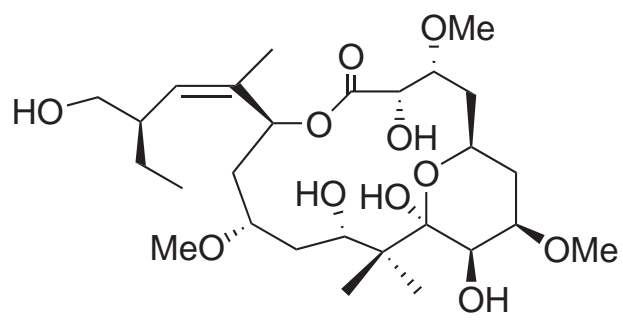

13

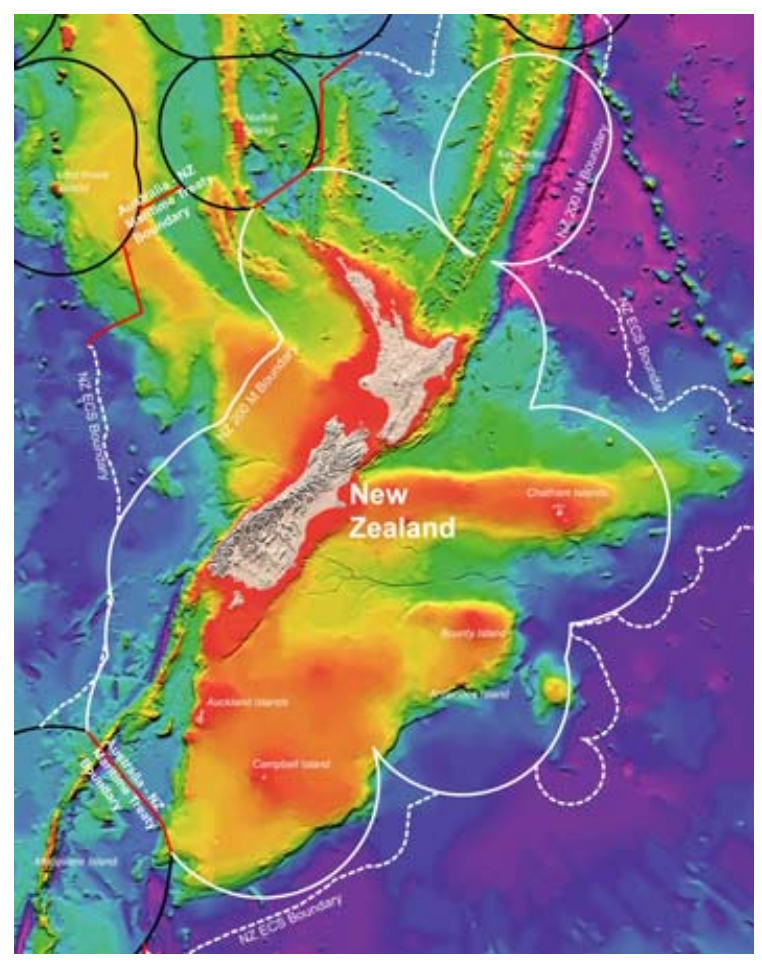

Figure 1.1. New Zealand EEZ (denoted with a solid white line). Image courtesy of National Institute of Water and Atmospheric Research (NIWA). 


\subsection{Discovery of New Natural Products at VUW}

The Marine Natural Products group at VUW utilises several novel techniques in their efforts to isolate new compounds from marine sources. These include a chromatographic method, cyclic loading, as well as an NMR based screening process, which are discussed below.

\subsubsection{Cyclic Loading}

Crude sponge extracts are typically difficult to concentrate under reduced pressure as they are often saturated in both polar and non-polar components. Crude extracts contain a wide range of compounds, from polar compounds such as sugars and amino acids, through amphiphilic compounds of intermediate polarity to very non-polar compounds like steroids and triglycerides. Finding a solvent that can accommodate this wide range of compounds is nearly impossible, which causes further problems for chromatographic separation. Cyclic loading is a technique developed by the Marine Natural Products group at VUW to deal with this problem (for a pictorial represenatation of the cyclic loading process see Scheme 1.1). ${ }^{36}$ This method involves loading the extract onto poly(styrene divinylbenzene) (PSDVB) resin. The extract is first passed through the resin, the eluent is then diluted with $\mathrm{H}_{2} \mathrm{O}$ and passed back through the column, the dilution and re-passage is continued until all the compounds of interest have been loaded onto the resin (usually three dilutions are all that is required). On the first pass through the resin only the most hydrophobic compounds adsorb to the resin. Then as the eluents are successively diluted the mobile phase becomes increasingly polar, encouraging the loading of the amiphiphilic and finally the polar components of the extract onto the stationary phase.

Biologically active metabolites tend to be amphiphilic as they need both hydrophobic and hydrophilic properties to enable them to be transported to their site of action. The hydrophilic nature allows solubility in body fluids, whilst the hydrophobic nature allows permeability through membranes. ${ }^{37}$ These compounds of intermediate polarity can be targeted using the cyclic loading method. Once the column is completely loaded, the resin 


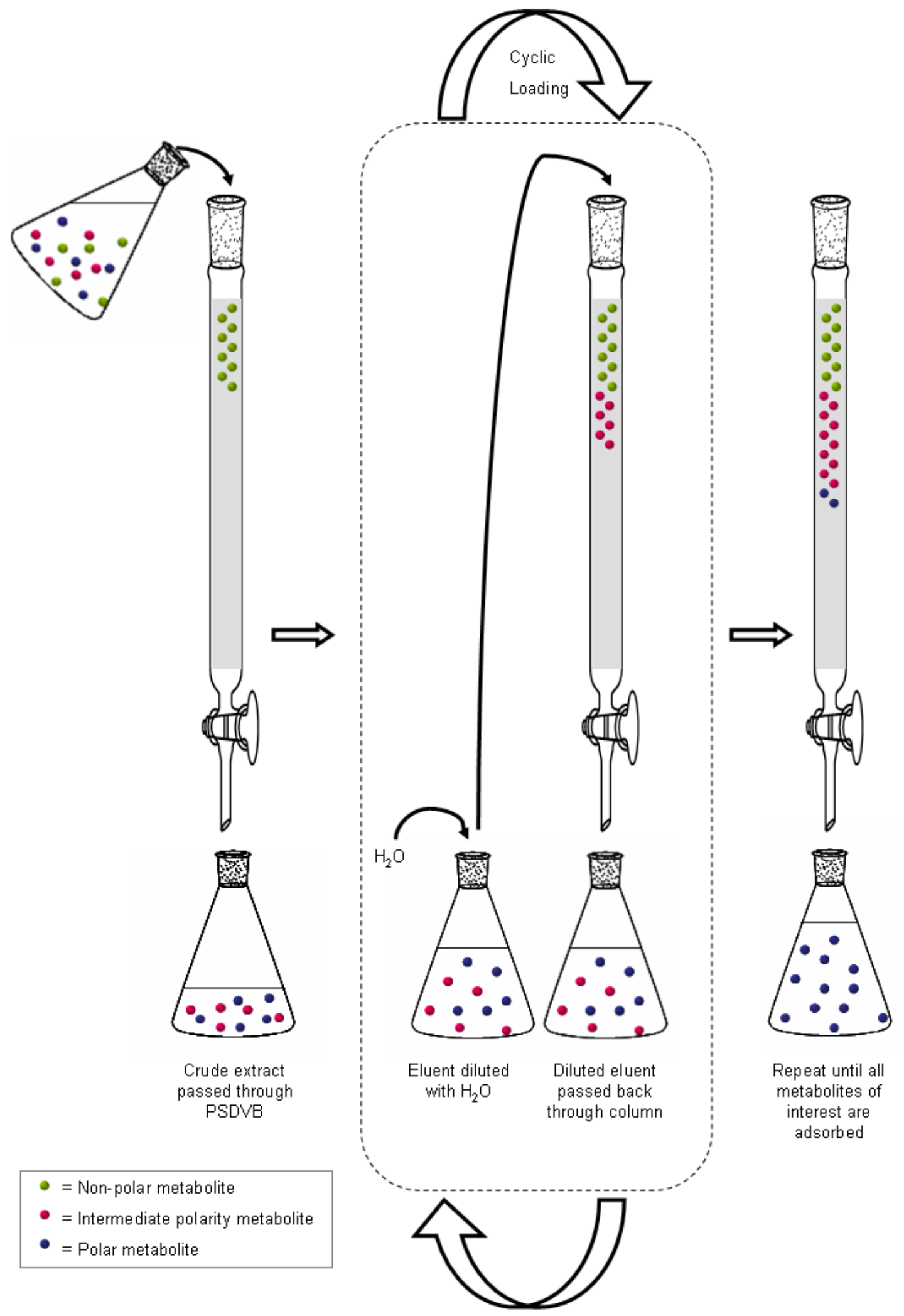

Scheme 1.1. Cyclic loading. 
is sequentially eluted with fractions of increasing amounts of organic modifier (usually $\mathrm{Me}_{2} \mathrm{CO}$ or $\left.\mathrm{MeOH}\right)$. The early fractions contain the polar sugars and amino acids whilst the final fractions contain the lipids and steroids. Compounds at the extremes of the polarity range tend to be primary metabolites and make up the majority of the extract mass. The middle fractions contain the compounds of intermediate polarity (amphiphilic molecules), which tend to be secondary metabolites. Thus cyclic loading allows the targeting of secondary metabolites (compounds likely to be biologically active), within one chromatographic step.

Mixtures of $\mathrm{Me}_{2} \mathrm{CO} / \mathrm{H}_{2} \mathrm{O}$ are notoriously difficult to concentrate as they are prone to excessive bumping. Back loading — an adaptation of cyclic loading — is a way of avoiding this problem. Back loading allows the conversion of the often water-rich cyclic loading eluents to $100 \% \mathrm{Me}_{2} \mathrm{CO}$ fractions which are easier to concentrate. Cyclic loading eluents are passed through a PSDVB back loading column, the eluent is diluted twofold and passed back through the column, the eluent is again diluted two-fold and passed through the column, ensuring all compounds have been adsorbed onto the resin. The resin is then washed with water before being eluted with $100 \%$ organic modifier. The eluent, now water free, is then concentrated under reduced pressure.

\subsubsection{NMR Based Screening}

The major advantage of traditional bioassay-guided natural product isolation is the guaranteed isolation of compounds with the desired bioactivity, however this method has several flaws. Firstly, a minor compound may be overlooked if the biological activity of a more major compound in the mixture overwhelms the activity of the minor. Secondly, the dereplication of known compounds is a major problem of bioassay-guided isolation. In recent times, several natural products groups have started to utilise NMR guided isolation in an attempt to avoid these problems. The majority employ LC-NMR for dereplication, ${ }^{38}$ whilst a few groups, including the Marine Natural Products group at VUW, use more unusual NMR based methods. ${ }^{36,39-41}$ The Gerwick and Kobayashi groups report using diffusion edited NMR to help with dereplication. ${ }^{42,43}$ Schroeder and 
co-workers report using differential analysis of 2D NMR spectra to characterise crude unfractionated extracts. ${ }^{44}$ The Marine Natural Products group at VUW has developed a 2D NMR-based screening method to assess crude sponge extracts (Appendix A). ${ }^{36,39-41}$ The screening technique allows researchers to target sponges which are rich producers of potentially novel secondary metabolites.

Sponge samples are extracted in $\mathrm{MeOH}$ and cyclic loaded on to PSDVB resin. The resin is eluted with $\mathrm{H}_{2} \mathrm{O}, 30 \% \mathrm{Me}_{2} \mathrm{CO} / \mathrm{H}_{2} \mathrm{O}, 75 \% \mathrm{Me}_{2} \mathrm{CO} / \mathrm{H}_{2} \mathrm{O}$ and $100 \% \mathrm{Me}_{2} \mathrm{CO}$. The $75 \%$ $\mathrm{Me}_{2} \mathrm{CO} / \mathrm{H}_{2} \mathrm{O}$ fraction is assumed to represent the majority of the amphiphilic molecules and is therefore analysed using 1D and 2D NMR. The HSQC experiment, one of the 2D NMR spectra obtained on the $75 \% \mathrm{Me}_{2} \mathrm{CO} / \mathrm{H}_{2} \mathrm{O}$ fraction, shows direct proton to carbon connectivity. Thus the HSQC screen has the potential to identify unusual functional groups.

A computer generated "mask" of additive HSQC data of all previously screened sponge samples in our laboratory has been created (see Figure 1.2, common correlations appear white whilst less common correlations appear blue). The HSQC data of new sponge extracts are compared to this mask. HSQC correlations are classified as either common (green peaks) or uncommon (red peaks). The threshold at which correlations are classified as uncommon are those correlations seen in $3 \%$ or less of the sponge samples. Two sponge extract screens have been used as illustrative examples of the extremes. Figure 1.3 is an example of an "uninteresting" extract — with a high number of common HSQC correlations (green peaks), whilst Figure 1.4 is an example of an "interesting" extract — with a high number of uncommon HSQC correlations (red peaks). Correlations that are frequently observed are from compounds that are common amongst the screened sponges and are therefore likely to be primary metabolites. Thus, uncommon correlations may indicate the presence of secondary metabolites. The intensity of a particular correlation indicates the relative amount of the compound present in the sponge. The promise of each new sponge sample is assessed and ranked based on 1) the number of uncommon HSQC correlations, 2) the intensity of uncommon HSQC correlations, 3) the functionality these peaks represent, 4) the amount of sponge collected and 5) the recollectability of the sponge. These criteria are not weighted equally. 


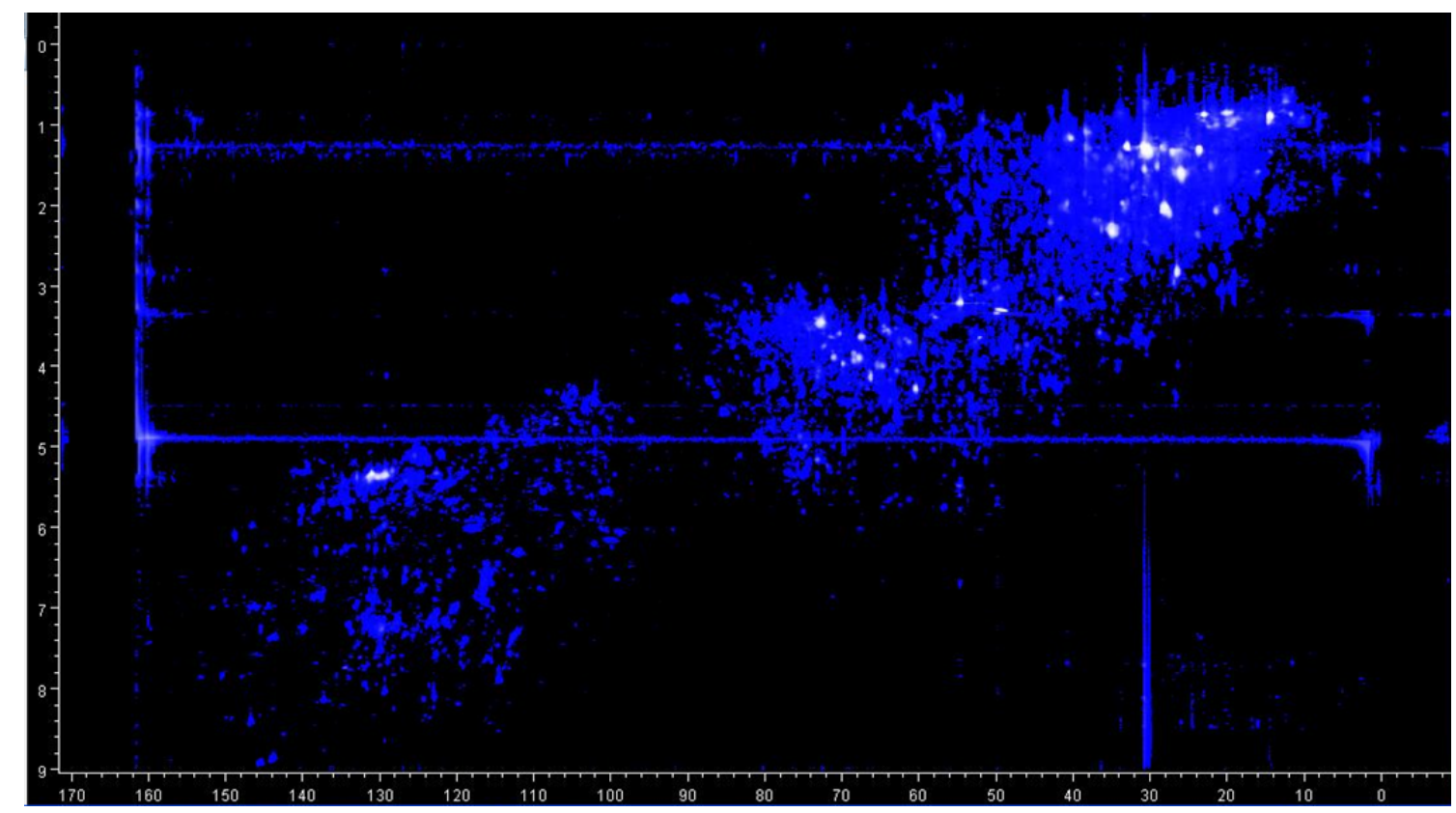

Figure 1.2. Computer generated "mask" of HSQC data

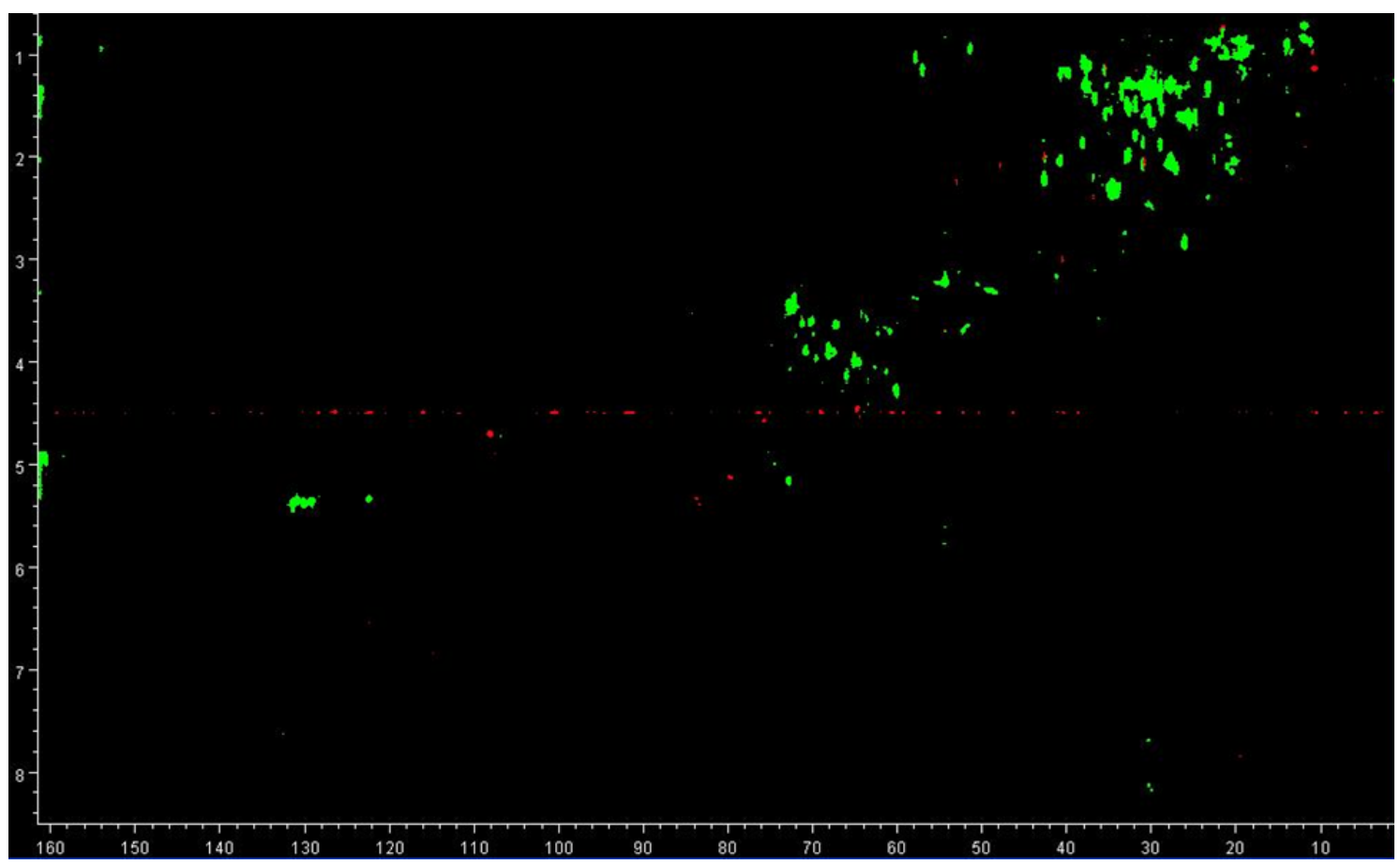

Figure 1.3. HSQC mask applied to a crude screen of an "uninteresting" extract. 


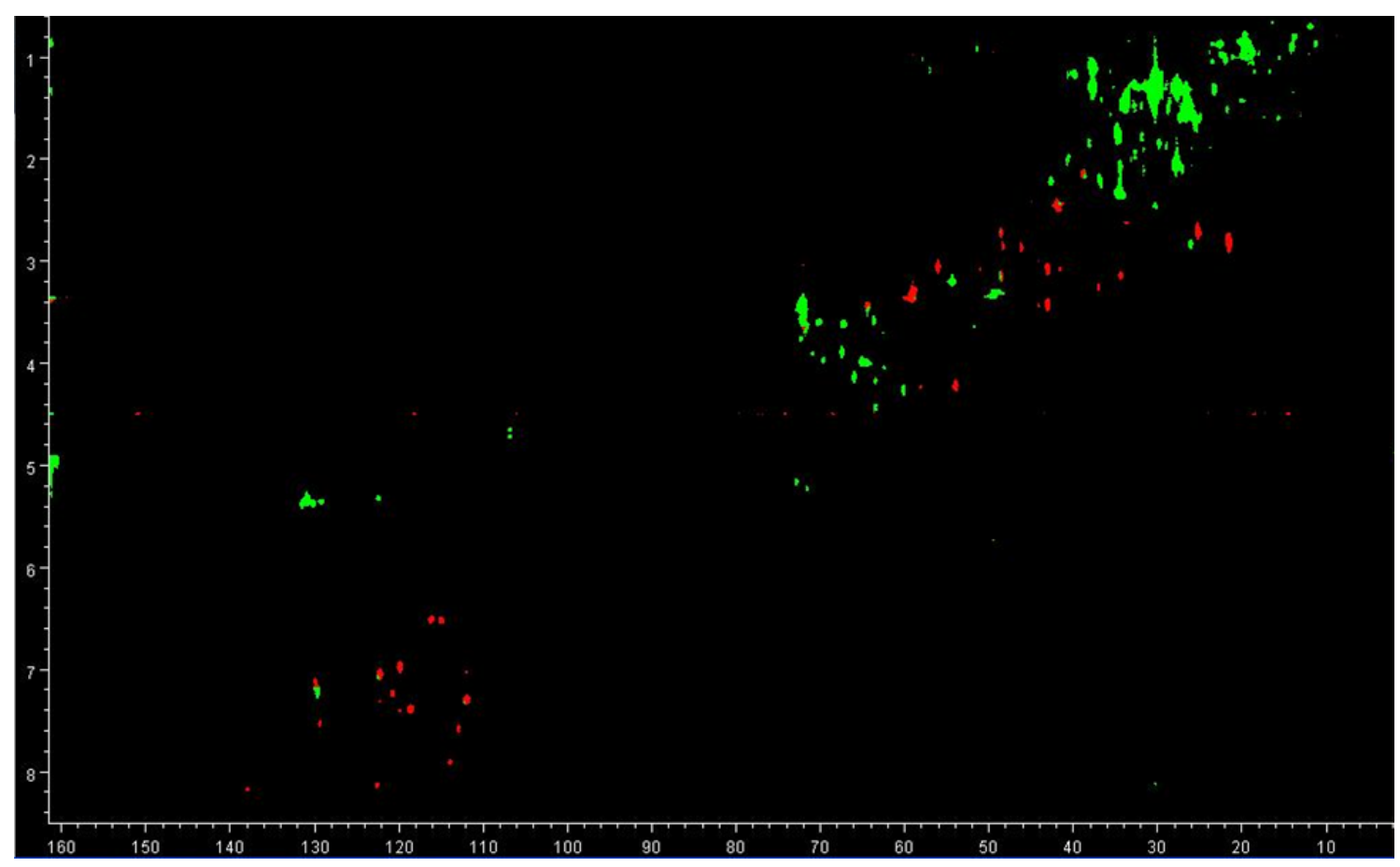

Figure 1.4. HSQC mask applied to a crude screen of an "interesting" extract.

\subsubsection{Sponges Examined in this Research}

In this study, five sponges were investigated based on their results in the screening protocol. These sponge samples had been previously screened and assessed by other members of the Marine Natural Products group at VUW. Darwinella oxeata, appeared the most interesting and further investigation into this sponge is discussed in Chapter 3. Dictyodendrilla dendyi and Raspailia topsenti as well as two unidentified sponge species, MNP0996 and MNP1003, were briefly investigated and are discussed in Chapter 2. 


\section{Chapter 2}

\section{Sponges Examined by Spectroscopic Screening}

As well as a thorough investigation of Darwinella oxeata described in Chapter 3, four other New Zealand marine sponges were briefly investigated in the course of this study, Dictyodendrilla dendyi and Raspailia topsenti, and two unidentified sponge species, MNP0996 and MNP1003. These sponges were selected for investigation based on their promising results in the 2D NMR based screening method (previously discussed in Chapter 1, Section 1.4.2) and the results of previous work on Dictyodendrilla dendyi and Raspailia topsenti. ${ }^{40,45}$

Each of the four sponges were extracted in $\mathrm{MeOH}$ and their extracts were cyclic loaded onto reversed-phase PSDVB resin. The resins were then batch eluted with increasing amounts of $\mathrm{Me}_{2} \mathrm{CO}$ in $\mathrm{H}_{2} \mathrm{O}$ and the fractions analysed by NMR, leading to a short study of Dictyodendrilla dendyi and Raspailia topsenti. No further investigation of MNP0996 or MNP1003 occurred, as the majority of this study focused on the bountiful Darwinella oxeata sample discussed in Chapter 3. Notable features of the four sponge extracts are discussed in the following sections.

\subsection{Investigation of Dictyodendrilla dendyi}

Due to its deep blue to black colouring, Dictyodendrilla dendyi (see Figure 2.1) is a very distinctive keratose sponge. ${ }^{19}$ This species had been previously worked on in our laboratory by Ryan, who reported the isolation of seven new lamellarins and one new dictyodendrin. ${ }^{40}$ Notably, many of these new compounds were isolated from relatively polar cyclic loading fractions $\left(20 \% \mathrm{Me}_{2} \mathrm{CO} / \mathrm{H}_{2} \mathrm{O}\right.$ and $\left.40 \% \mathrm{Me}_{2} \mathrm{CO} / \mathrm{H}_{2} \mathrm{O}\right) .{ }^{40}$ The success of Ryan, along with its promising result in the HSQC screen depicted in Figure 2.2, led to the brief re-investigation of this species in this study. The HSQC screen showed many interesting and uncommon signals in the aromatic region (Figure 2.2). 


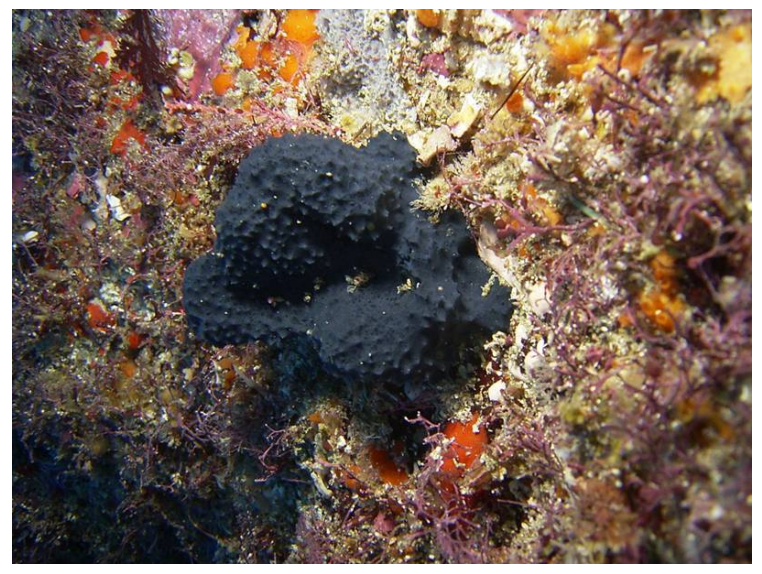

Figure 2.1. Underwater photo of Dictyodendrilla dendyi, courtesy of Peter Northcote.

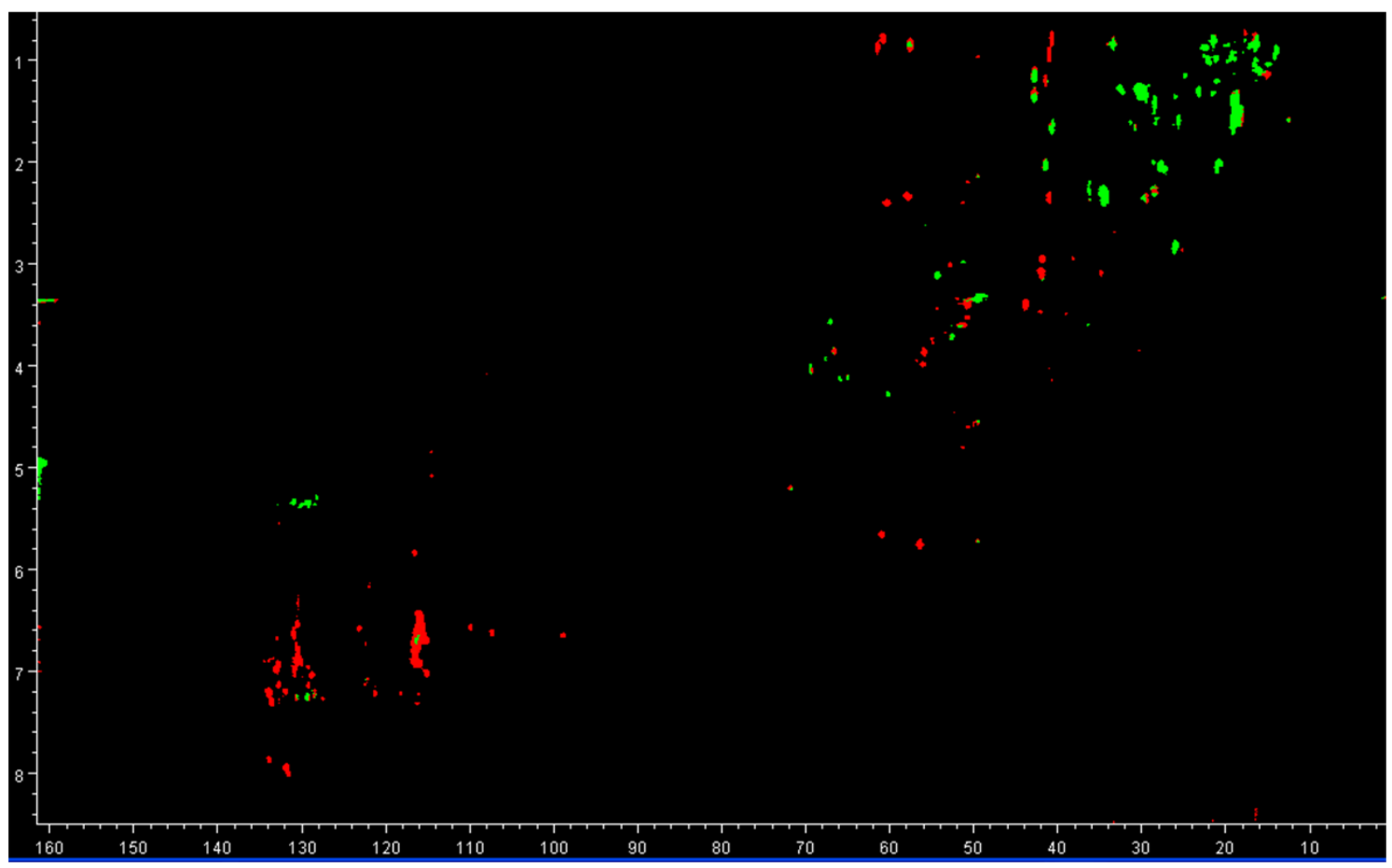

Figure 2.2. HSQC mask applied to the crude screen of Dictyodendrilla dendyi. 
Interestingly, the methanolic extract of Dictyodendrilla dendyi was almost black in colour. On completion of the cyclic loading process, the diluted eluent, which is normally discarded at this stage, had retained this colour. The diluted eluent would have contained only the most polar compounds that had not previously adsorbed to the PSDVB resin during the cyclic loading process (see Scheme 1.1). The diluted eluent was then saturated with $\mathrm{NaCl}$, and loaded onto another column of PSDVB. The $\mathrm{NaCl}$ appeared to facilitate the adsorbtion of the black pigment onto the resin as the eluent was lighter and the resin appeared to discolour (from white to grey). This column was then eluted with $\mathrm{Me}_{2} \mathrm{CO}$. NMR analysis of this fraction along with the other fractions (generated during cyclic loading) proved interesting. In an attempt to isolate the compound or compounds responsible for the black colour many different types of chromatography were performed, including normal phase and size exclusion columns. The source of the black colouration was not isolated. However, in the process of tracking the black coloured residue the known compound lamellarin $\theta 4^{\prime \prime}, 4^{\prime \prime \prime}$-disulfate (14) was isolated. No further investigation was undertaken as there was no sign of lamellarins or dictyodendrins not previously isolated by this research group.

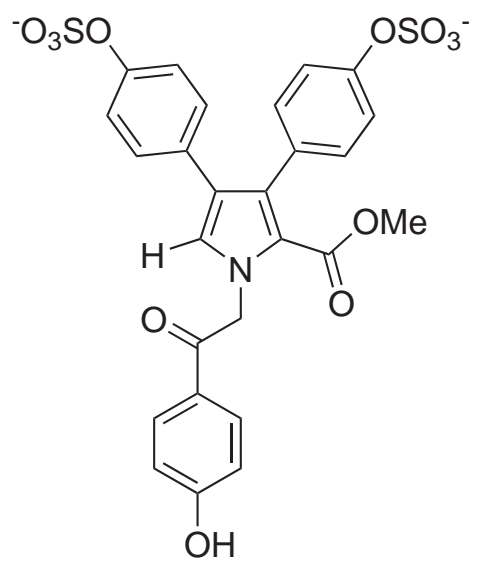

14

\subsection{Investigation of Raspailia topsenti}

Raspailia topsenti, an orange finger sponge (see Figure 2.3), ${ }^{19}$ had previously been extensively worked on in our laboratory by West, Moraes, Ryan and Dowle leading to the isolation of thirteen new clerodane diterpenes. ${ }^{36,40,45,46}$ The previous success of this 
species as a source of new compounds along with its promising result in the HSQC screen as shown in Figure 2.4 led to another brief re-investigation of this species in this study.

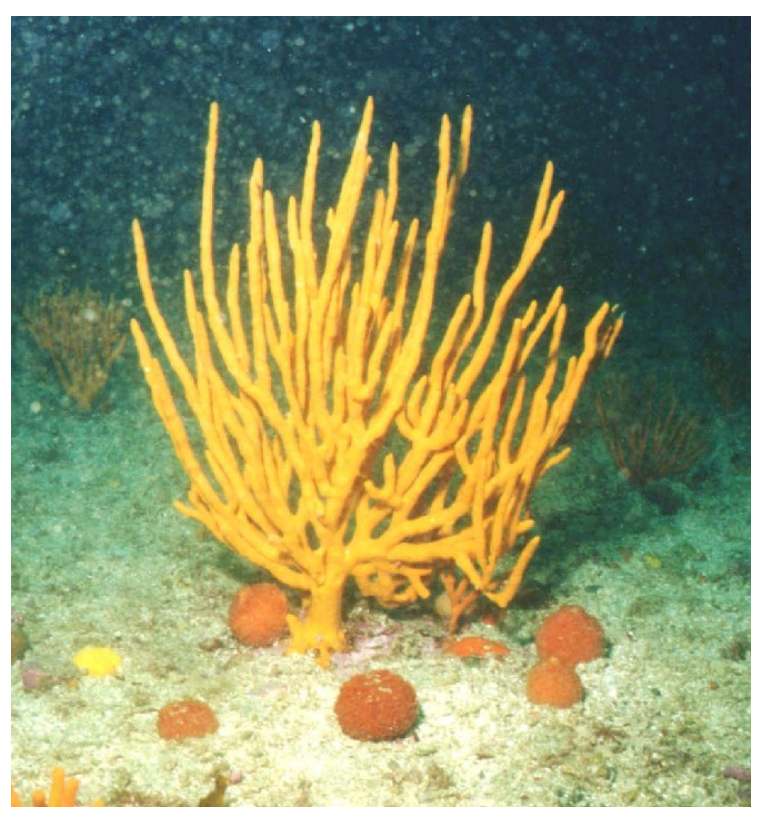

Figure 2.3. Underwater photo of Raspailia topsenti, courtesy of Alan Duckworth.

The HSQC screen showed a large amount of uncommon resonances (red peaks in Figure 2.4), which were predominantly in the oxymethine, aliphatic and aromatic regions. NMR analysis of some of the cyclic loading factions had signals reminiscent of the clerodane diterpenes with some structural features not seen in known compounds. Repeated normal phase columns were performed in attempts to isolate further metabolites of $R$. topsenti. Unfortunately, due to the paucity of these metabolites, no new compounds were isolated. Further analysis was discontinued but when new populations of this sponge are encountered they will warrant reinvestigation. 


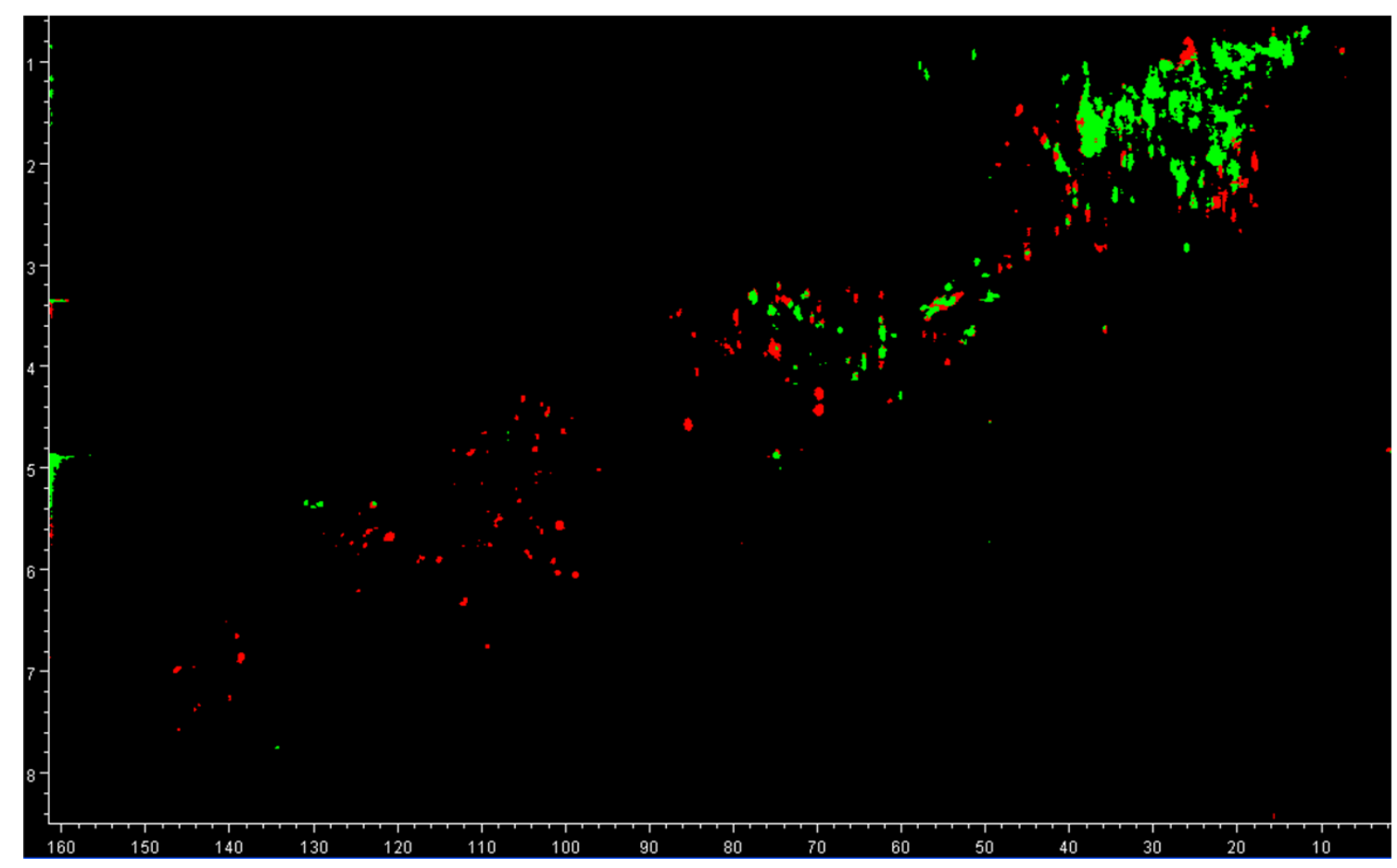

Figure 2.4. HSQC mask applied to the crude screen of Raspailia topsenti.

\subsection{Investigation of Two Unidentified Sponge Species}

Promising HSQC screen results lead to the brief investigation of two unidentified sponges, MNP0996 and MNP1003. The HSQC screen of MNP0996 (Figure 2.5) shows a variety of low intensity uncommon resonances whilst the screen of MNP1003 (Figure 2.6) shows a variety of uncommon resonances with a slightly higher intensity.

Interestingly the mass of the $20 \% \mathrm{Me}_{2} \mathrm{CO} / \mathrm{H}_{2} \mathrm{O}$ fraction of MNP0996 was unexpectedly high when compared to the masses of the other fractions. Attempts to obtain a ${ }^{1} \mathrm{H}$ NMR spectrum of this fraction were relatively unsuccessful as it was not completely soluble in $\mathrm{CD}_{3} \mathrm{OD}, d_{6}$-DMSO or $\mathrm{D}_{2} \mathrm{O}$.

The ${ }^{1} \mathrm{H}$ NMR analysis of the other cyclic loading fractions of MNP0996 and MNP1003 showed some interesting resonances, despite this no further analysis was performed, as the focus of the study shifted to Darwinella oxeata (Chapter 3). However both sponges warrant further investigation by another researcher. 


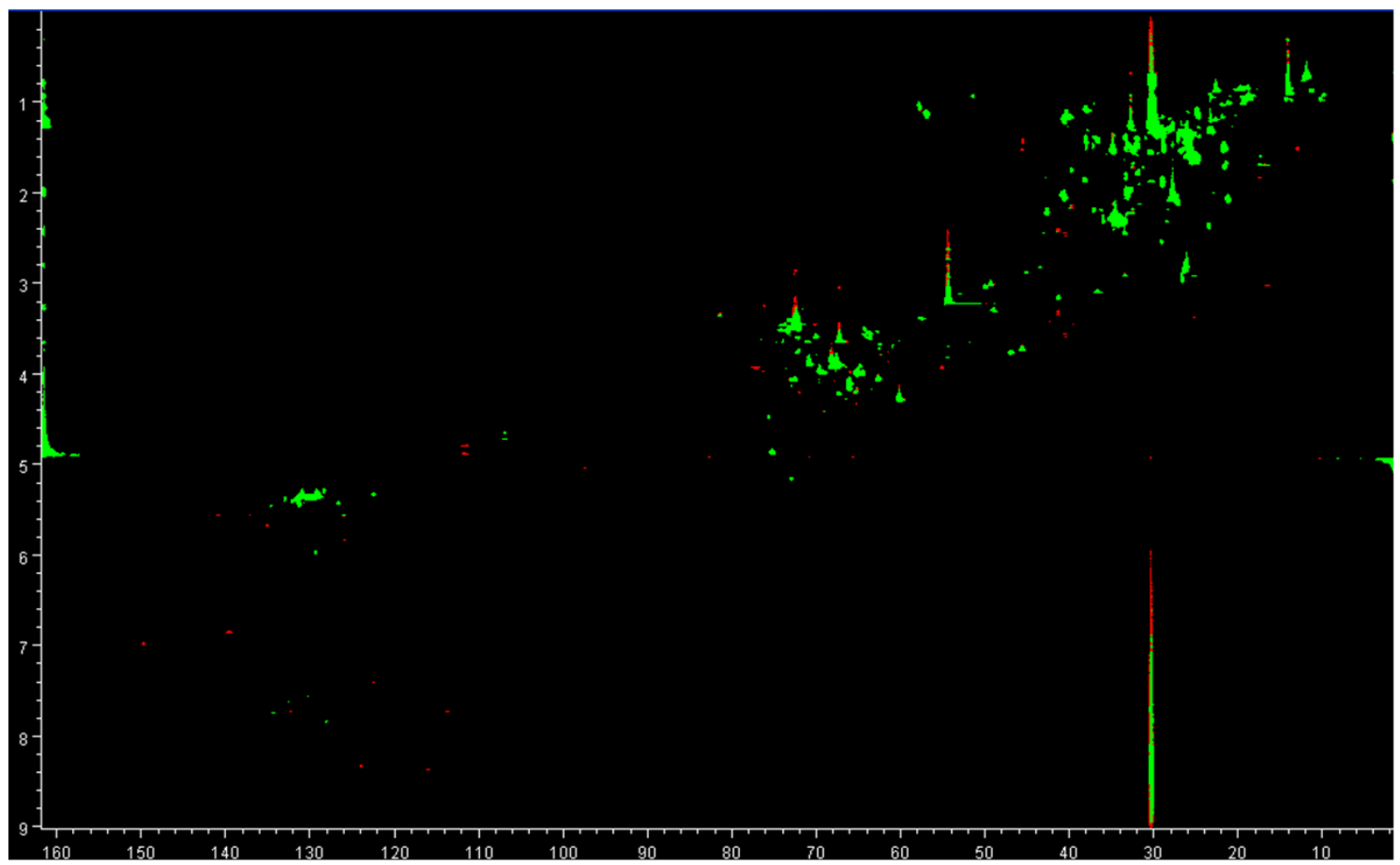

Figure 2.5. HSQC mask applied to the crude screen of MNP0996.

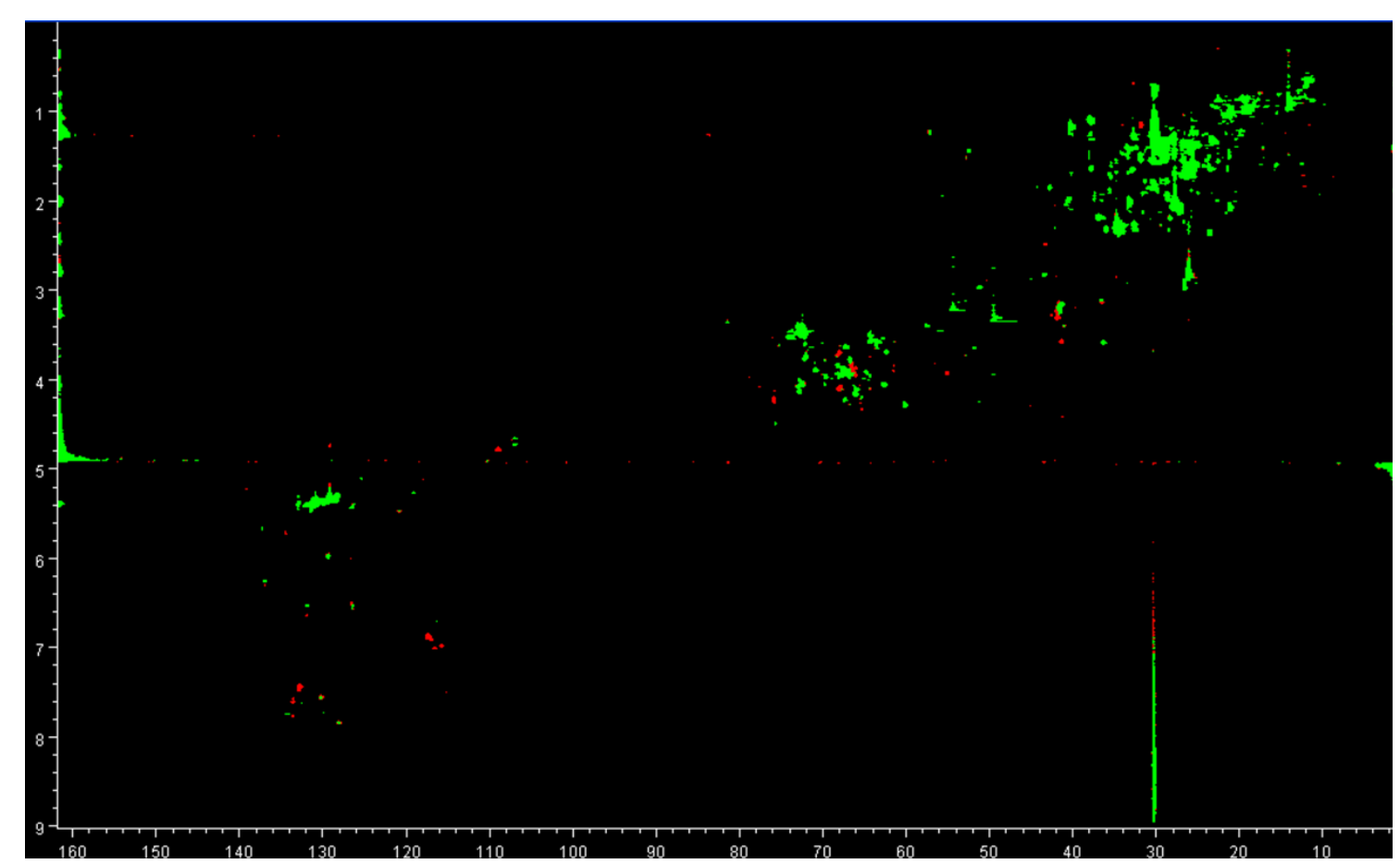

Figure 2.6. HSQC mask applied to the crude screen of MNP1003. 


\section{Chapter 3}

\section{Investigation of Darwinella oxeata}

\subsection{Darwinella oxeata}

A large group within the Demospongiae class, known as keratose sponges (encompassing the Dendroceratida, Dictyoceratida and Verongida orders), lack mineral spicules and instead possess spongian fibres which reinforce the sponge matrix. ${ }^{19}$ Taxonomic classification of keratose sponges relies on such factors as fibre arrangement and chemotaxonomic trends. The isolation of spongian diterpenes from keratose sponges in part led to the revision of the Dendroceratida order in $1990 .{ }^{21}$ Keratose sponges lack the physical protection of spicules and are thus a target for predation. ${ }^{19}$ The high levels of secondary metabolites isolated from the keratose sponges may be an example of the evolutionary response to the enhanced threat of predation.

Darwinella oxeata belongs to the family Darwinellidae, which, along with Dictyodendrillidae, are members of the Dendroceratida order (Table 3.1). D. oxeata (Figure 3.1) is a sulfur yellow coloured, thin, encrusting sponge most commonly located on steep-sloping reefs and canyon walls at depths around $15 \mathrm{~m} .{ }^{47}$ It is found throughout New Zealand and Australian waters. ${ }^{47,48}$ The species, whilst lacking inorganic spicules, can be distinguished from other Darwinella species by the notched surface of its spongian fibres. ${ }^{47}$ Collections of this species from Australasian waters have in the past been misidentified as Aplysilla sulphurea due to similar surface pigmentation and morphology. ${ }^{19,48,49}$ Hooper and van Soest believe that there is a very low incidence of Aplysilla within Australasia and that the majority of common encrusting darwinellids are species of Darwinella. ${ }^{19}$ 


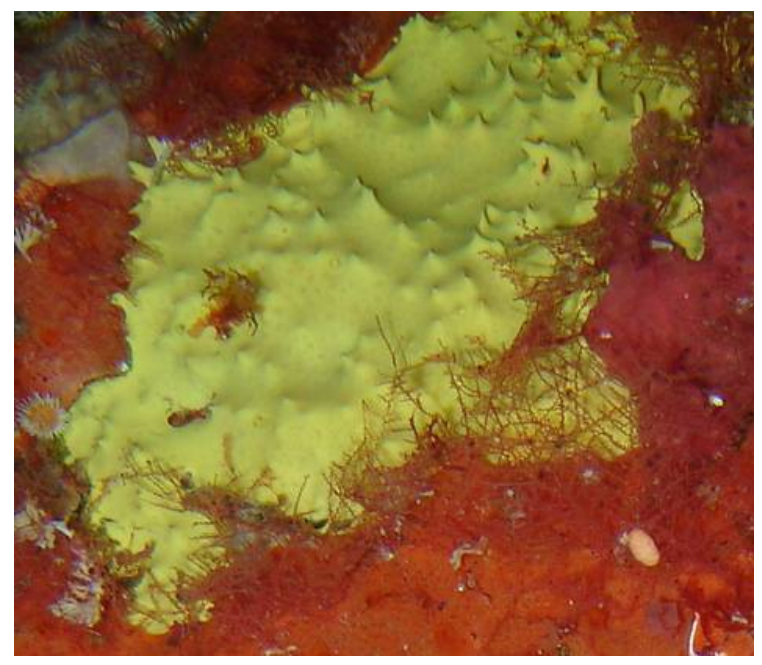

Figure 3.1. Underwater photo of Darwinella oxeata, courtesy of Kel Nairn.

Table 3.1. Taxonomic classification of genus Darwinella from order Dendroceratida. ${ }^{19}$

\begin{tabular}{llll}
$\begin{array}{l}\text { Order } \\
\text { Dendroceratida }\end{array}$ & Family & Genus & Species \\
\hline & Darwinellidae & \\
\cline { 2 - 3 } & & & \\
& & Aplysilla \\
& Chelonaplysilla & \\
& Darwinella & oxeata \\
& Dendrilla & \\
& Dictyodendrilidae & & \\
\hline & & Acanthodendrilla \\
& & Dictyodendrilla \\
& Igernella \\
& Spongionella
\end{tabular}




\subsection{Chemical Ecology of Darwinella oxeata}

Nine compounds have been reported from Darwinella oxeata, including $13^{2}, 17^{3}$-cyclopheophorbide (15), the first porphyrin reported from a sponge. ${ }^{41,48-50}$ The majority of the compounds isolated from this sponge are in fact rearranged spongian diterpenoids with the aplysulphurane backbone (16). ${ }^{41,48,49,51}$ The first compound reported from D. oxeata was aplysulphurin (17) in $1984 .{ }^{48}$ Though the sponge was initially identified as Aplysilla sulphurea, it was later reclassified in 1986 by the same group. ${ }^{49}$ The tetrahydroaplysulphurins $-1(\mathbf{1 8}),-2(\mathbf{1 9})$ and $-3(\mathbf{2 0})$ were reported by Karuso et al. in 1986. ${ }^{49}$ Most recently, Wojnar reported four nitrogenous rearranged spongian diterpenes in 2008: oxeatamide A (21), oxeatamide A 23-methyl ester (22), iso-oxeatamide A (23) and oxeatamide B (24). ${ }^{41}$

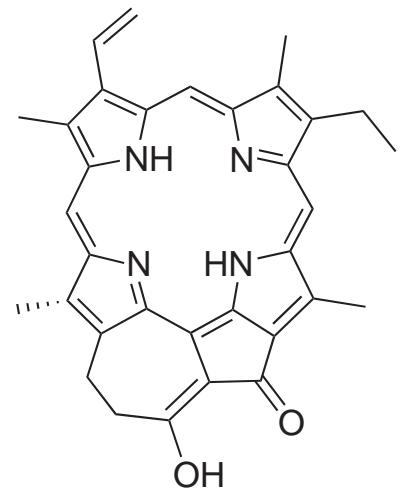

15<smiles>CC(=O)O[C@H]1CCC2=C([C@]3(C)CCCC(C)(C)C3)[C@H](C)C(=O)O[C@@H]2O1</smiles>

18<smiles>CC(C)c1ccc2c(c1[C@H](C)C(=O)O)CN(C)C2=O</smiles><smiles>CC(C)C1C2CCCC2CCC1[C@]1(C)CCCC(C)(C)C1</smiles>

16<smiles>CC(=O)O[C@H]1CC[C@H](C2(C)CCCC(C)(C)C2)C2=C1[C@H](C)C(=O)O[C@H]2O</smiles>

19<smiles>CC(=O)OC1O[C@@H]2OC(=O)[C@H](C)c3c(C4(C)CCCC(C)(C)C4)ccc1c32</smiles>

17<smiles>CC(=O)O[C@H]1O[C@@H]2OC(=O)C(C)=C3C(C4(C)CCCC(C)(C)C4)CC[C@@H]1[C@@H]32</smiles>

20

$21 \mathrm{R}=\xi^{-3} \mathrm{COOH}$

$22 \mathrm{R}=\xi^{\mathrm{s}} \mathrm{COOMe}$

$24 \mathrm{R}=$<smiles>C[C@H](C(=O)O)c1c([C@]2(C)CCCC(C)(C)C2)ccc2c1C(=O)N(CC(=O)O)C2</smiles>

23 


\subsubsection{Isolation of New Nitrogenous Aplysulphuranes from Darwinella}

\section{oxeata}

A sponge identified as Darwinella oxeata was collected from Archway Bay, Cape Brett, Northland. A sample of this sponge was screened by other researchers in the Marine Natural Products Group at VUW, using the screening protocol described in Chapter 1. The screen was assessed as promising due to the high number of uncommon HSQC correlations that can be seen in red in Figure 3.2.

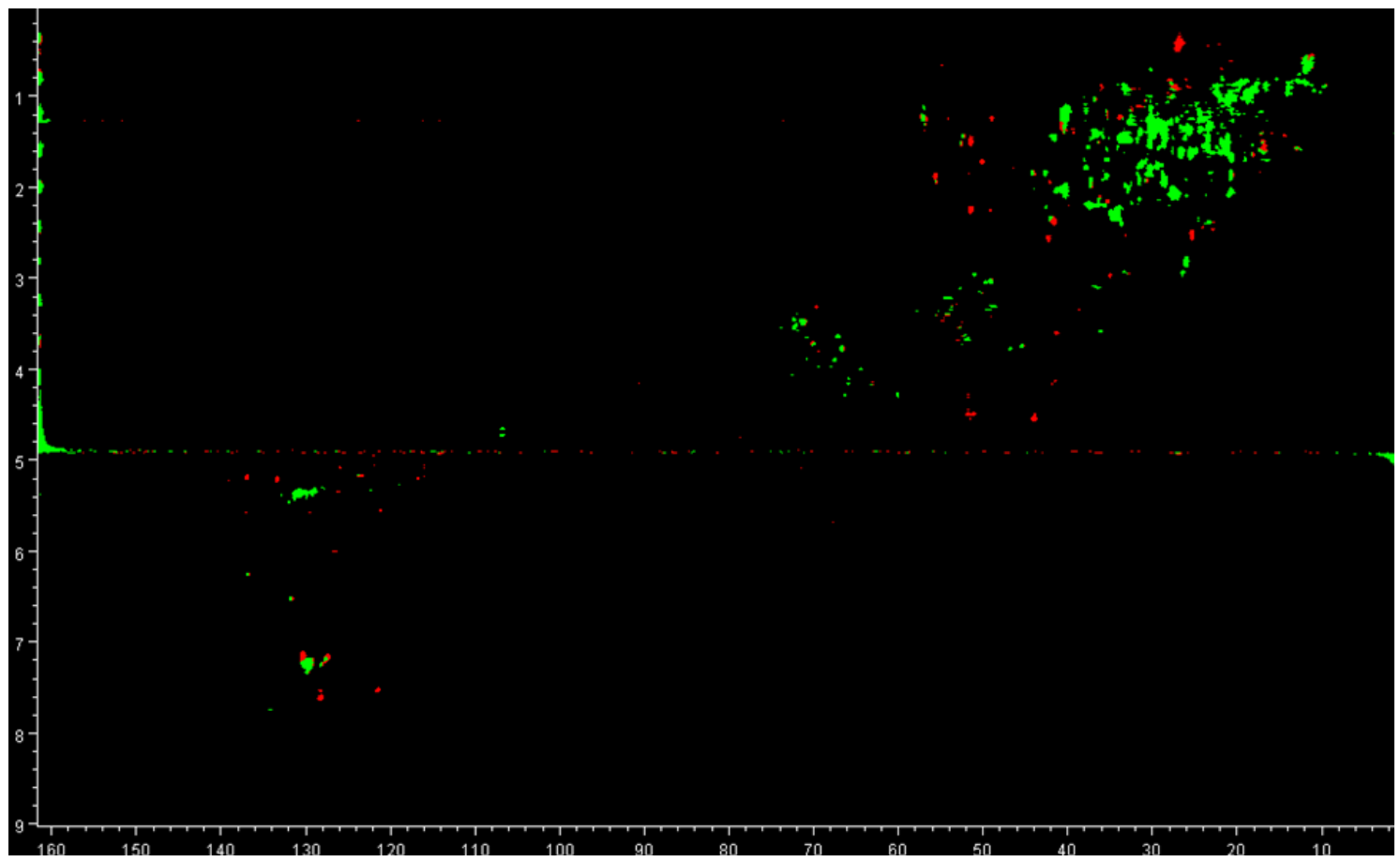

Figure 3.2. HSQC mask applied to the crude screen of Darwinella oxeata.

The sponge was extracted in $\mathrm{MeOH}$ and the extract was cyclic loaded on to a column of reversed-phase PSDVB resin. The resin was batch eluted with increasing amounts of $\mathrm{Me}_{2} \mathrm{CO}$ in $\mathrm{H}_{2} \mathrm{O}$ and the fractions analysed by NMR. The ${ }^{1} \mathrm{H}$ NMR spectra of the $20 \%$ and $40 \% \mathrm{Me}_{2} \mathrm{CO} / \mathrm{H}_{2} \mathrm{O}$ fractions appeared to contain one main compound, later identified as the known compound oxeatamide A (21). Further chromatographic steps employing bench-top normal-phase chromatography followed by reversed-phase HPLC (depicted in Scheme 3.1) led to the isolation of three known compounds oxeatamide A (21), isooxeatamide A (23) and oxeatamide B (24), and one new compound, oxeatamide C (25).

The NMR spectra of the $60 \% \mathrm{Me}_{2} \mathrm{CO} / \mathrm{H}_{2} \mathrm{O}$ fraction showed a mixture of structurally similar compounds and contained many interesting resonances. Futher chromatographic 
steps including normal-phase bench-top chromatography followed by reversed-phase HPLC (Scheme 3.2), led to the isolation of four new compounds oxeatamides D (26), E (27), F (28) and G (29), as well as two known compounds membranolides C (30) ${ }^{52}$ and $\mathrm{D}(\mathbf{3 1}){ }^{52}$ 


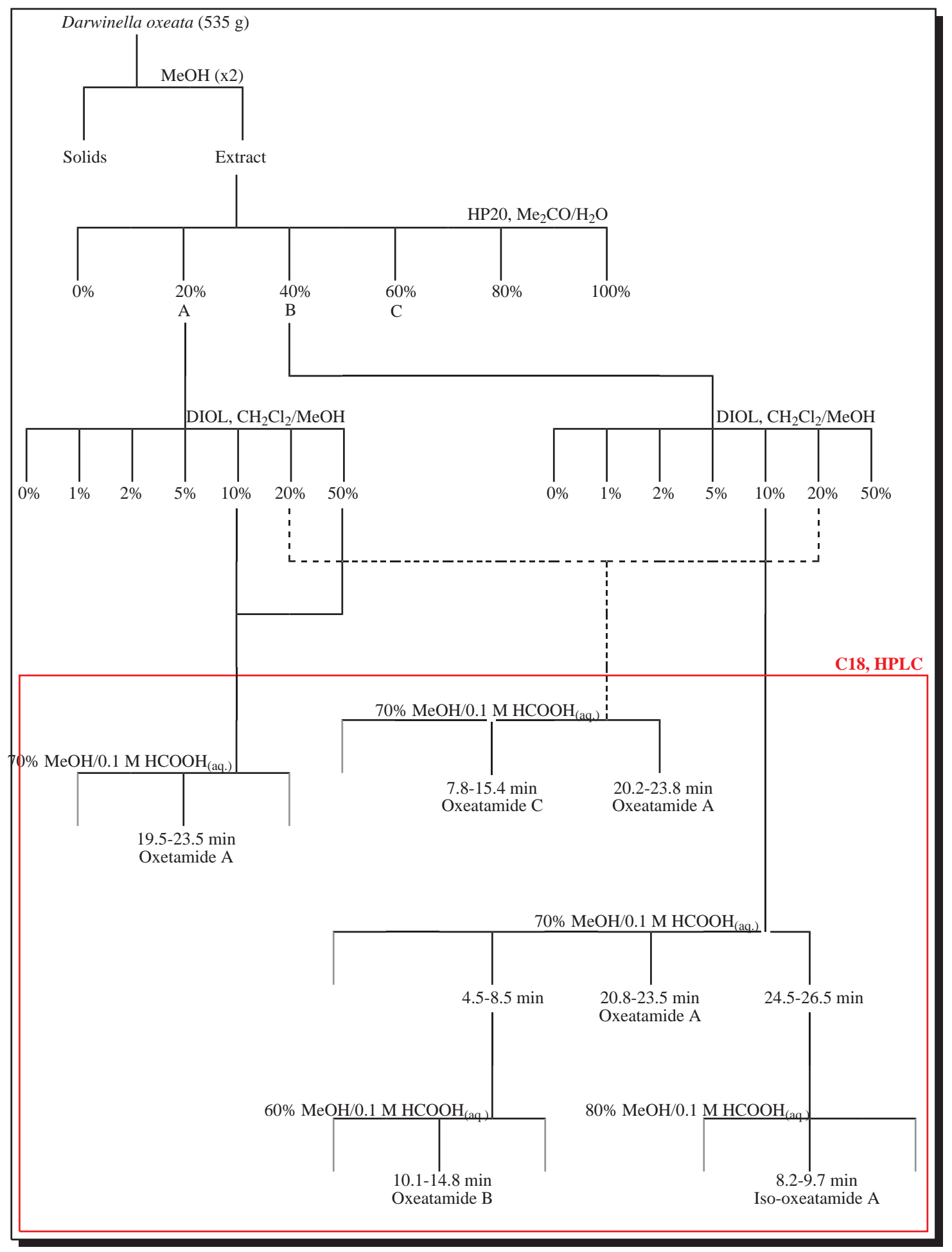

Scheme 3.1. Isolation of oxeatamides A (21), B (24) and C (25), and iso-oxeatamide A (23). 


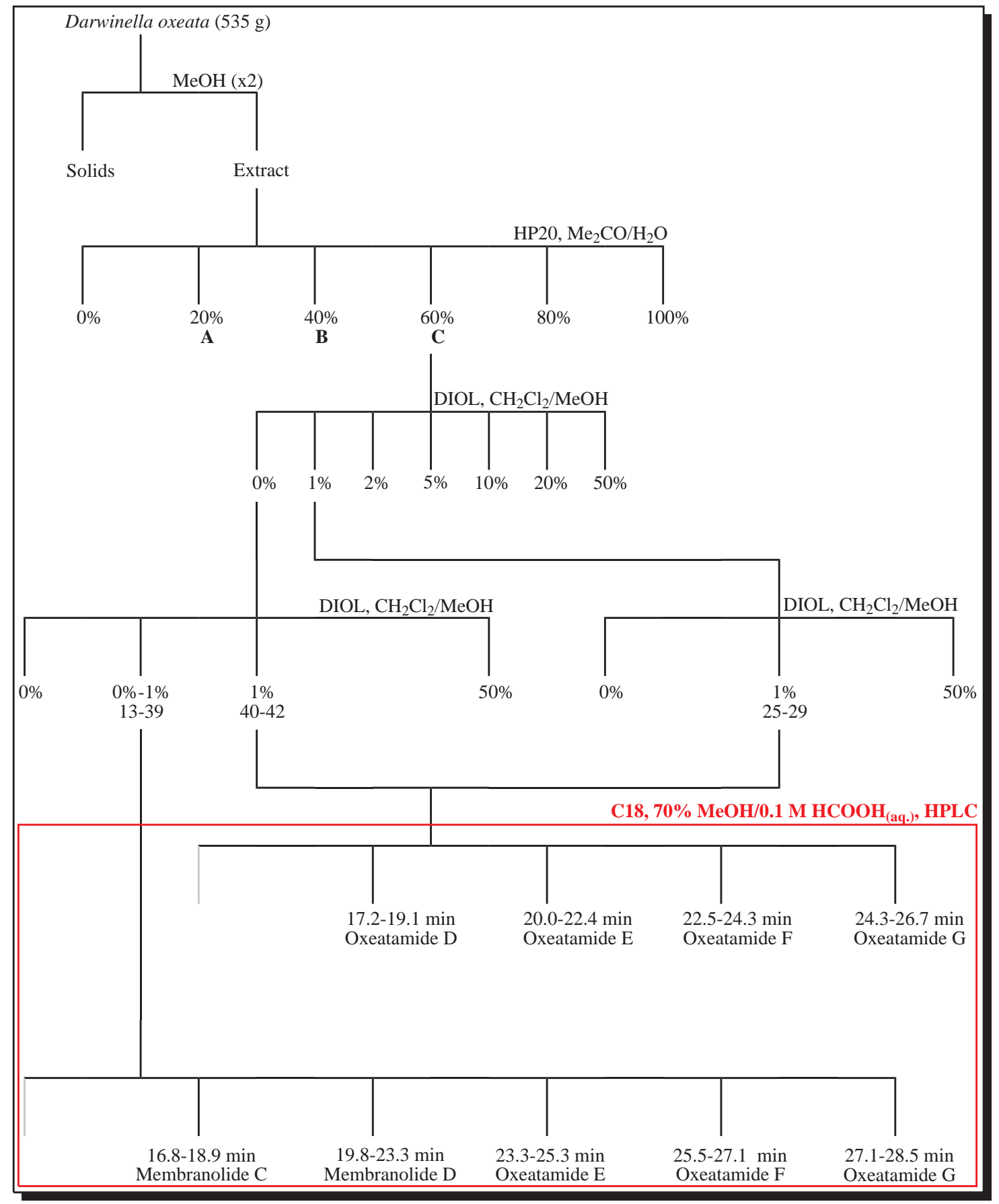

Scheme 3.2. Isolation of oxeatamides D (26), E (27), F (28) and G (29), and membranolides C (30) and D (31). 


\subsection{Known Compounds Isolated from Darwinella oxeata}

Five known compounds were isolated from Darwinella oxeata, oxeatamides A (21), B (24), iso-oxeatamide A (23) and membranolides C (30) and D (31).

\subsubsection{Oxeatamide A, B and Iso-oxeatamide A}

Purification with HPLC led to the isolation of oxeatamides A (21), B (24) and isooxeatamide A (23). As these compounds had been recently isolated by Wojnar, another member of the Marine Natural Products group at VUW, they were readily identified by comparison of their NMR data. ${ }^{41}$

\subsubsection{Membranolide $\mathrm{C}$ and $\mathrm{D}$}

Use of HPLC led the isolation of two impure compounds with a different chromophore to the oxeatamides (depicted in diode array trace, Figure 3.3). Preliminary NMR analysis showed similarites to the aplysulphurane diterpene skeleton (16) of the oxeatamides, however the signals characteristic of the nitrogenous moiety were notably absent and instead two acetal signals were apparent. A literature search of the aplysulphurane class and comparison of the NMR data revealed the compounds to be membranolides $\mathrm{C}$ (30) and D (31). Membranolides C (30) and D (31) had not previously been isolated from Darwinella oxeata, however Ankisetty et al. reported $\mathbf{3 0}$ and $\mathbf{3 1}$ from the Antarctic sponge Dendrilla membranosa in $2004 .^{52}$ 


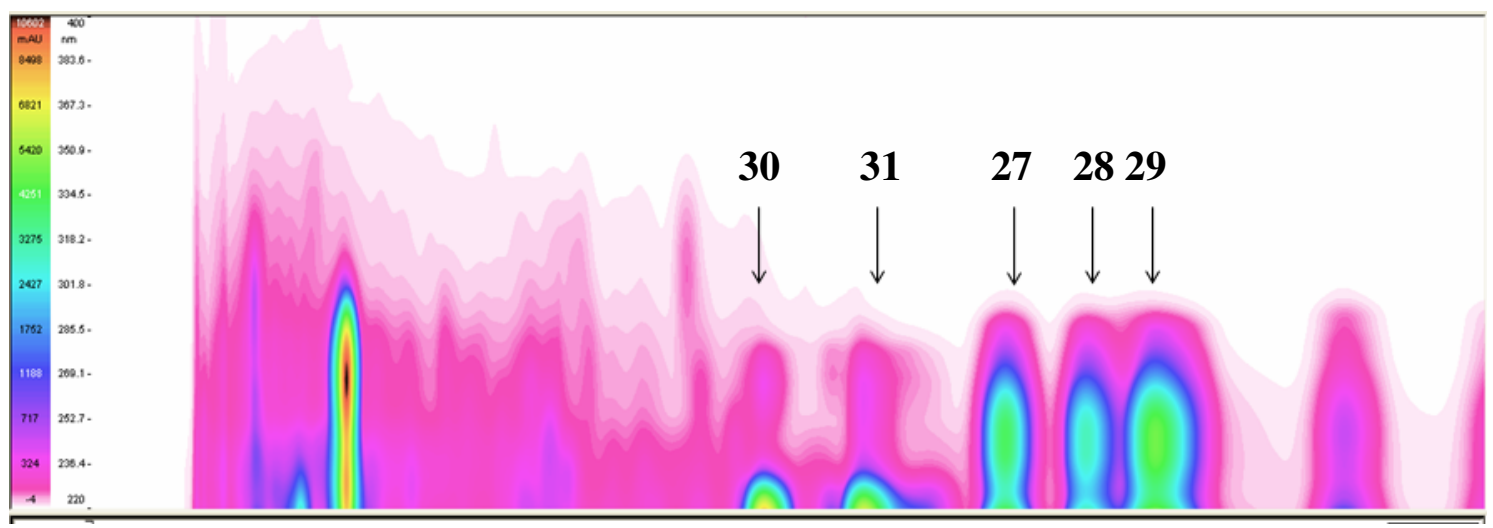

Figure 3.3. Diode array trace of HPLC separation of the membranolides C (30) and D (31), and oxeatamides E (27), F(28) and G (29).

\subsection{New Oxeatamides Isolated}

Five new oxeatamides were isolated from Darwinella oxeata. Oxeatamide C (25) was isolated from an early polar fraction that was also found to contain three previously reported oxeatamides - oxeatamide A (21), iso-oxeatamide A (23) and oxeatamide B (24) — as detailed in Scheme 3.1. Oxeatamides D to G (26-29) were isolated from a mid-polarity fraction that also contained membranolides C (30) and D (31), as detailed in Scheme 3.2. The diode array trace of the HPLC separation of oxeatamides D to G (26-29) is depicted in Figure 3.4. The structure elucidation of these new compounds follows, a summary of the new structures can be found on page 58 .

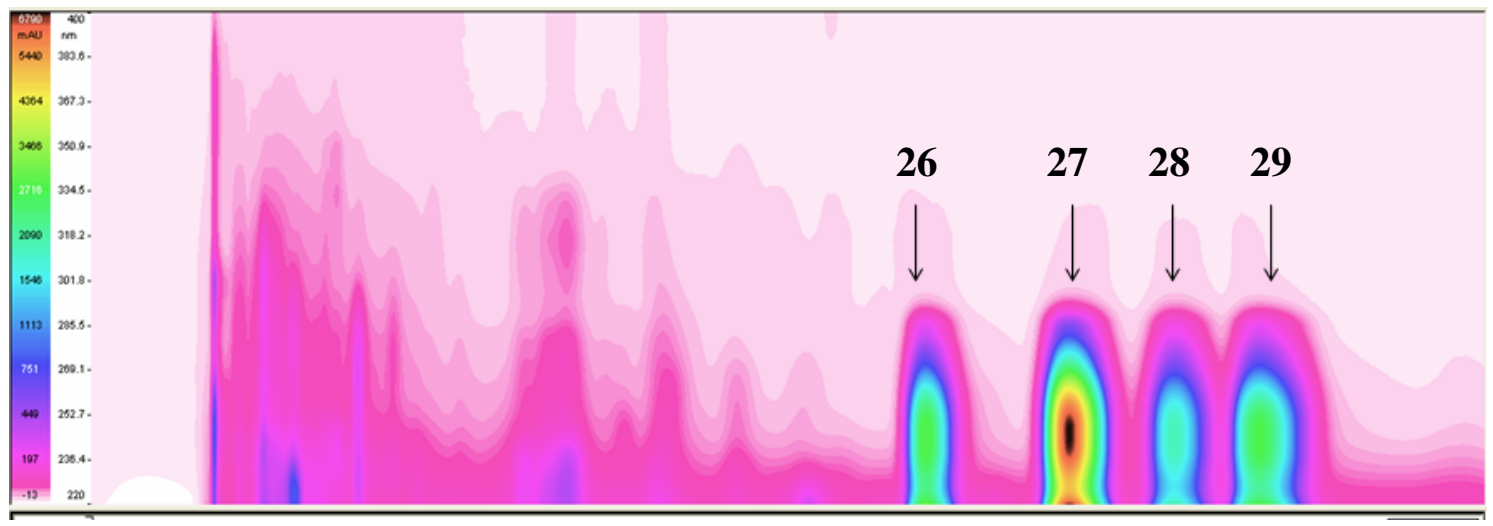

Figure 3.4. Diode array trace of HPLC separation of oxeatamides D, (26) E (27), F(28) and $\mathrm{G}(\mathbf{2 9})$. 


\subsubsection{Oxeatamide D}

Due to the relative lack of spectral overlap and the fact that oxeatamide D (26) possessed only one nitrogen and one set of aromatic ring signals, the structure of $\mathbf{2 6}$ was elucidated first.

The molecular formula $\mathrm{C}_{24} \mathrm{H}_{35} \mathrm{NO}_{3}$ was determined for oxeatamide $\mathrm{D}$ (26) by HRESIMS with the $[\mathrm{M}+\mathrm{Na}]^{+}$pseudomolecular ion at $\mathrm{m} / z 408.2520(\Delta 1.2 \mathrm{ppm})$, requiring eight double bond equivalents. The ${ }^{13} \mathrm{C}$ NMR spectrum contained only 19 resonances, however an additional five resonances were observed in the HSQC and/or HMBC spectra, accounting for all carbons present in the formula. The ${ }^{1} \mathrm{H}$ NMR spectrum accounted for 34 protons, suggesting one exchangeable proton. Initial analysis of the ${ }^{13} \mathrm{C}$ and multiplicity-edited HSQC spectra revealed 16 protonated carbons, six methyls, six methylenes and four methines leaving eight non-protonated carbons. Some carbon resonances were tentatively assigned due to their typical chemical shift values: a carboxylic acid/ester carbonyl C-6 ( $\left.\delta_{\mathrm{C}} 175.8\right)$, an amide/lactam carbonyl C-16 $\left(\delta_{\mathrm{C}} 168.4\right)$ and aromatic resonances $\mathrm{C}-8\left(\delta_{\mathrm{C}} 134.3\right), \mathrm{C}-9\left(\delta_{\mathrm{C}} 150.3\right), \mathrm{CH}-11\left(\delta_{\mathrm{H}} 7.61 ; \delta_{\mathrm{C}} 127.6\right)$, $\mathrm{CH}-12\left(\delta_{\mathrm{H}} 7.68 ; \delta_{\mathrm{C}} 122.4\right), \mathrm{C}-13\left(\delta_{\mathrm{C}} 131.6\right)$ and $\mathrm{C}-14\left(\delta_{\mathrm{C}} 141.3\right) .{ }^{53}$ The presence of an aromatic ring was supported by the typical aromatic chemical shifts of the proton resonances attached to the two aromatic methines. ${ }^{53}$ The two carbonyl groups and the aromatic ring system accounted for six double bond equivalents suggesting the compound contained two other ring systems.

COSY correlations between methylene $\mathrm{H}_{2}-1\left(\delta_{\mathrm{H}} 2.36,1.47 ; \delta_{\mathrm{C}} 41.0\right)$ and methylene $\mathrm{H}_{2}-2$ $\left(\delta_{\mathrm{H}} 1.82,1.66 ; \delta_{\mathrm{C}} 20.0\right)$, and between $\mathrm{H}_{2}-2$ and methylene $\mathrm{H}_{2}-3\left(\delta_{\mathrm{H}} 1.33,1.27 ; \delta_{\mathrm{C}} 39.6\right)$ established the methylene chain $\mathrm{CH}_{2}-1$ to $\mathrm{CH}_{2}-3$ (Figure 3.5).

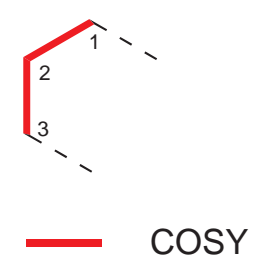

Figure 3.5. COSY correlations establishing connectivity of C-1 to C-3 of oxeatamide D (26).

Analysis of the HMBC spectrum showed four correlations from $\mathrm{H}_{3}-20\left(\delta_{\mathrm{H}} 1.46 ; \delta_{\mathrm{C}} 32.9\right)$ 
to $\mathrm{C}-1, \mathrm{C}-5\left(\delta_{\mathrm{H}} 2.06,1.51 ; \delta_{\mathrm{C}} 50.8\right), \mathrm{C}-10\left(\delta_{\mathrm{C}} 39.7\right)$ and C-9. As a methyl singlet, $\mathrm{CH}_{3}-20$ must be attached to the alkyl quaternary carbon $\mathrm{C}-10$ which in turn must be adjacent to C-1, C-5 and C-9. The assignment of C-5 and C-10 as adjacent carbons was supported by HMBC correlations observed from H-5b to C-10 and C-20, in conjunction with longrange W-coupling observed in the COSY spectrum between H-1a and H-5a (Figure 3.6).

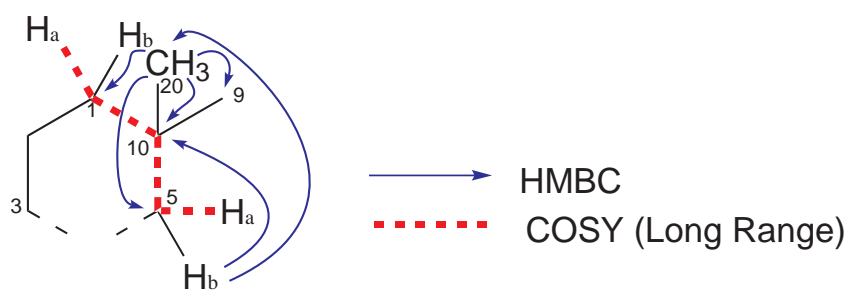

Figure 3.6. Key HMBC and COSY correlations establishing the connectivity around the quaternary centre C-10 of oxeatamide D (26).

A gem-dimethyl moiety was established from $\mathrm{HMBC}$ correlations from $\mathrm{H}_{3}-18\left(\delta_{\mathrm{H}} 0.41\right.$; $\left.\delta_{\mathrm{C}} 27.3\right)$ and $\mathrm{H}_{3}-19\left(\delta_{\mathrm{H}} 0.91 ; \delta_{\mathrm{C}} 32.9\right)$ to each other's carbons, their attachment point C-4 $\left(\delta_{\mathrm{C}} 31.8\right)$ and to the methylene carbons C-3 and C-5 on either side. An HMBC correlation from $\mathrm{H}_{2}-5$ to $\mathrm{C}-4$ was also evident. $\mathrm{HMBC}$ correlations from $\mathrm{H}_{3}-18$ and $\mathrm{H}_{3}-19$ to $\mathrm{C}-3$ indicated that the gem-dimethyl moiety was attached to the $\mathrm{CH}_{2}-3$ side of the methylene chain fragment. This established substructure A (depicted in Figure 3.7), as a trimethyl substituted cyclohexane ring.

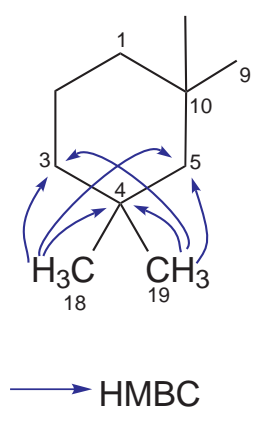

Figure 3.7. Key HMBC correlations establishing the connectivity of the cyclohexane ring, substructure A, of oxeatamide D (26).

Six aromatic signals were observed in the ${ }^{13} \mathrm{C}$ NMR consisting of two methines, $\mathrm{CH}-$ 11 and $\mathrm{CH}-12$, and four non-protonated carbons C-8, C-9, C-13 and C-14, suggesting a tetra-substituted benzene ring. The aromatic methine protons $\mathrm{H}-11$ and $\mathrm{H}-12$ appeared as doublets in the ${ }^{1} \mathrm{H}$ NMR spectrum with a coupling constant of $8.1 \mathrm{~Hz}$, indicating ortho placement, ${ }^{53}$ this was supported by the COSY correlation observed between them. 
HMBC correlations observed from the protons of the two aromatic methines helped to define the connectivity of the ring. The HMBC experiment is generally optimised for ${ }^{\mathrm{X}} J_{\mathrm{CH}}$ of $8 \mathrm{~Hz}$. HMBC correlations in aromatic systems are unusual as ${ }^{3} J_{\mathrm{CH}}$ values are typically larger than ${ }^{2} J_{\mathrm{CH}}$ values; in benzene the ${ }^{2} J_{\mathrm{CH}}$ is $1.0 \mathrm{~Hz}$ whilst the ${ }^{3} J_{\mathrm{CH}}$ is $7.4 \mathrm{~Hz} .{ }^{53}$ Thus two-bond HMBC correlations usually appear weaker than three-bond HMBC correlations in aromatic systems. Proton H-11 showed strong HMBC correlations to C-13 and C-8, indicating three-bond connectivity and weak HMBC correlations to C-9 indicating twobond connectivity. Strong HMBC correlations observed from H-12 to C-9 and C-14 indicated three-bond connectivity, while weak HMBC correlations were also observed to C-11 and C-13 indicating two-bond connectivity, allowing the assignment of the aromatic positions and establishing substructure B, depicted in Figure 3.8.

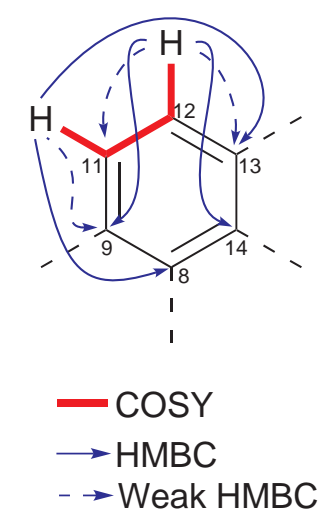

Figure 3.8. COSY and HMBC correlations establishing substructure B of oxeatamide D (26).

COSY correlations observed between methine $\mathrm{H}-7\left(\delta_{\mathrm{H}} 4.75 ; \delta_{\mathrm{C}} 40.5\right)$ and methyl $\mathrm{H}_{3}-17$ $\left(\delta_{\mathrm{H}} 1.63 ; \delta_{\mathrm{C}} 15.5\right)$ suggested that $\mathrm{C}-7$ and $\mathrm{C}-17$ were adjacent carbons. This was supported by the doublet signal observed in the ${ }^{1} \mathrm{H}$ NMR for $\mathrm{H}_{3}-17$, which indicated methyl $\mathrm{CH}_{3}-17$ was attached to a methine. Correlations apparent in the HMBC spectrum from $\mathrm{H}-7$ and $\mathrm{H}_{3}-17$ to the carbonyl resonance $\mathrm{C}-6\left(\delta_{\mathrm{C}} 175.8\right)$ suggested that $\mathrm{C}-6$ was adjacent to $\mathrm{CH}-7$ establishing substructure C (Figure 3.9). 


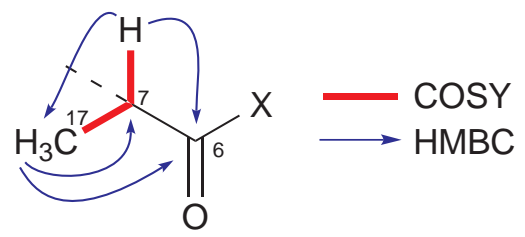

Figure 3.9. $\mathrm{COSY}$ and $\mathrm{HMBC}$ correlations used to establish substructure $\mathrm{C}$ of oxeatamide D (26).

The substitution pattern of the aromatic ring (depicted in Figure 3.10) was assigned based on $\mathrm{HMBC}$ correlations observed to and from positions of the aromatic ring. HMBC correlations observed from $\mathrm{H}-11$ of the aromatic ring to C-10 of the cyclohexyl ring , and similarly from $\mathrm{H}-5 \mathrm{~b}$ of the cyclohexyl ring to $\mathrm{C}-9$ of the aromatic ring as well as from $\mathrm{CH}_{3}-20$ to $\mathrm{C}-9$ placed the cyclohexane ring (substructure A) attached to C-9 and ortho to $\mathrm{H}-11$. HMBC correlations from $\mathrm{H}-7$ and $\mathrm{H}_{3}-17$ to $\mathrm{C}-8$ were used to position substructure $\mathrm{C}$ as the substituent at C-8.

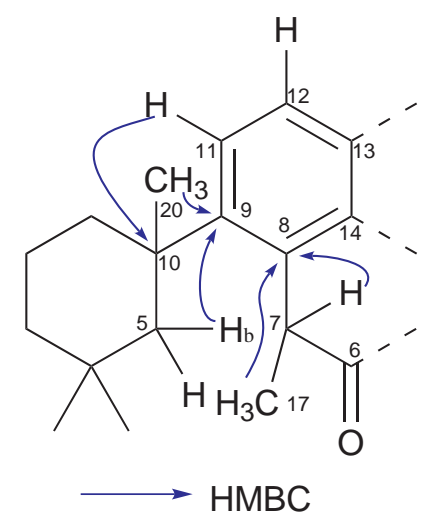

Figure 3.10. Placement of aromatic substituents of oxeatamide D (26).

A second carbonyl C-16 $\left(\delta_{\mathrm{C}} 168.4\right)$ was positioned adjacent to $\mathrm{C}-13$ based on HMBC correlations observed from $\mathrm{H}-12$ to $\mathrm{C}-16$. $\mathrm{HMBC}$ correlations from $\mathrm{H}_{2}-15$ to $\mathrm{C}-14$ and C-8 suggested $\mathrm{CH}_{2}-15\left(\delta_{\mathrm{H}} 4.38,4.21 ; \delta_{\mathrm{C}} 50.1\right)$ was adjacent to C-14. HMBC correlations were observed from $\mathrm{H}_{2}-15$ to $\mathrm{C}-13$ and $\mathrm{C}-16$. The chemical shift of $\mathrm{C}-16\left(\delta_{\mathrm{C}} 168.4\right)$ was consistent with that of the carbonyl of a lactam (150 ppm-185 ppm) and $\mathrm{CH}_{2}-15$ has ${ }^{1} J_{\mathrm{CH}}$ of $140 \mathrm{~Hz}$ consistent with that for a carbon adjacent to nitrogen. ${ }^{53}$ The chemical nature of $\mathrm{CH}_{2}-15$ and $\mathrm{C}-16$ along with the HMBC correlations observed from $\mathrm{H}_{2}-15$ suggested the presence of a lactam ring (depicted in Figure 3.11) which also accounted for the remaining double bond equivalent. 


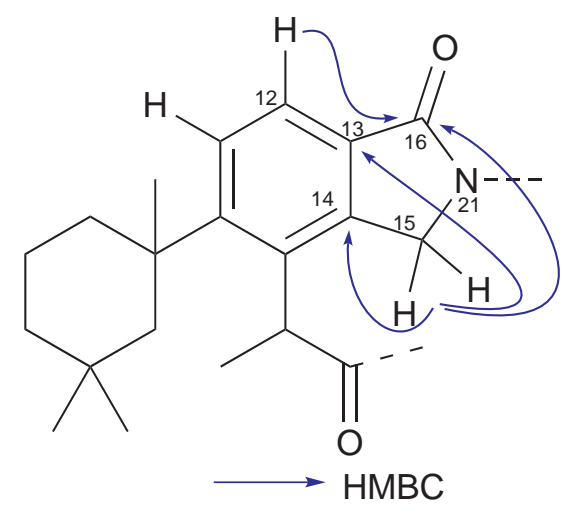

Figure 3.11. HMBC correlations used to establish the connectivity of the lactam ring in oxeatamide D (26).

The NMR data for the aromatic ring and lactam of oxeatamide D (26) were compared to that for oxeatamide A (21) and iso-oxeatamide A (23) to ensure the correct structural isomer of the lactam was assigned (Table 3.2). In 21 the lactam carbonyl is adjacent to C-13 whilst in 23 the lactam carbonyl is adjacent to $\mathrm{C}-14$. The placements of the lactam carbonyl affects the ${ }^{1} \mathrm{H}$ NMR resonance of the aromatic methine proton $\mathrm{H}-12$. In 21, the aromatic methine proton $\mathrm{H}-12$ appears at $7.63 \mathrm{ppm}$ compared to $7.23 \mathrm{ppm}$ for $\mathbf{2 3}$. Thus, the placement of the lactam carbonyl adjacent to $\mathrm{C}-14$, as opposed to $\mathrm{C}-13$, caused the upfield shift of the H-12 resonance in the ${ }^{1} \mathrm{H}$ NMR spectrum. The chemical shift of $\mathrm{H}-$ 11 was not greatly affected by the position of the lactam carbonyl, $7.58 \mathrm{ppm}$ for 21 and $7.61 \mathrm{ppm}$ for 23. The lactam carbonyl placement also affects the chemical shifts of C-13 and $\mathrm{C}-14$. The ${ }^{1} \mathrm{H}$ and ${ }^{13} \mathrm{C}$ NMR data for $\mathbf{2 6}$ were consistent with that for 21, supporting the placement of the lactam carbonyl adjacent to C-13.

Table 3.2. Comparison of the ${ }^{13} \mathrm{C}$ and ${ }^{1} \mathrm{H} \mathrm{NMR}$ chemical shifts $\left(\mathrm{CDCl}_{3}\right)$ for oxeatamide A (21), iso-oxeatamide A (23) and oxeatamide D (26).

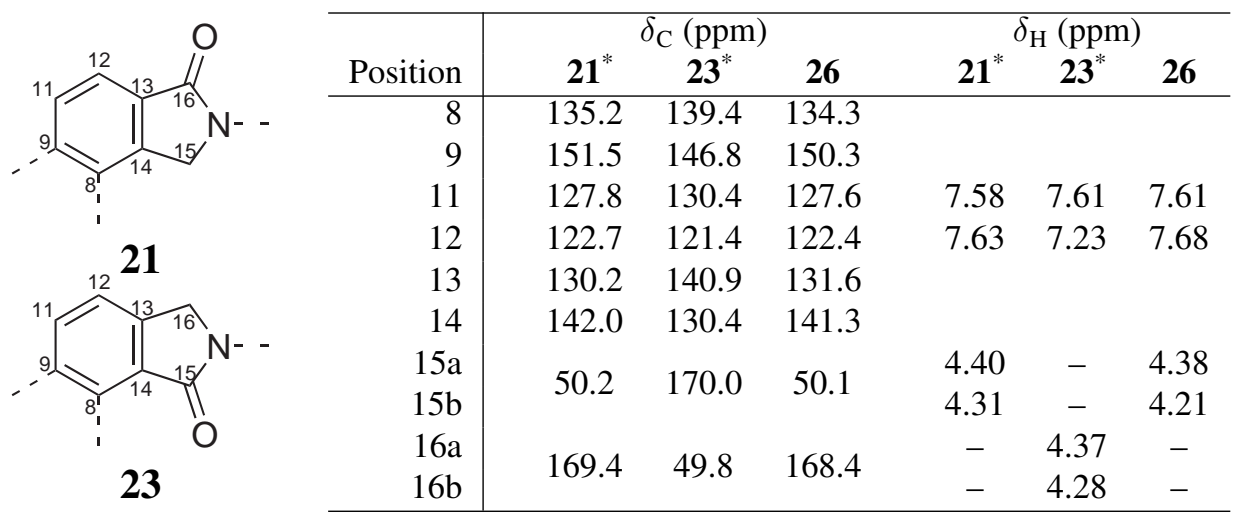

*Wojnar, J. M. Isolation of Novel Secondary Metabolites from New Zealand Marine Organisms, Ph.D. thesis, Victoria University of Wellington, 2008. 
With the carbon skeleton of the oxeatamide backbone (32) established, 20 of the 24 carbons and 25 of the protons were accounted for, leaving a fragment as well as an oxygen and exchangeable proton unassigned. The chemical shift of the C-6 carbonyl was typical of a carboxylic acid, ${ }^{53}$ and thus the exchangable proton and oxygen were assumed to be attached to C-6. Also supporting this assumption was the fact that all the double bond equivalents were already accounted for, precluding a lactone as found in other spongian diterpenes. ${ }^{21}$ The carboxylic acid functionality at C-6 was consistent with the chromatographic behaviour observed (use of $\mathrm{HCOOH}_{\text {(aq.) }}$ during $\mathrm{HPLC}$ as detailed in Scheme 3.2) and the known oxeatamides. ${ }^{41}$

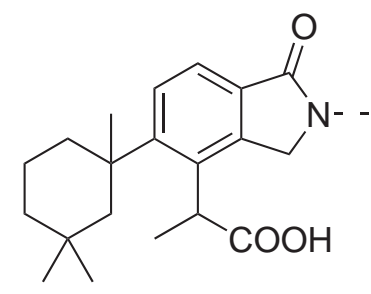

32

Methyls $\mathrm{CH}_{3}-24\left(\delta_{\mathrm{H}} 0.92 ; \delta_{\mathrm{C}} 20.1\right)$ and $\mathrm{CH}_{3}-25\left(\delta_{\mathrm{H}} 0.92 ; \delta_{\mathrm{C}} 20.1\right)$ have the same chemical shifts in both the ${ }^{1} \mathrm{H}$ and ${ }^{13} \mathrm{C}$ NMR spectra, implying identical chemical environments. COSY and HMBC correlations were observed from $\mathrm{H}_{3}-24$ and $\mathrm{H}_{3}-25$ to the methine $\mathrm{CH}$ $23\left(\delta_{\mathrm{H}} 2.02 ; \delta_{\mathrm{C}} 27.8\right)$, and attached $\mathrm{CH}_{3}-24$ and $\mathrm{CH}_{3}-25$ to $\mathrm{CH}-23$, in an isopropyl moiety. HMBC correlations were apparent from $\mathrm{H}-23, \mathrm{H}_{3}-24$ and $\mathrm{H}_{3}-25$ to a methylene C-22 $\left(\delta_{\mathrm{H}} 3.38,3.35 ; \delta_{\mathrm{C}} 50.0\right)$ indicating that $\mathrm{C}-23$ and C-22 were adjacent carbons. Further correlations were observed in the HMBC spectrum from $\mathrm{H}_{2}-22$ to $\mathrm{C}-15$ and $\mathrm{C}-16$ of the lactam ring, these in conjuction with $\mathrm{A}^{1} J_{\mathrm{CH}}$ of $137 \mathrm{~Hz}$ for $\mathrm{CH}_{2}-22$ - consistent for a carbon attached to nitrogen — led to the establishment of the $N$-substituted lactam, depicted in Figure 3.12. The nitrogenous moiety N-21 to C-25 is proposed to arise from a reaction between a terpene precursor and the decarboxylated amino acid valine, this is discussed in more detail in Section 3.6.2.

Whilst the molecular formula of oxeatamide D (26) differs from that of the known oxeatamides, ${ }^{41}$ detailed analysis of the ${ }^{1} \mathrm{H},{ }^{13} \mathrm{C}, \mathrm{COSY}$, HSQC and HMBC showed similar NMR data and structural parallels to oxeatamides A (21) and B (24) with the common oxeatamide backbone (32) $\mathrm{C}_{20} \mathrm{H}_{26} \mathrm{NO}_{3}$ identified. The oxeatamide backbone (32) accounted for all but $\mathrm{C}_{4} \mathrm{H}_{9}$ of the determined molecular formular of 26 . The 


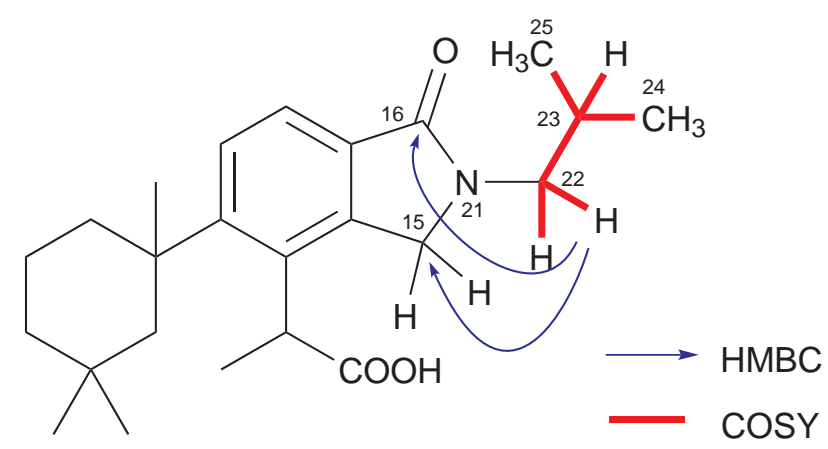

Figure 3.12. COSY and key HMBC correlations establishing the attachment and connectivity of the C-22 to C-25 fragment of oxeatamide D (26).

placement of the 3-methylpropyl $\left(\mathrm{C}_{4} \mathrm{H}_{9}\right)$ fragment, as a substituent of $\mathrm{N}-21$ of the lactam ring completed the structure elucidation of oxeatamide D (26). Therefore the structure of oxeatamide D is given as $\mathbf{2 6}$ with NMR data presented in Table 3.3. 


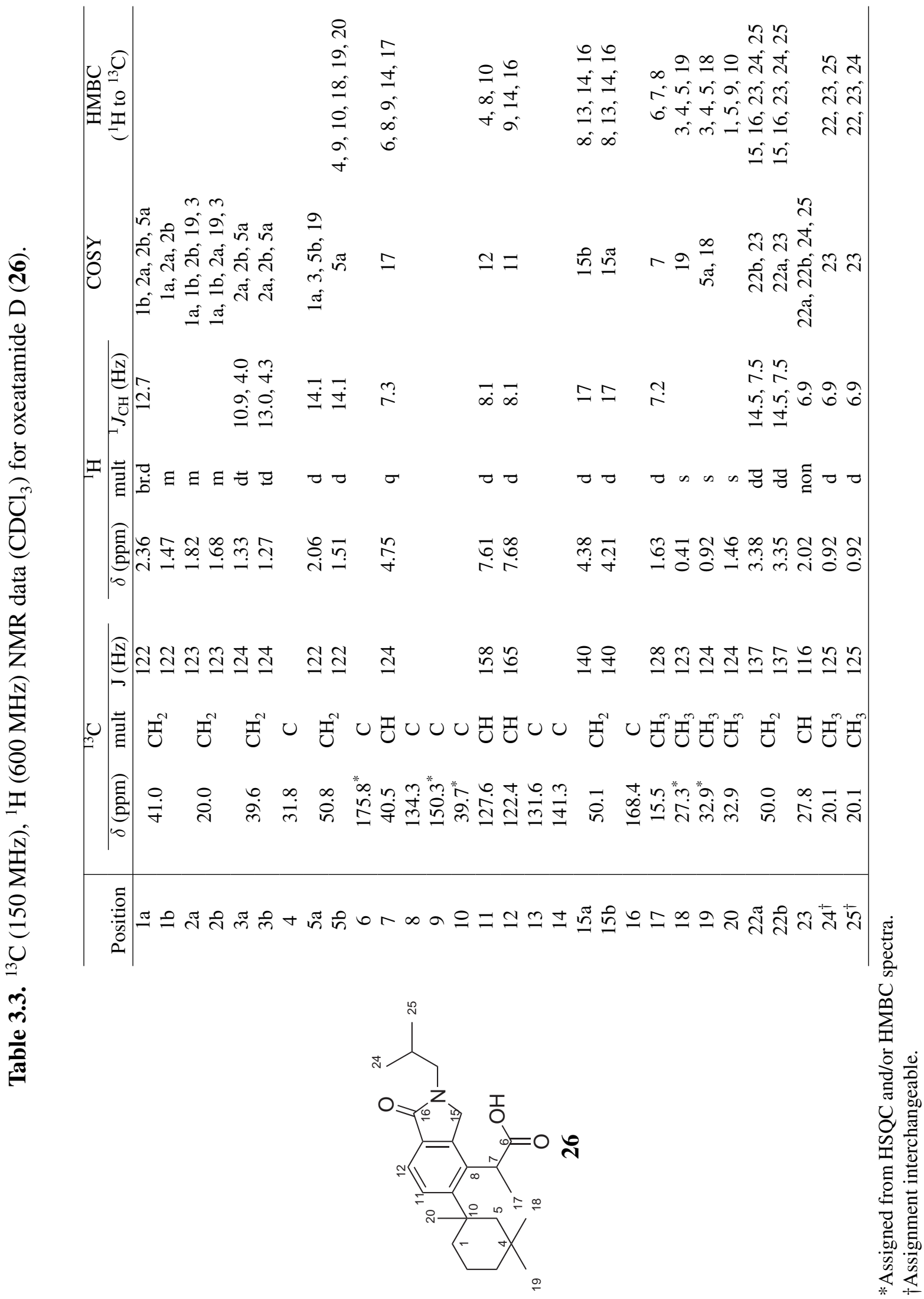




\subsubsection{Relative Configuration of Oxeatamide D}

Interestingly the 2D NOESY spectrum of oxeatamide $\mathrm{D}(\mathbf{2 6})$ obtained in $\mathrm{CDCl}_{3}$ resulted in negative correlations, some of which appeared to be inter- rather than intramolecular. This was consistent with the all negative NOE enhancements observed by Wojnar for oxeatamide $\mathrm{A}(\mathbf{2 1})$ in $\mathrm{CDCl}_{3} \cdot{ }^{41}$ The sign of NOE enhancements are dependent on several factors, including the size of the molecule, the strength of the magnetic field, and the temperature at which the spectrum is run at. It is possible that in $\mathrm{CDCl}_{3}$ (a non-hydrogen bonding solvent), 26 is able to exist as ${ }^{1} \mathrm{H}$-bonded dimers. By running the NOESY spectrum of $\mathbf{2 6}$ in a protic solvent, $\mathrm{CD}_{3} \mathrm{OD}$, dimerisation can not occur and thus positive NOE enhancements were observed.

Oxeatamide D (26) has two chiral centres C-7 and C-10 at which relative configuration was established using selected key NOE enhancements and long-range COSY correlations, depicted in Figure 3.13. NOE enhancements observed between methine $\mathrm{CH}-11$ of the benzene ring and $\mathrm{H}-2 \mathrm{a}$ and $\mathrm{H}_{3}-18$ as well as 1,3-diaxial enhancements observed between $\mathrm{H}-2 \mathrm{a}$ and $\mathrm{H}_{3}-18$ implied that the benzene ring was on the same face of the cyclohexane ring as $\mathrm{CH}_{3}-18$ and $\mathrm{H}-2 \mathrm{a}$, and that they were all axial. The placement of C-9 as axial on the top face implies that methyl C-20 was equatorial.

Also consistent with the major conformer were the $\mathrm{W}$-couplings observed between $\mathrm{CH}_{3}$ 18 and $\mathrm{H}-5 \mathrm{~b}$ and between $\mathrm{H}-5 \mathrm{a}$ and $\mathrm{H}-1 \mathrm{a}$, placing $\mathrm{H}-5 \mathrm{~b}$ axial on the bottom face and $\mathrm{H}-5 \mathrm{a}$ equatorial on the top side. Thus, the major conformer of the ring has $\mathrm{H}-1$ a equatorial, $\mathrm{H}$ 2a axial, $\mathrm{CH}_{3}-18$ axial, $\mathrm{H}-5 \mathrm{~b}$ equatorial and $\mathrm{C}-9$ axial on the top face and $\mathrm{H}-1 \mathrm{~b}$ axial, $\mathrm{H}-2 \mathrm{~b}$ equatorial, $\mathrm{CH}_{3}-19$ equatorial, $\mathrm{H}-5 \mathrm{~b}$ axial and $\mathrm{C}-20$ equatorial on the bottom face. The configuration of methylene protons $\mathrm{H}-3 \mathrm{a}$ and $\mathrm{H}-3 \mathrm{~b}$ was not assigned as there was spectral overlap of their ${ }^{1} \mathrm{H}$ NMR resonances. The relative configuration of chiral centre C-10 was thus assigned to be $S^{*}$.

NOE enhancements were observed between $\mathrm{H}_{3}-17$ and $\mathrm{H}-5 \mathrm{a}$ and $\mathrm{H}_{3}-18$. An NOE enhancement was also seen between $\mathrm{H}_{3}-17$ and $\mathrm{H}-15 \mathrm{a}$. These NOE enhancements, in conjunction with NOE enhancement observed between $\mathrm{H}-7$ and $\mathrm{CH}_{3}-20$, were used to establish the relative configuration of chiral centre C-7 as $R^{*}$. 
Typically for molecules with cyclohexane rings the molecule adopts a conformation where bulky substituents such as phenyl rings are placed equatorially. ${ }^{54}$ For the membranolides and known oxeatamides, which all possess cyclohexane rings, the benzene substituent of the cyclohexane ring is in fact axial. ${ }^{41,52,55}$ This unusual axial placement of the benzene substituent of a cyclohexane ring was also seen in oxeatamide D (26). The overall relative configuration assigned to $26,7 R^{*} 10 S^{*}$, was consistent with the known compounds. ${ }^{41,52,55}$ 


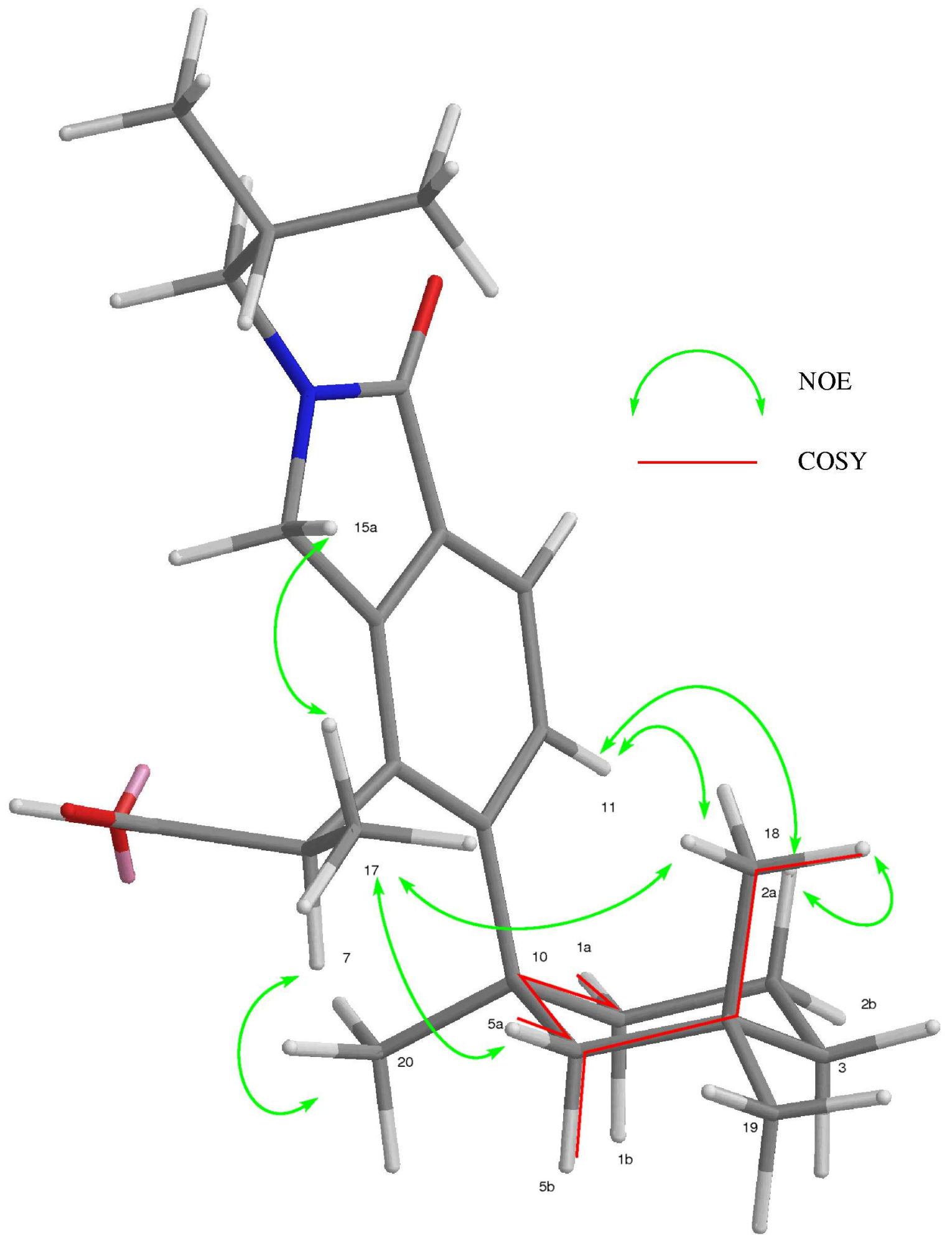

Figure 3.13. Key NOE enhancements of oxeatamide D (26) establishing the relative configuration. W-coupling shown in red. 


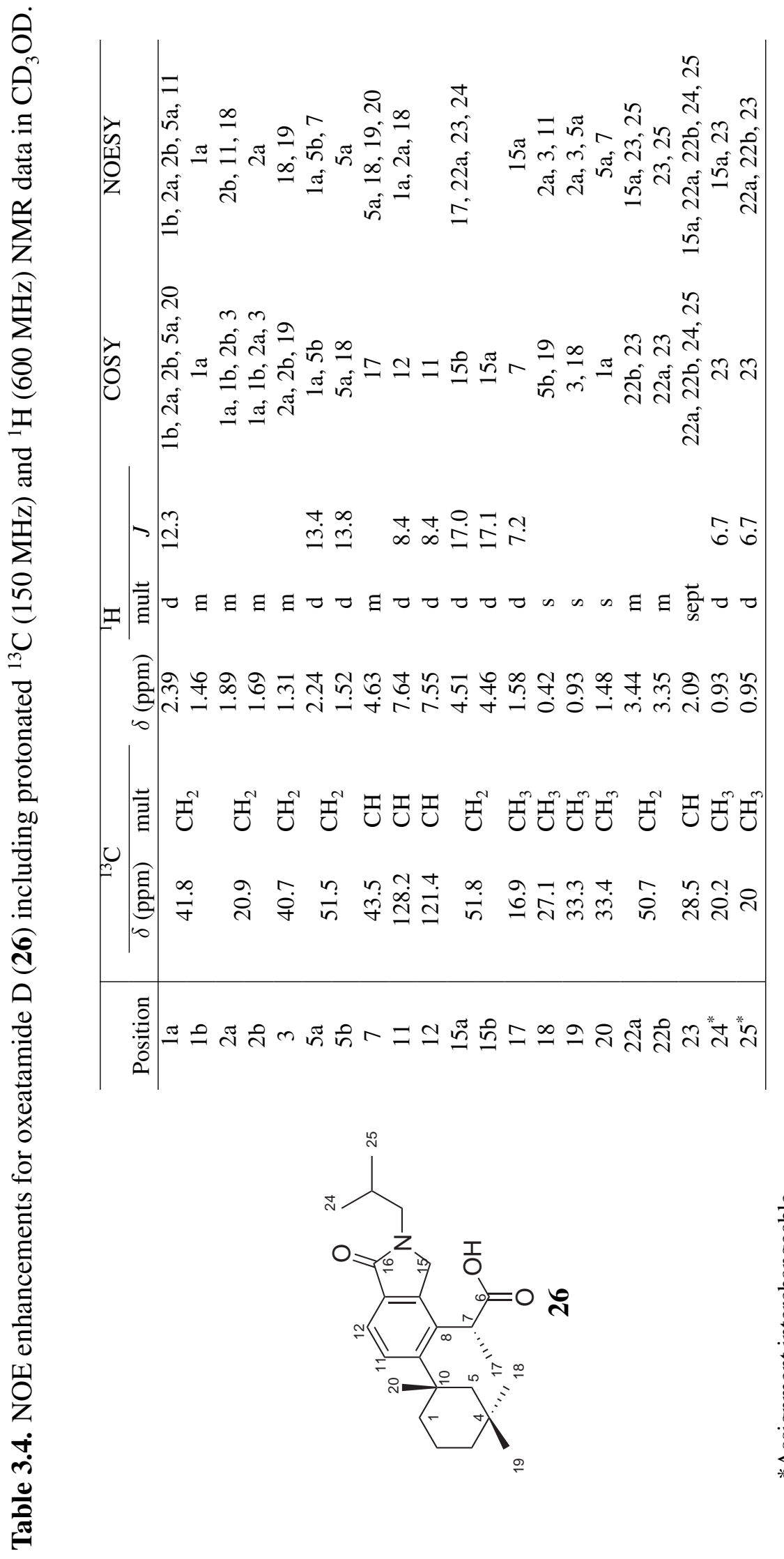




\subsubsection{Oxeatamide $\mathbf{E}$}

The HRESIMS pseudomolecular ion observed at $m / z 456.2518\left([\mathrm{M}+\mathrm{Na}]^{+}\right)$was used to determine the molecular formula $\mathrm{C}_{28} \mathrm{H}_{35} \mathrm{NO}_{3}, \Delta 0.7 \mathrm{ppm}$, for oxeatamide $\mathrm{E}$ (27), which required 12 double bond equivalents. The ${ }^{13} \mathrm{C}$ NMR spectrum contained 26 unique resonances leaving two carbon resonances unaccounted for, indicating spectral overlap or symmetry. The ${ }^{1} \mathrm{H}$ NMR spectrum accounted for only 34 protons, again suggesting the likely presence of one exchangeable proton. Initial analysis of the ${ }^{13} \mathrm{C}$ and multiplicity-edited HSQC NMR spectra revealed 17 unique protonated carbons, four methyls, seven methylenes and six methines, leaving nine non-protonated carbons. The ten aromatic resonances observed indicated the presence of two aromatic aromatic rings. This along with the tentative assignment of a carboxylic acid/ester carbonyl $\left(\delta_{\mathrm{C}} 176.8\right)$ and an amide/lactam carbonyl $\left(\delta_{\mathrm{C}} 168.4\right),{ }^{53}$ accounted for ten double bond equivalents, suggesting the compound contained two other ring systems.

In a similar manner to oxeatamide $\mathrm{D}(\mathbf{2 6})$, the methylene chain $\mathrm{CH}_{2}-1$ to $\mathrm{CH}_{2}-3$ was established via COSY correlations between $\mathrm{H}_{2}-1\left(\delta_{\mathrm{H}} 2.34,1.47 ; \delta_{\mathrm{C}} 40.9\right)$ and $\mathrm{H}_{2}-2$ $\left(\delta_{\mathrm{H}} 1.81,1.66 ; \delta_{\mathrm{C}} 20.0\right)$ and between $\mathrm{H}_{2}-2$ and $\mathrm{H}_{2}-3\left(\delta_{\mathrm{H}} 1.31,1.29 ; \delta_{\mathrm{C}} 39.6\right)$. Four correlations were observed in the HMBC spectrum of oxeatamide E (27) from methyl $\mathrm{H}_{3}$ $20\left(\delta_{\mathrm{H}} 1.44 ; \delta_{\mathrm{C}} 32.8\right)$ to $\mathrm{C}-1, \mathrm{C}-5\left(\delta_{\mathrm{H}} 2.03,1.50 ; \delta_{\mathrm{C}} 50.7\right), \mathrm{C}-10\left(\delta_{\mathrm{C}} 39.7\right), \mathrm{C}-9\left(\delta_{\mathrm{C}} 150.5\right)$. Like oxeatamide D (26), $\mathrm{CH}_{3}-20$ must therefore be attached to the alkyl quaternary carbon $\mathrm{C}-10$ which in turn is adjacent to $\mathrm{C}-1, \mathrm{C}-5$ and $\mathrm{C}-9$. Long range $\mathrm{W}$-coupling observed in the COSY spectrum between $\mathrm{H}-1 \mathrm{a}$ and $\mathrm{H}-5 \mathrm{a}$ in conjunction with the HMBC correlations observed from $\mathrm{H}_{2}-5$ to C-1, C-10 and C-20, indicated C-5 and C-10 were adjacent. HMBC correlations from methyls $\mathrm{H}_{3}-18\left(\delta_{\mathrm{H}} 0.38 ; \delta_{\mathrm{C}} 27.1\right)$ and $\mathrm{H}_{3}-19\left(\delta_{\mathrm{H}} 0.91 ; \delta_{\mathrm{C}} 33.0\right)$ to each other, their attachment point $\mathrm{C}-4\left(\delta_{\mathrm{C}} 31.8\right)$ and to the methylene carbons C-3 and C-5 on either side, were used to establish the gem-dimethyl moiety and placed it between C-3 and C-5. An HMBC correlation from $\mathrm{H}_{2}-5$ to $\mathrm{C}-4$ was also evident. Thus the cyclohexane ring of oxeatamide E (27), depicted in Figure 3.14, was established.

In oxeatamide E (27) 10 unique aromatic signals were observed in the ${ }^{13} \mathrm{C} \mathrm{NMR}$ consisting of five distinct methine resonances, $\mathrm{CH}-11\left(\delta_{\mathrm{H}} 7.59 ; \delta_{\mathrm{C}} 127.5\right), \mathrm{CH}-12$ 


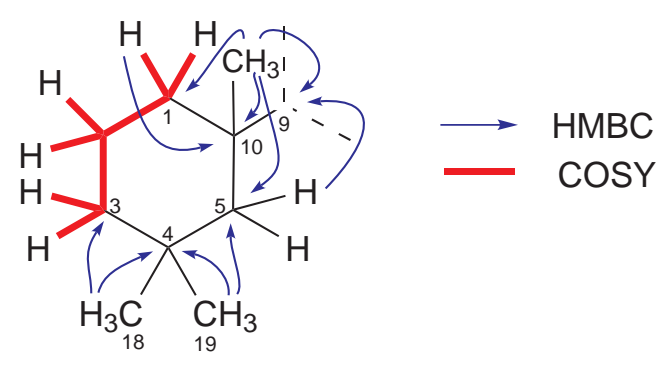

Figure 3.14. COSY and key HMBC correlations establishing connectivity of cyclohexane ring of oxeatamide $\mathrm{E}$ (27).

$\left(\delta_{\mathrm{H}} 7.67 ; \delta_{\mathrm{C}} 122.0\right), \mathrm{CH}-25[29]\left(\delta_{\mathrm{H}} 7.20 ; \delta_{\mathrm{C}} 128.8\right), \mathrm{CH}-26[28]\left(\delta_{\mathrm{H}} 7.25 ; \delta_{\mathrm{C}} 128.6\right)$ and $\mathrm{CH}-27\left(\delta_{\mathrm{H}} 7.19 ; \delta_{\mathrm{C}} 126.5\right)$, and five non-protonated carbons C-8 $\left(\delta_{\mathrm{C}} 135.1\right), \mathrm{C}-9, \mathrm{C}-$ $13\left(\delta_{\mathrm{C}} 131.2\right), \mathrm{C}-14\left(\delta_{\mathrm{C}} 141.5\right)$ and $\mathrm{C}-24\left(\delta_{\mathrm{C}} 138.7\right)$. The aromatic methine resonance $\mathrm{CH}-26[28]$ integrated for two proton equivalents in the ${ }^{1} \mathrm{H}$ NMR which indicated the presence of symmetry in an aromatic ring. The carbon resonances of the aromatic methines C-25[29] and C-26[28] were also almost twice the intensity of the other aromatic methines signals. Though the intensity of signals in the ${ }^{13} \mathrm{C}$ NMR are not always a reliable indication of the number of carbons in the chemical environment this along with the information from the ${ }^{1} \mathrm{H}$ NMR spectra supports the assumption of symmetry in an aromatic ring and suggests there are actually seven aromatic methines with two sets of overlapping resonances, $\mathrm{CH}-25[29]$ and $\mathrm{CH}-26[28] .{ }^{53} \mathrm{HMBC}$ correlations observed from H-11 to C-8, C-9, C-13 and C-14 and from H-12 to C-8, C-9, C-11 and C-14, suggested that $\mathrm{C}-8, \mathrm{C}-9, \mathrm{CH}-11, \mathrm{CH}-12, \mathrm{C}-13$ and $\mathrm{C}-14$ formed one of the aromatic rings (ring A, Figure 3.15) leaving the resonances C-24, CH-25[29], $\mathrm{CH}-26[28]$ and $\mathrm{CH}-27$ to form aromatic ring B (Figure 3.18).

The four non-protonated carbons of aromatic ring A suggested it was a tetra-substituted aromatic ring. Methines $\mathrm{CH}-11$ and $\mathrm{CH}-12$ were placed ortho to each other as both resonances appeared as doublets in the ${ }^{1} \mathrm{H}$ NMR spectrum with a coupling constant of 8.2 Hz. ${ }^{53}$ HMBC correlations observed from $\mathrm{H}-11$ and $\mathrm{H}-12$ defined the connectivity of ring A. Strong HMBC correlations were observed from $\mathrm{H}-11$ to C-13 and C-8, indicating three-bond connectivity, as well as weak HMBC correlations to C-9 indicating two-bond connectivity. ${ }^{53}$ The other aromatic methine, H-12, showed strong HMBC correlations to C-9 and C-14 which indicated three-bond connectivity, a weak HMBC correlation was also observed from H-12 to C-11 again indicating two-bond connectivity (Figure 3.15). ${ }^{53}$ 


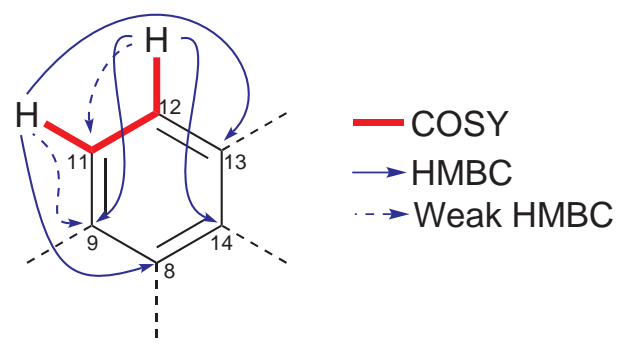

Figure 3.15. Aromatic ring A of oxeatamide E (27).

Methyl $\mathrm{H}_{3}-17\left(\delta_{\mathrm{H}} 1.52 ; \delta_{\mathrm{C}} 15.4\right)$ appeared as doublet in the ${ }^{1} \mathrm{H} \mathrm{NMR}$, which indicated that it was adjacent to a methine. COSY correlations observed between $\mathrm{H}-7\left(\delta_{\mathrm{H}} 4.69 ; \delta_{\mathrm{C}} 40.8\right)$ and $\mathrm{H}_{3}-17$ suggested that $\mathrm{CH}_{3}-17$ was attached to methine $\mathrm{CH}-7$. Correlations observed from $\mathrm{H}-7$ and $\mathrm{H}_{3}-17$, to the carbonyl resonance $\mathrm{C}-6\left(\delta_{\mathrm{C}} 176.8\right)$ in the HMBC spectrum suggested that C-6 and C-7 were adjacent.

The substitution pattern of aromatic ring A was again assigned on the basis of HMBC correlations observed to and from positions of the ring as depicted in Figure 3.16. The cyclohexane ring was attached to $\mathrm{C}-9$ and placed ortho to methine $\mathrm{CH}-11$ based on $\mathrm{HMBC}$ correlations observed from $\mathrm{H}-11$ to $\mathrm{C}-10, \mathrm{H}-5$ b to $\mathrm{C}-9$ and $\mathrm{H}_{3}-20$ to $\mathrm{C}-9$. The substitution of $\mathrm{C}-7$ at $\mathrm{C}-8$ of aromatic ring A was assigned based on HMBC correlations from $\mathrm{H}-7$ and $\mathrm{H}_{3}-17$ to the aromatic non-protonated carbon resonance C-8.

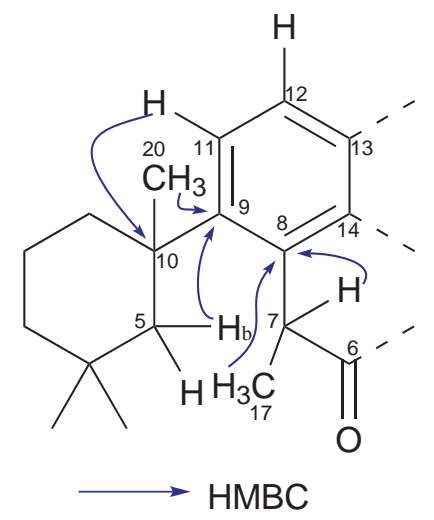

Figure 3.16. Placement of aromatic substituents of aromatic ring A of oxeatamide E (27).

HMBC correlations observed from H-11 and H-12 to C-16 ( $\left.\delta_{\mathrm{C}} 168.4\right)$ were again used to position the lactam carbonyl $\mathrm{C}-16$ adjacent to aromatic ring A resonance $\mathrm{C}-13$. Similarly, methine $\mathrm{CH}_{2}-15\left(\delta_{\mathrm{H}} 4.38,4.21 ; \delta_{\mathrm{C}} 50.3\right)$ was assigned adjacent to $\mathrm{C}-14$ based on HMBC correlations from $\mathrm{H}_{2}-15$ to $\mathrm{C}-14$ and a weak correlation observed betwenn $\mathrm{H}_{2}-15$ and C-8. HMBC correlations were also observed from $\mathrm{H}_{2}-15$ to $\mathrm{C}-13$ and $\mathrm{C}-16$. These correlations, 
as well as the chemical shift for $\mathrm{C}-16$ being consistent with that of a lactam carbonyl and the ${ }^{1} J_{\mathrm{CH}}$ of $143 \mathrm{~Hz}$ for $\mathrm{CH}_{2}-15$, which is typical for a carbon adjacent to nitrogen, again suggested the presence of a lactam. ${ }^{53}$

The NMR data for the aromatic ring and lactam of oxeatamide E (27) was compared to that for oxeatamide A (21) ${ }^{41}$ and D (26) and was consistent with the placement of the lactam carbonyl adjacent to C-13.

Similarly to oxeatamide D (26) the carbon skeleton of the oxeatamide backbone (32) was established, leaving $\mathrm{C}_{8} \mathrm{H}_{9}$ as well as hydroxyl (an oxygen and exchangeable proton) unaccounted for. As the carbon resonance of carbonyl C-6 was typical of a carboxylic acid, ${ }^{53}$ it was again assumed that the hydroxyl was attached to C-6. The carboxylic acid functionality at C-6 was once again consistent with the known oxeatamides, ${ }^{53}$ and the need for an acidic mobile phase during HPLC separation (Scheme 3.2).

COSY correlations, depicted in Figure 3.17, were observed between methylene protons $\mathrm{H}_{2}-22\left(\delta_{\mathrm{H}} 3.83,3.74 ; \delta_{\mathrm{C}} 44.1\right)$ and $\mathrm{H}_{2}-23\left(\delta_{\mathrm{H}} 2.94 ; \delta_{\mathrm{C}} 34.7\right)$ suggesting $\mathrm{CH}_{2}-22$ and $\mathrm{CH}_{2}-23$ were adjacent. Methylene $\mathrm{CH}_{2}-22$ had a ${ }^{1} J_{\mathrm{CH}}$ of $140 \mathrm{~Hz}$ consistent for a carbon adjacent to nitrogen, ${ }^{53}$ suggesting $\mathrm{CH}_{2}-22$ was adjacent to $\mathrm{N}-21$. This was supported by HMBC correlations observed from $\mathrm{H}_{2}-22$ to $\mathrm{C}-15$ and C-16. HMBC correlations observed from $\mathrm{H}_{2}-22$ and $\mathrm{H}_{2}-23$ to $\mathrm{C}-24$ indicated that $\mathrm{CH}_{2}-23$ was adjacent to $\mathrm{C}-24$ which was part of the previously identified aromatic ring B.

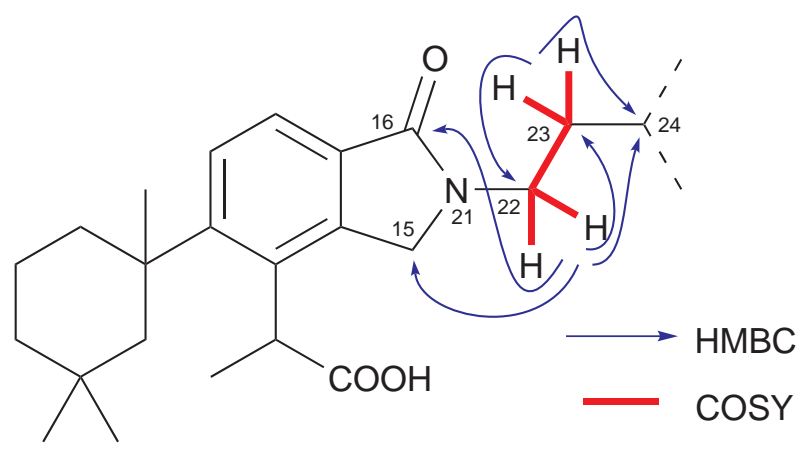

Figure 3.17. COSY and HMBC correlations establishing the attachment and connectivity of C-22 to C-24 of oxeatamide E (27).

Aromatic ring B appeared to have symmetry as only four distinct resonances were observed in the ${ }^{13} \mathrm{C}$ NMR. Analysis of the ${ }^{1} \mathrm{H},{ }^{13} \mathrm{C}$ and HSQC determined that methine resonances $\mathrm{CH}-25$ and $\mathrm{CH}-26$ also accounted for $\mathrm{CH}-29$ and $\mathrm{CH}-28$ respectively. This 
was supported by the pseudo ${ }^{1} J_{\mathrm{CH}}$ HMBC correlations observed from $\mathrm{H}-25$ to $\mathrm{C}-25$ and H-26 to C-26 which were actually correlations from H-25 to C-29, H-29 to C-25, H-26 to C-28, and $\mathrm{H}-28$ to $\mathrm{C}-26$. The $\mathrm{CH}-27$ resonance accounted for only one methine and was thus placed para to the non-protonated aromatic carbon C-24. Correlations observed in the HMBC spectrum to C-23 from H-25[29] and from $\mathrm{H}-23$ to $\mathrm{C}-25[29]$ in conjunction with the doublet observed in the ${ }^{1} \mathrm{H}$ NMR for H-25[29] indicated aromatic methines C25[29] were adjacent to the attachment point C-24 and a methine. The placement of C-24, $\mathrm{CH}-25[29]$ and $\mathrm{CH}-27$ as well as HMBC and COSY correlations helped to determine that $\mathrm{CH}-26$ [28], a triplet in the ${ }^{1} \mathrm{H}$ NMR spectrum, was adjacent to both $\mathrm{CH}-25$ [29] and $\mathrm{CH}$ 27 (Figure 3.18). The amnio acid origin of the N-21 to C-29 fragment, decarboxylated phenylalanine, is discussed in Section 3.6.2.

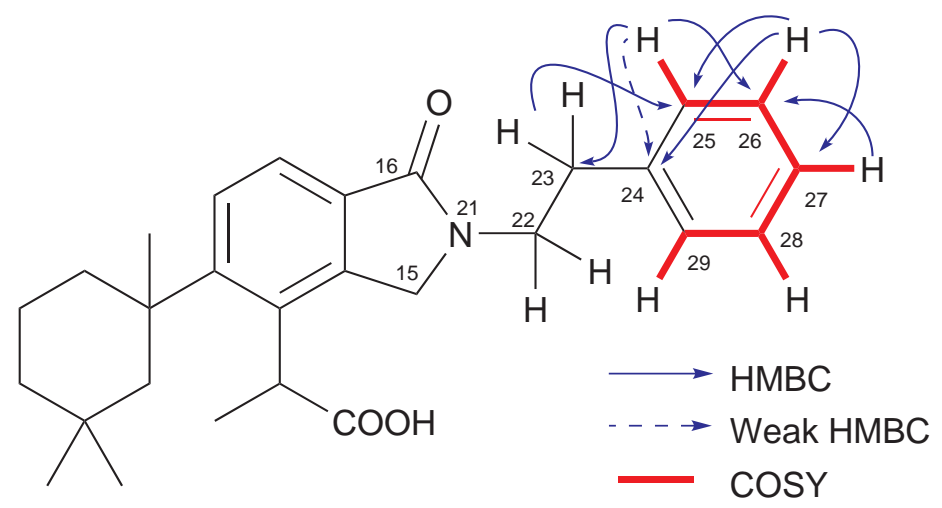

Figure 3.18. COSY and key HMBC correlations establishing aromatic ring B of oxeatamide E (27).

With the oxeatamide backbone accounting for the majority of the determined molecular formula, $\mathrm{C}_{28} \mathrm{H}_{35} \mathrm{NO}_{3}$, of 27 , the remaining ethyl phenyl fragment was found to be attached to the lactam nitrogen $\mathrm{N}-21$. Therefore the structure of oxeatamide $\mathrm{E}$ is given as $\mathbf{2 7}$ with NMR data presented in Table 3.5. Due to the similarity in chemical shifts and coupling constants the configuration of oxeatamide E (27) was assumed to be analogous to that established for oxeatamide D (26), previously discussed in Section 3.4.2. 


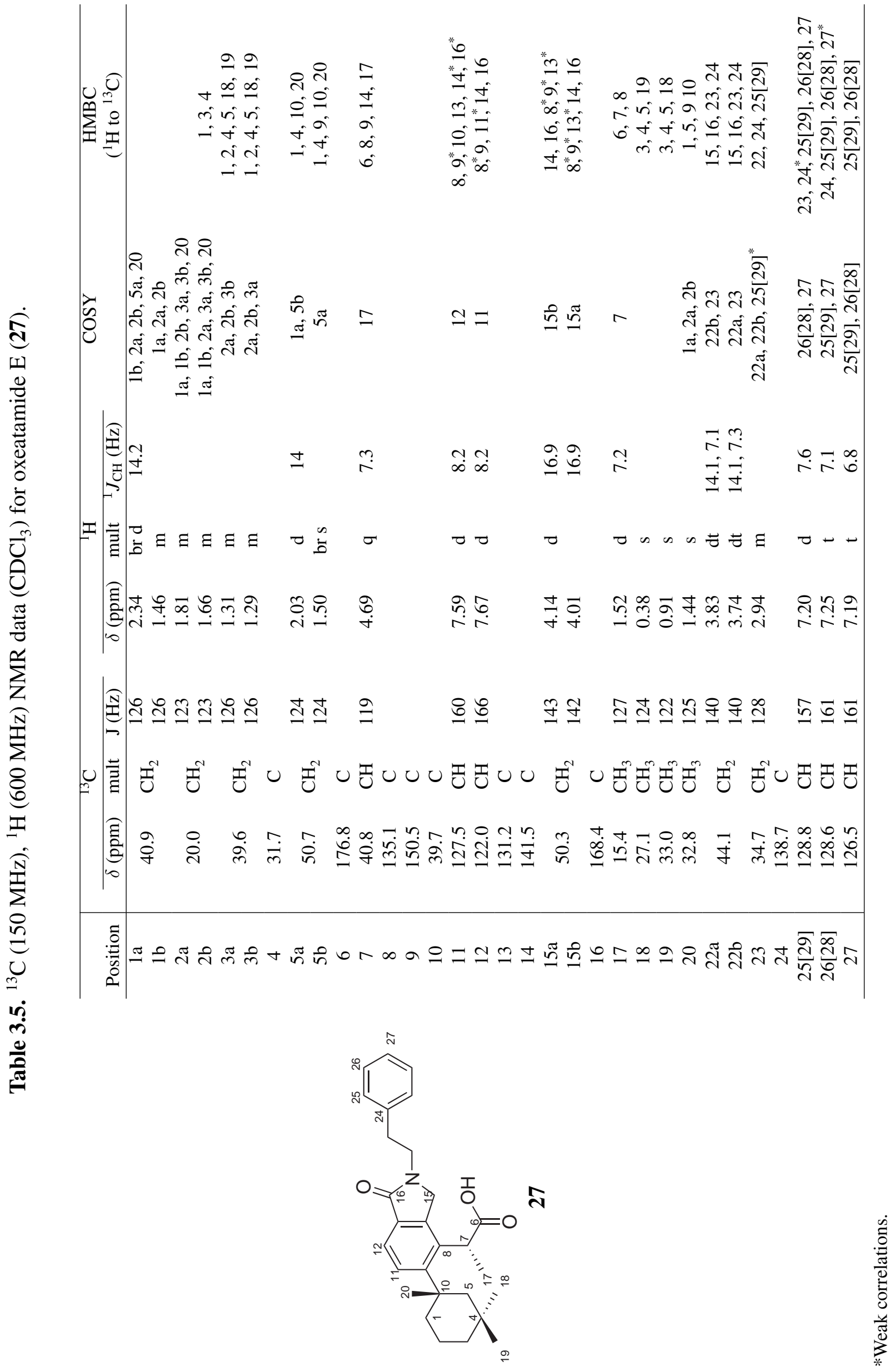




\subsubsection{Oxeatamide F}

The positive ion HRESIMS analysis of oxeatamide $\mathrm{F}(\mathbf{2 8})$ showed an $[\mathrm{M}+\mathrm{Na}]^{+}$ pseudomolecular ion at $m / z 422.2669$ revealing the molecular formula of $\mathrm{C}_{25} \mathrm{H}_{37} \mathrm{NO}_{3}$, ( $\Delta 0.5 \mathrm{ppm}$ ), which required eight double bond equivalents. The ${ }^{13} \mathrm{C}$ NMR spectrum contained 22 resonances, which along with the three other resonances observed in the HSQC and/or HMBC spectra was consistent with the formula. Integration of the ${ }^{1} \mathrm{H} N M R$ spectrum revealed 36 protons, suggesting one exchangeable proton. Initial analysis of the

${ }^{13} \mathrm{C}$ and multiplicity-edited HSQC spectra (Table 3.6) revealed 17 protonated carbons, six methyls, seven methylenes and four methines leaving eight non-protonated carbons. A carboxylic acid/ester carbonyl C-6 $\left(\delta_{\mathrm{C}} 176.3\right)$, an amide/lactam carbonyl C-16 $\left(\delta_{\mathrm{C}} 168.6\right)$ and six aromatic resonances- $-\mathrm{C}-8\left(\delta_{\mathrm{C}} 134.4\right) \mathrm{C}-9\left(\delta_{\mathrm{C}} 150.4\right), \mathrm{CH}-11\left(\delta_{\mathrm{H}} 7.61 ; \delta_{\mathrm{C}} 127.6\right)$, $\mathrm{CH}-12\left(\delta_{\mathrm{H}} 7.68 ; \delta_{\mathrm{C}} 122.4\right), \mathrm{C}-13\left(\delta_{\mathrm{C}} 131.6\right)$ and $\mathrm{C}-14\left(\delta_{\mathrm{C}} 141.3\right)$ - were again tentatively assigned due to their typical chemical shift values. ${ }^{53}$ The aromatic ring system along with the two carbonyl groups accounted for six double bond equivalents suggesting the compound contained two other ring systems.

In a similar fashion to oxeatamide D (26) and E (27) COSY correlations led to the establishment of a methylene chain $\mathrm{CH}_{2}-1$ to $\mathrm{CH}_{2}-3$. HMBC correlations attached $\mathrm{C}$ 10 to $\mathrm{C}-1, \mathrm{C}-5$ and C-20. Unlike 26 and 27 an HMBC correlation was observed from $\mathrm{H}-1 \mathrm{a}$ to $\mathrm{C}-10$. Likewise, the gem-dimethyl moiety, $\mathrm{CH}_{3}-18$ and $\mathrm{CH}_{3}-19$, was attached to $\mathrm{C}-4$ and placed adjacent to $\mathrm{CH}_{2}-3$ and $\mathrm{CH}_{2}-5$ using COSY and HMBC correlations forming the cyclohexane ring (Figure 3.19).

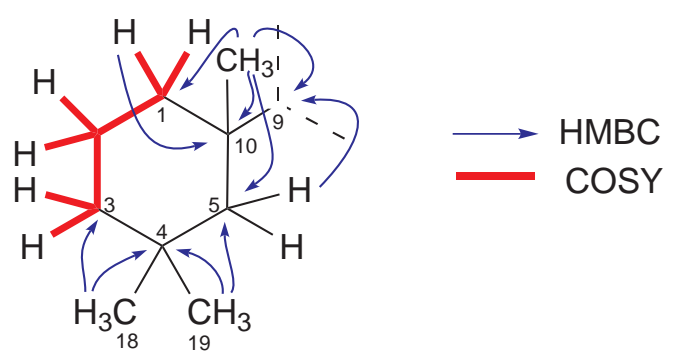

Figure 3.19. COSY and key HMBC correlations establishing connectivity of cyclohexane ring of oxeatamide $\mathrm{F}(\mathbf{2 8})$.

Once again the coupling constant of $8.2 \mathrm{~Hz}$, as well as a COSY correlation were used to establish the ortho positioning of the aromatic methine protons. ${ }^{53}$ Again correlations 
observed in the $\mathrm{HMBC}$ spectrum from the aromatic methine protons $\mathrm{H}-11$ and $\mathrm{H}-12$ were used to establish the connectivity of the tetra-substituted aromatic ring (Figure 3.20).

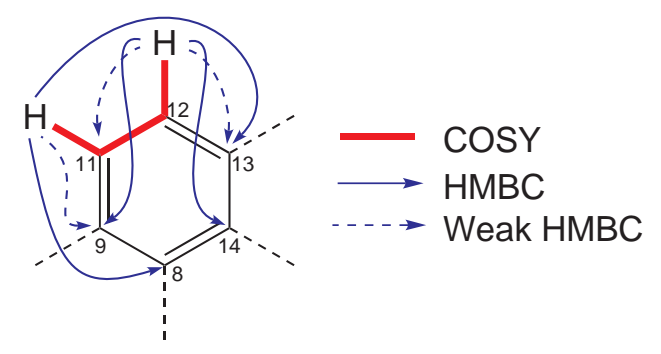

Figure 3.20. Aromatic ring connectivity of oxeatamide F (28).

Similarly, the methyl $\mathrm{CH}_{3}-17$ was placed adjacent to methine $\mathrm{CH}-7$ using COSY and HMBC correlations. HMBC correlations were again used to establish the carbonyl C-6 was adjacent to C-7 (Figure 3.21).

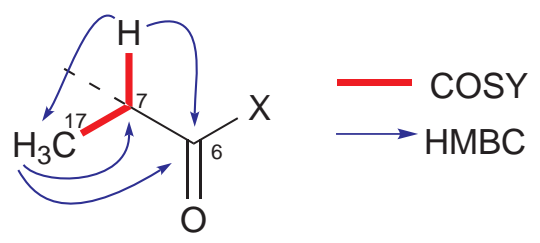

Figure 3.21. Connectivity around carbonyl C-6 of oxeatamide F (28).

In a similar fashion to $\mathbf{2 6}$ and $\mathbf{2 7}$ the substitution pattern of the aromatic ring was assigned based on correlations observed in the HMBC spectrum. The 1,3,3-trimethyl cyclohexane ring was placed ortho to $\mathrm{H}-11$ and attached to $\mathrm{C}-9$. The methine $\mathrm{CH}-7$ was positioned adjacent to $\mathrm{C}-8$. The substituents at C-13 and C-14 were also established through HMBC correlations. The carbonyl C-16 was positioned adjacent to C-13 and the methylene C15 was placed adjacent to C-14. Similarly $\mathrm{CH}_{2}-15$ had a ${ }^{1} J_{\mathrm{CH}}$ of $142 \mathrm{~Hz}$, consistent for a carbon attached to nitrogen, ${ }^{53}$ and the chemical shift of C-16 was consistent with a carbonyl of a lactam again indicating the presence of a $\gamma$-lactam ring (Figure 3.22).

Thus the elucidation of the carbon skeleton of the oxeatamide backbone (32) was complete leaving a $\mathrm{C}_{5} \mathrm{H}_{11}$ fragment as well as an exchangeable proton and oxygen to be assigned. The chemical shift of the C-6 carbonyl was again typical of a carboxylic acid, ${ }^{53}$ and therefore the oxygen and exchangeable proton were once again assumed to be attached to C-6. Likewise the proposed carboxylic acid functionality at C-6 was consistent with the chromatographic behaviour observed (Scheme 3.2) and the known 
oxeatamides. $^{41}$

Methyl $\mathrm{CH}_{3}-25$ appeared as a triplet in the ${ }^{1} \mathrm{H}$ NMR indicating it was attached to a methylene. COSY correlations observed between $\mathrm{H}_{3}-25$ and $\mathrm{H}_{2}-24$ established that C-25 was adjacent to $\mathrm{C}-24$. $\mathrm{HMBC}$ correlations from $\mathrm{H}_{3}-25$ to $\mathrm{C}-24$ as well as methine $\mathrm{C}-23$ were also observed, suggesting that C-24 and C-23 were adjacent. HMBC correlations were also observed from $\mathrm{H}_{2}-24$ to C-23. COSY correlations observed between $\mathrm{H}-23$ and methylene $\mathrm{H}_{2}-22$ placed them adjacent to each other. Methyl $\mathrm{H}_{2}-26$ appeared as a doublet in the ${ }^{1} \mathrm{H}$ NMR indicating it was attached to a methine, HMBC correlations from it to C-23 as well as C-22 and C-24 were used to attach it to C-23. $\mathrm{CH}_{2}-22\left(\delta_{\mathrm{H}} 3.42,3.39\right.$; $\left.\delta_{\mathrm{C}} 48.5\right)$ had a ${ }^{1} J_{\mathrm{CH}}$ value of $137 \mathrm{~Hz}$ suggesting that it was adjacent to a nitrogen, ${ }^{53}$ this in conjunction with $\mathrm{HMBC}$ correlations observed from $\mathrm{H}_{2}-22$ to $\mathrm{C}-15$ and $\mathrm{C}-16$ indicated that $\mathrm{CH}_{2}-22$ was adjacent to $\mathrm{N}-21$. Thus completing the elucidation of the $\mathrm{C}_{5} \mathrm{H}_{11}$ fragment remaining (Figure 3.23). This fragment is proposed to arise from a reaction of a terpene precursor and amino acid isoleucine, which is discussed later in Section 3.6.2.

Therefore the structure of oxeatamide F is given as $\mathbf{2 8}$ with NMR data presented in Table 3.6. The $7 R^{*} 10 S^{*}$ relative configuration is assumed, based on that previously assigned for oxeatamide D and the other known oxeatamides. ${ }^{41}$

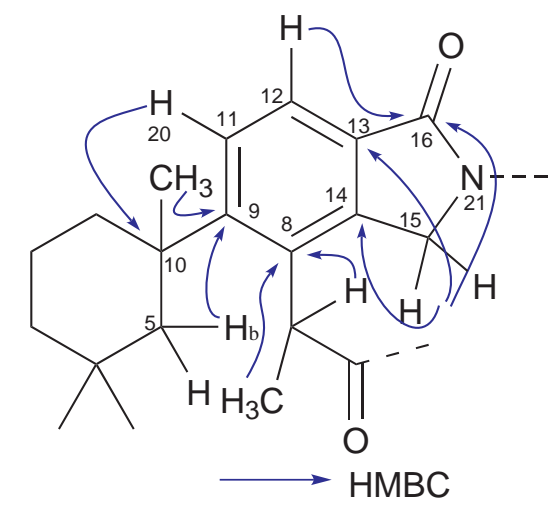

Figure 3.22. Placement of aromatic substituents of oxeatamide F (28). 


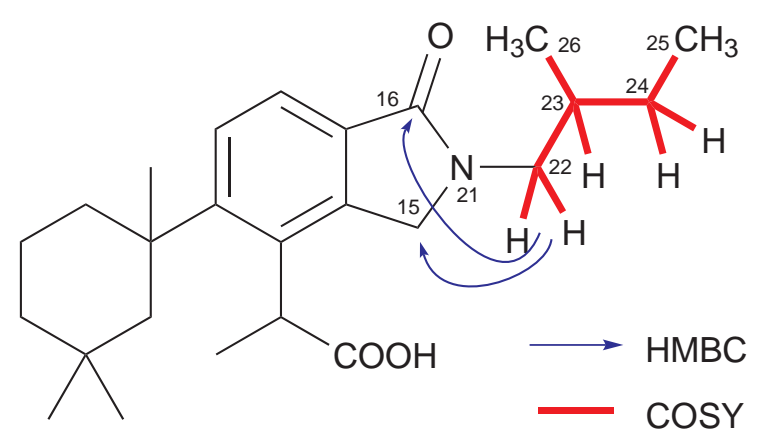

Figure 3.23. COSY and key HMBC correlations establishing the attachment and connectivity of C-22 to C-26 fragment of oxeatamide F (28). 


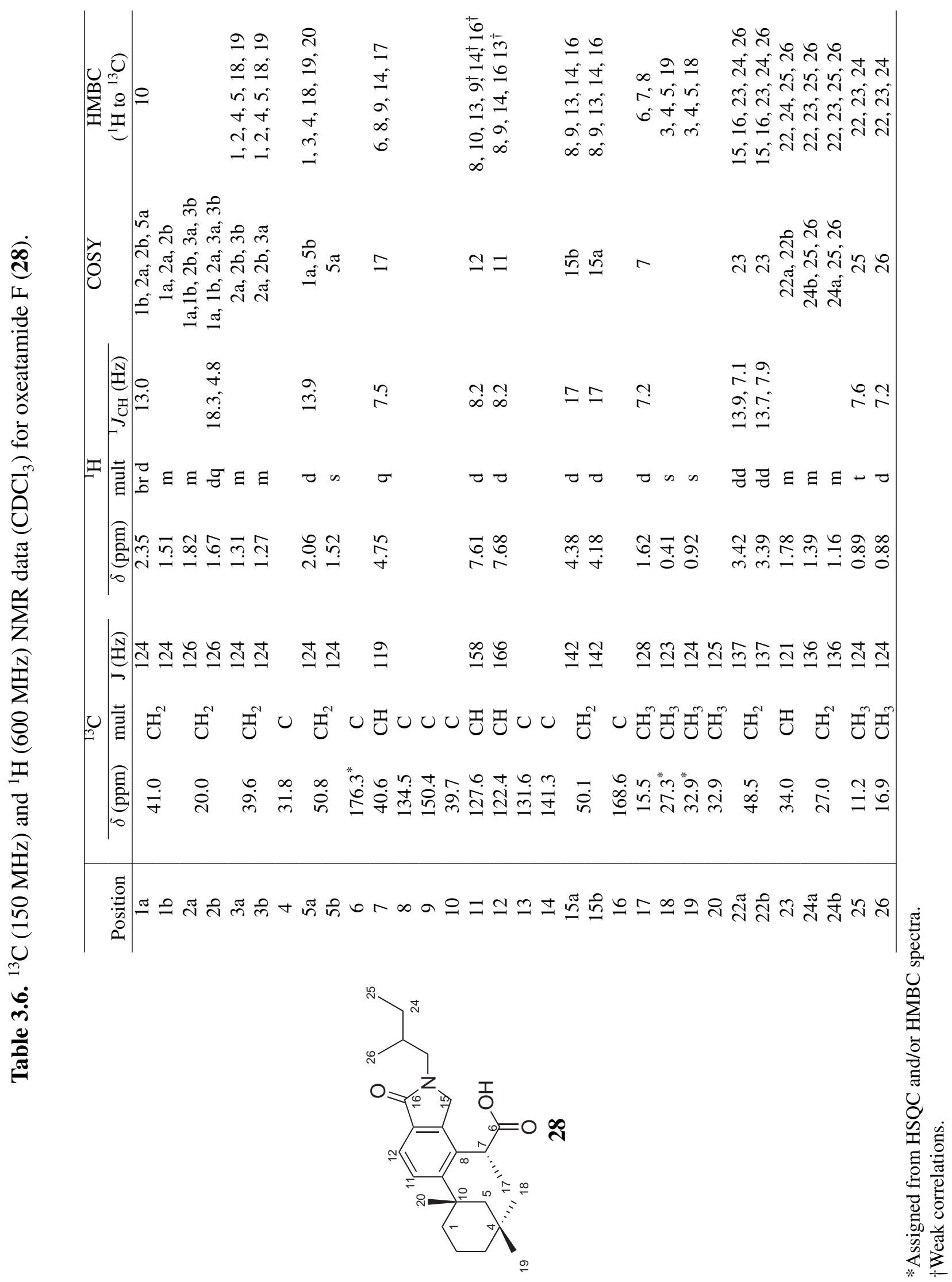




\subsubsection{Oxeatamide G}

Observation of the the positive ion mode HRESIMS pseudomolecular ion $[\mathrm{M}+\mathrm{Na}]^{+}$ $m / z 422.2670$, enabled the formula of oxeatamide $\mathrm{G}(\mathbf{2 9})$ to be established as $\mathrm{C}_{25} \mathrm{H}_{37} \mathrm{NO}_{3}$, $\Delta 0.2 \mathrm{ppm}$, requiring eight double bond equivalents. The molecular formula of 29 was identical to oxeatamide F (28) establishing them as structural isomers. A notable difference was the upfield methyl signals observed in the ${ }^{13} \mathrm{C}$ NMR for C-25 and C-26 of 28 appeared to be shifted downfield in 29 . The ${ }^{13} \mathrm{C}$ NMR spectrum of 29 contained 22 resonances, this in conjunction with the three other resonances observed in the HSQC and/or the HMBC was consistent with its molecular formula. Thirty-six protons were accounted for in the ${ }^{1} \mathrm{H}$ NMR spectrum, suggesting one exchangeable proton. Preliminary analysis of the ${ }^{13} \mathrm{C}$ and multiplicity-edited HSQC NMR spectra revealed 17 protonated carbons, six methyls, seven methylenes and four methines which left eight non-protonated carbons. Analogous with the other oxeatamides, a carboxylic acid/ester carbonyl C-6 $\left(\delta_{\mathrm{C}} 176.8\right)$, an amide/lactam carbonyl C-16 $\left(\delta_{\mathrm{C}} 168.0\right)$ and six aromatic resonances, C-8 $\left(\delta_{\mathrm{C}} 134.7\right) \mathrm{C}-9\left(\delta_{\mathrm{C}} 150.3\right), \mathrm{CH}-11\left(\delta_{\mathrm{H}} 7.59 ; \delta_{\mathrm{C}} 127.6\right), \mathrm{CH}-12\left(\delta_{\mathrm{H}} 7.65 ; \delta_{\mathrm{C}} 122.3\right), \mathrm{C}-13$ $\left(\delta_{\mathrm{C}} 131.7\right)$ and $\mathrm{C}-14\left(\delta_{\mathrm{C}} 141.3\right)$, were assigned due to their typical chemical shift values leaving two double bond equivalents unaccounted for, indicating the compound contained two other ring systems.

Again, COSY and HMBC correlations were used to construct a 1,3,3-trimethyl cyclohexane ring, consistent with the other oxeatamides. Likewise, correlations observed in the HMBC spectrum from the aromatic methine protons $\mathrm{H}-11$ and $\mathrm{H}-12$ were used to establish the connectivity of the tetra-substituted aromatic ring. The C-6, C-7 and C-17 fragment was similarly established using COSY and HMBC correlations. Once again the substitution pattern of the aromatic ring was assigned based on correlations observed in the HMBC spectrum. The lactam ring was established using HMBC correlations, completing the oxeatamide diterpene backbone.

As before these substructures accounted for $\mathrm{C}_{20} \mathrm{H}_{26} \mathrm{NO}_{3}$ leaving $\mathrm{C}_{5} \mathrm{H}_{11}$ as the side chain of $\mathrm{N}-21$. 
Methyls C-25 and C-26 had almost identical chemical shifts, and both appeared as doublets in the ${ }^{1} \mathrm{H}$ NMR indicating they were attached to a methine. HMBC correlations from $\mathrm{H}_{3}-25$ and $\mathrm{H}_{3}-26$ to each other as well as to methine C-24, indicated that C-24 was adjacent to C-25 and C-26. HMBC correlations were also observed from $\mathrm{H}-24, \mathrm{H}_{3}$ 25 and $\mathrm{H}_{3}-26$ to methylene C-23, placing C-24 adjacent to C-23. COSY correlations between C-23 and methylene C-22, established they were adjacent carbons. Methylene $\mathrm{CH}_{2}-22$ had a ${ }^{1} J_{\mathrm{CH}}$ value of $143 \mathrm{~Hz}$, which in conjunction with the methylene's downfield chemical shift, again suggested that $\mathrm{CH}_{2}-22$ was adjacent to nitrogen. ${ }^{53}$ In conjunction with $\mathrm{HMBC}$ correlations observed from $\mathrm{H}_{2}-22$ to $\mathrm{C}-15$ and C-16 this indicated that $\mathrm{CH}_{2}$ 22 was adjacent to $\mathrm{N}-21$, therefore completing the structure elucidation of oxeatamide $\mathrm{G}$ (29) which is depicted in Figure 3.24.

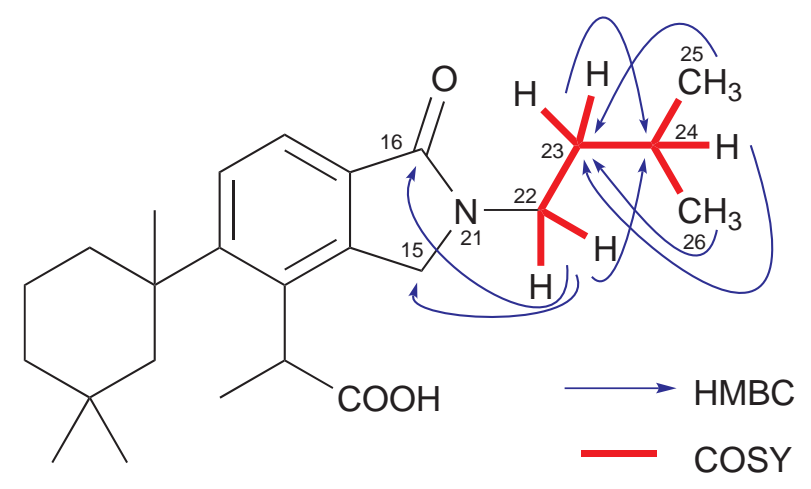

Figure 3.24. COSY and key HMBC correlations establishing the attachment and connectivity of C-22 to C-26 fragment of oxeatamide G (29).

A 3-methyl butyl moiety, possibly originating from decarboxylated leucine (discussed later in Section 3.6.2), was found to be attached to the lactam nitrogen N-21 of the oxeatamide backbone (32). The structure of oxeatamide $G$ is given as 29 with NMR data presented in Table 3.7. The relative configuration is assumed to be analogous to the oxeatamide D (26). 


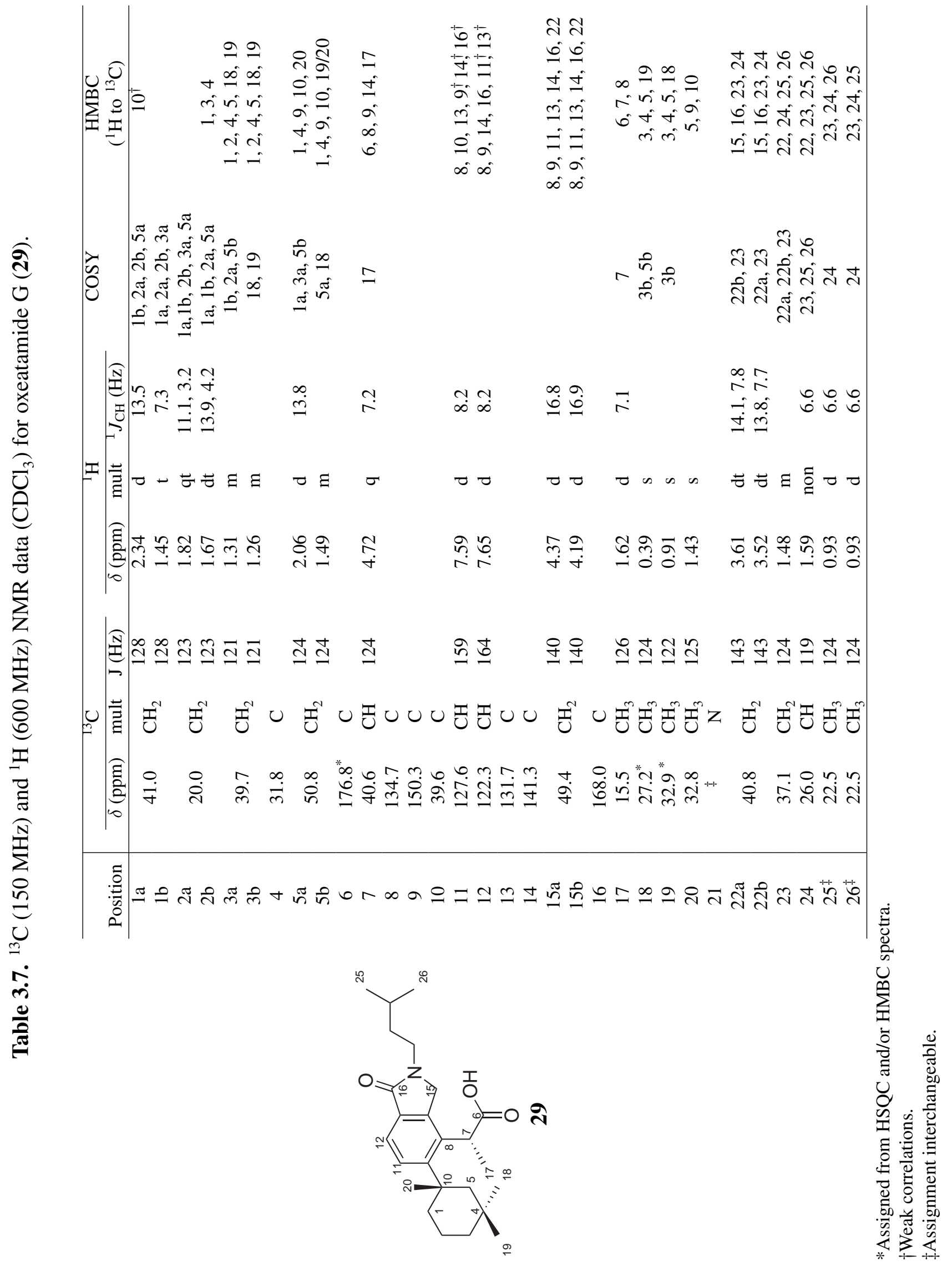




\subsubsection{Methylation of Oxeatamide G}

A derivatisation reaction of oxeatamide $G(\mathbf{2 9})$ was performed to confirm the presence of the carboxylic acid moiety at C-6. A small amount of 29, approximately $100 \mu \mathrm{g}$, was methylated to 33 using $\mathrm{TMSCHN}_{2}$. The reaction went to completion and a new methyl signal was seen at $3.64 \mathrm{ppm}$ in the ${ }^{1} \mathrm{H}$ NMR. An HMBC correlation was observed from this new methyl resonance to carbonyl resonance C-6 $\left(\delta_{\mathrm{C}} 174.5\right)$, this in conjunction with the correlation observed from methine $\mathrm{H}-7,\left(\delta_{\mathrm{H}} 1.63 \mathrm{ppm}\right)$ to the same carbonyl resonance indicated that the new methyl resonance was attached through an oxygen to carbonyl C-6.

Unfortunately, during the methylation process the sample was contaminated with plasticsizers of unknown origin. The plasticsizers co-eluted with $\mathbf{3 3}$ off PSDVB and further attempts at separation were unsuccessful. To confirm the presence of the methylated product the sample was submitted for MS. The pseudo-molecular ion peak $[\mathrm{M}+\mathrm{H}]^{+}$observed at $\mathrm{m} / \mathrm{z} 414.3005$ revealed the molecular formula $\mathrm{C}_{26} \mathrm{H}_{39} \mathrm{NO}_{3},(\Delta 0.3$ ppm) indicating the methylation was successful, thus proving that carbonyl C-6 is in fact a carboxylic acid. A carboxylic acid moiety at C-6 is consistent with the known oxeatamides, ${ }^{41}$ as well as the chromatographic behaviour observed (depicted in Schemes 3.1 and 3.2).

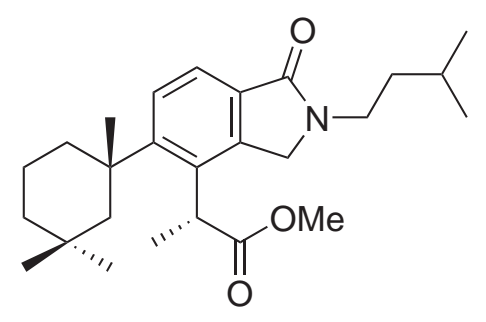

33 


\subsubsection{Oxeatamide C}

The molecular formula $\mathrm{C}_{22} \mathrm{H}_{32} \mathrm{~N}_{2} \mathrm{O}_{3}$ for oxeatamide $\mathrm{C}$ (25) was determined from a HRESIMS of the $[\mathrm{M}+\mathrm{Na}]^{+}$pseudo-molecular ion at $\mathrm{m} / \mathrm{z} 395.2318(\Delta 0.5 \mathrm{ppm})$, requiring eight double bond equivalents. Like oxeatamide B (24) and unlike the other known oxeatamides, ${ }^{41} \mathbf{2 5}$ was only sparingly soluble in $\mathrm{CDCl}_{3}$ and all NMR data were obtained in $d_{6}$-DMSO. The use of $d_{6}$-DMSO revealed the three exchangeable protons as a broad signal centred around $4 \mathrm{ppm}$. The ${ }^{1} \mathrm{H}$ NMR spectrum accounted for all 32 protons. Only 13 resonances were observed in the ${ }^{13} \mathrm{C}$ NMR spectrum, in part due to overlap with the $d_{6}$-DMSO residual solvent signal, these resonances in conjunction with the nine other carbon resonances observed in the HSQC and/or HMBC spectra was consistent with the formula. Initial analysis of the ${ }^{13} \mathrm{C}$ and multiplicity-edited HSQC NMR spectra (Table 3.8) revealed 14 protonated carbons leaving eight quaternary carbons. Several carbon resonances were tentativily assigned including a carboxylic acid/ester carbonyl $\left(\delta_{\mathrm{C}} 175.1\right)$, an amide/lactam carbonyl $\left(\delta_{\mathrm{C}} 167.1\right)$ and six aromatic resonances $\left(\delta_{\mathrm{C}} 122.2,127.5,131.6,136.7,142.4,150.0\right) .{ }^{53}$ This accounted for six of the double bond equivalents.

In a similar fashion to the other oxeatamides COSY and HMBC correlations were used to construct the oxeatamide backbone, leaving $\mathrm{C}_{2} \mathrm{H}_{6} \mathrm{~N}$ as the lactam substituent.

C-22 had a ${ }^{1} J_{\mathrm{CH}}$ value of $140 \mathrm{~Hz}$ suggesting that it was adjacent to nitrogen, this in conjunction with $\mathrm{HMBC}$ correlations observed from $\mathrm{H}_{2}-22$ to $\mathrm{C}-16$ indicated that $\mathrm{C}$ 22 was adjacent to $\mathrm{N}-21$. COSY correlations were observed between $\mathrm{H}_{2}-22$ and $\mathrm{H}_{2}-23$ suggesting the two methylenes were adjacent. C-23 had a ${ }^{1} J_{\mathrm{CH}}$ value of $137 \mathrm{~Hz}$ suggesting it was also adjacent to a nitrogen, N-24. With all the carbons assigned this suggested that $\mathrm{N}-24$ was a primary amine with two exchangeable protons attached (Figure 3.25). This left one exchangeable proton and oxygen unaccounted for. The proposed carboxylic acid functionality at C-6 was consistent with the chromatographic behaviour observed (Scheme 3.1) and the known oxeatamides. Therefore the structure of oxeatamide $\mathrm{C}$ is given as $\mathbf{2 5}$ with NMR data presented in Table 3.8, the relative configuration is assumed to be $7 R^{*} 10 S^{*}$. 


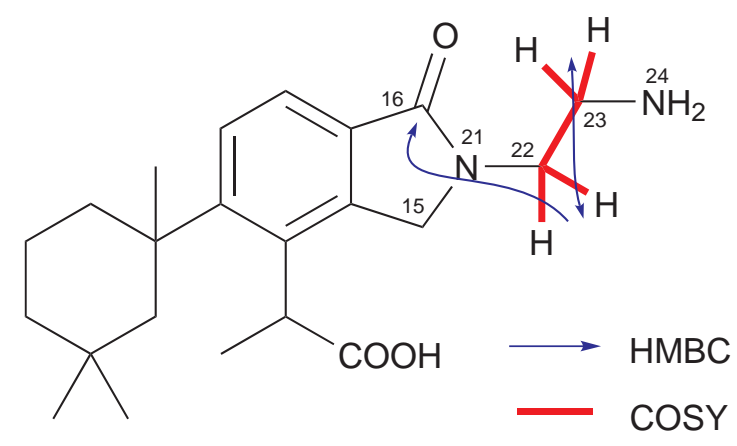

Figure 3.25. COSY and key HMBC correlations establishing the attachment and connectivity of C-22 to N-24 fragment of oxeatamide C (25). 


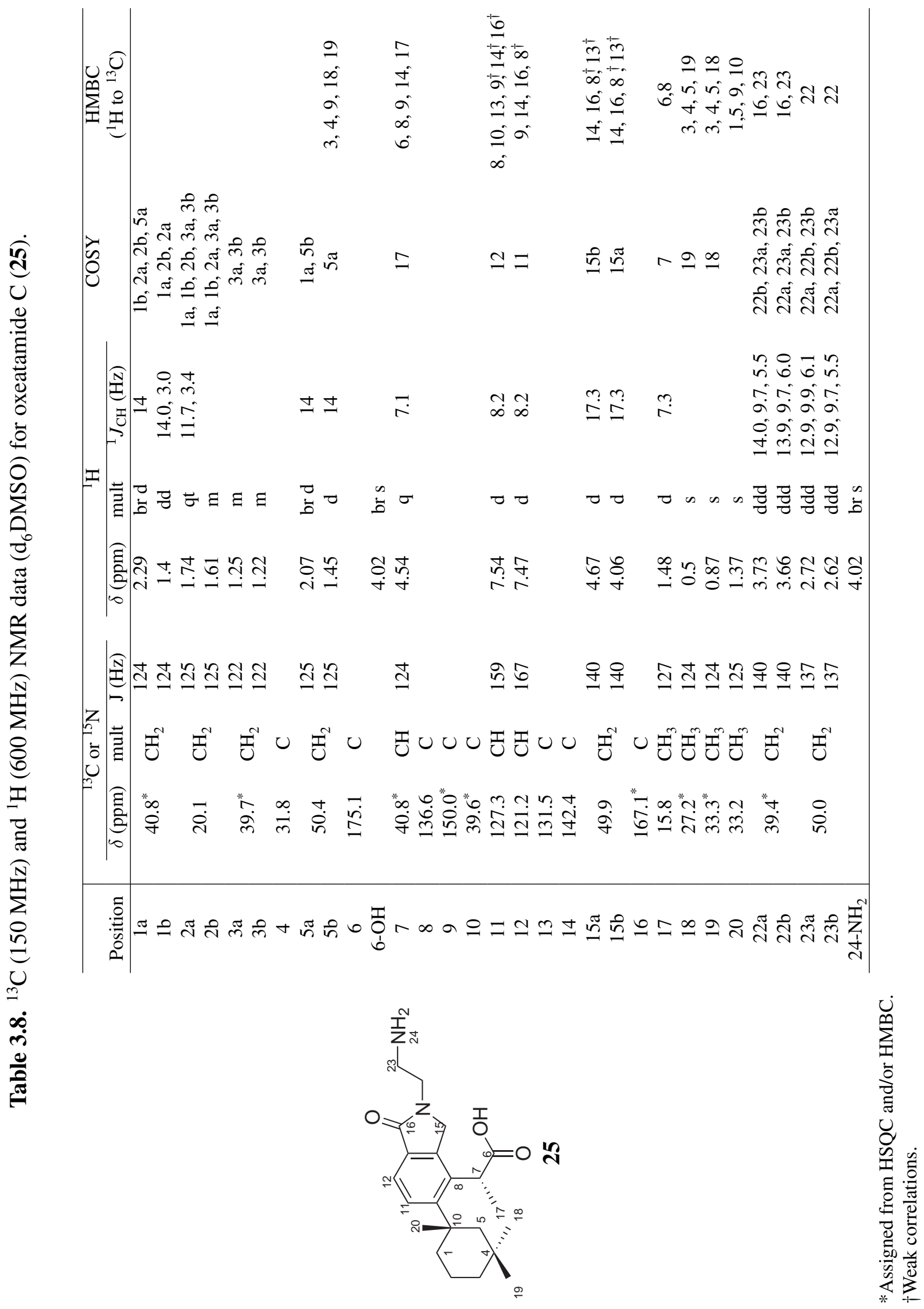




\subsubsection{Biological activity of oxeatamides}

The cytotoxicity of oxeatamides $\mathrm{C}$ to $\mathrm{G}(\mathbf{2 5}-\mathbf{2 9})$ against human cancer cell lines has undergone preliminary investigation. An MTT assay on HL-60 cells was run. The oxeatamides were found to be moderately cytotoxic with $\mathrm{IC}_{50}$ values in the 10 to 50 micromolar range. ${ }^{56}$ This was consistent with the activity of the known oxeatamides. ${ }^{41}$

The known oxeatamides also exhibited some promising antimycobacterial activity. ${ }^{41}$ Based on this knowledge, oxeatamides $\mathrm{C}$ to $\mathrm{G}$ have been submitted for antibacterial testing to the School of Biological Sciences at VUW, however the results are still pending.

\subsubsection{Summary}<smiles>C[C@H](C(=O)O)c1c(C2(C)CCCC(C)(C)C2)ccc2c1CN(CCN)C2=O</smiles>

25<smiles>CCC(C)CN1Cc2c(ccc([C@]3(C)CCCC(C)(C)C3)c2[C@H](C)C(=O)O)C1=O</smiles>

28<smiles>CC(C)CN1Cc2c(ccc([C@@]3(C)CCCC(C)(C)C3)c2[C@H](C)C(=O)O)C1=O</smiles>

26<smiles>CC(C)CCN1Cc2c(ccc([C@@]3(C)CCCC(C)(C)C3)c2[C@H](C)C(=O)O)C1=O</smiles>

29<smiles>C[C@H](C(=O)O)c1c(C2(C)CCCC(C)(C)C2)ccc2c1CN(CCc1ccccc1)C2=O</smiles>

27<smiles>COC(=O)[C@H](C)c1c(C2(C)CCCC(C)(C)C2)ccc2c1CN(CCC(C)C)C2=O</smiles>

33

Five new oxeatamides were isolated from Darwinella oxeata in this study. All shared the oxeatamide backbone (34), and differed only in the lactam substituent. The lactam substiuents were found to be ethyl amine, 2-methyl propyl, ethyl benzyl, 2-methyl butyl and 3-methyl butyl for oxeatamides C (25), D (26), E (27), F (28) and G (29), respectively. The proposed amino acid origin of the lactam substituents of the oxeatamides is discussed later in Section 3.6.3.

The relative configuration of oxeatamide $\mathrm{D}(\mathbf{2 6})$ was established as $7 R^{*}, 10 S^{*}$ based on analysis of NMR data obtained in $\mathrm{CD}_{3} \mathrm{OD}$. The configuration of the other new oxeatamides is thought to be analogous to that proposed for oxeatamide D. 
Oxeatamide G (29) was methylated to 33 using TMS diazomethane to prove the carboxylic acid functionality of the new oxeatamides proposed in the structure elucidation. 


\subsection{Spongian Diterpenoids}

Over 150 spongian and rearranged spongian diterpenoids had been isolated from the sponge orders Dendroceratida and Dictyoceratida up to $2004 .{ }^{21}$ Compounds with the spongian diterpene backbone (35) are often highly oxygenated in a variety of positions, many have undergone a carbon skeleton rearrangement. All of the compounds isolated from Darwinella have a specific rearranged spongian diterpenoid backbone known as the the aplysulphurane backbone (16). ${ }^{41,48,49}$

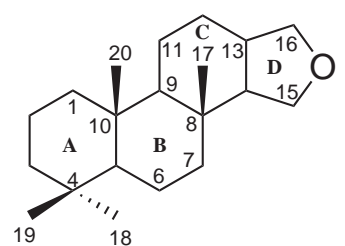

35

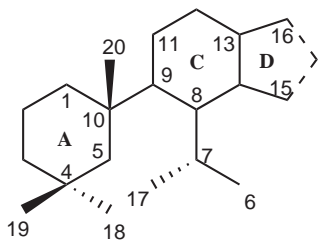

16

The proposed biogenesis of the aplysulphrane backbone (16) from the spongian diterpene backbone (35) involves the Wagner-Meerwin rearrangent of the C-17 methyl from C-8 to adjacent C-7, followed by the oxidative cleavage of the C-5/C-6 bond (Scheme 3.3). ${ }^{57}$

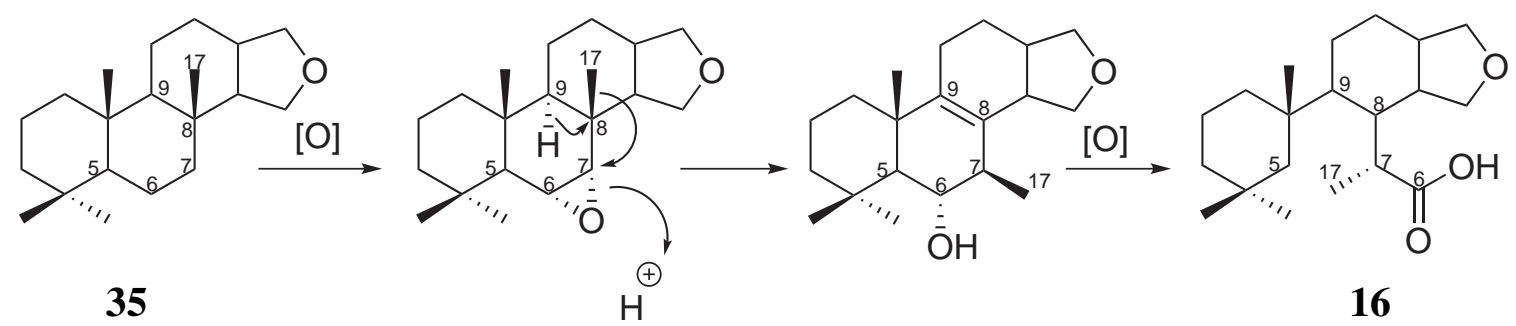

Scheme 3.3. Proposed biogenesis of the aplysulphurane (16) backbone from the spongian diterpene backbone (35) adapted from Keyzers et al. ${ }^{57}$

The first reported aplysulphurane was aplysulphurin (17) by Karuso et al. in $1984 .{ }^{48}$ Aplysulphurin along with the other aplysulphuranes (16) isolated from Darwinlela oxeata — including the tetrahydroaplysulphurins $(\mathbf{1 8 - 2 0})$ and the nitrogenous oxeatamides $(\mathbf{2 1 -}$ 24) - have been discussed earlier in Section 3.2. In 1987, Molinski and Faulkner reported the isolation of membranolide (36) from the Antarctic sponge Dendrilla membranosa. ${ }^{55}$ Tischler and Andersen then reported the isolation of cadlinolides A (37) and B (38), from Aplysilla glacialis in 1991. ${ }^{58}$ Membranolides B (39), C (30) and D (31) were isolated by Ankisetty et al. from D. membranosa in $2004 .{ }^{52}$ The membranolides possessed modest antibacterial activity when tested. ${ }^{52}$ Also in 2004 Keyzers et al. reported the isolation 
of five new aplysulphuranes from Chelonaplysilla violacea: cadlinolide C (40) and D (41), pourewic acid (42), 15-methoxypourewic acid (43) and methyl pourewate (44). ${ }^{39,57}$ Cadlinolide C (40), pourewic acid (42) and methyl pourewate (44) exhibited moderate activity in a neutrophil superoxide anti-inflammatory assay. ${ }^{39,57}$ Simultaneously with Keyzers et al. Diaz-Marrero et al. reported the isolation of cadlinolide C (40) and pourewic acid (42), as well as compound $45 .{ }^{51}$

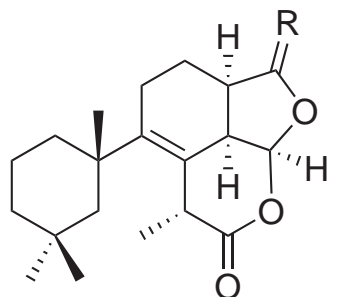

$37 \mathrm{R}=\mathrm{O}$

$38 \mathrm{R}=$ epimeric $\mathrm{H}, \mathrm{OH}$

$40 \mathrm{R}=\mathrm{H}, \mathrm{H}$

$41 \mathrm{R}=$ epimeric $\mathrm{H}, \mathrm{OMe}$

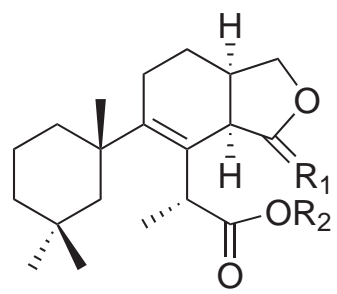

$42 \quad \mathbf{R}_{1}=\alpha-\mathrm{H}, \beta-\mathrm{OMe} \quad \mathrm{R}_{2}=\mathrm{H}$

$45 \quad \mathrm{R}_{1}=\mathrm{O} \quad \mathrm{R}_{2}=\mathrm{Me}$<smiles>[R7][C@@H](C(=O)O)c1c([C@H](C)C(=O)O)ccc2c1C(OC)OC2(C)C</smiles><smiles>COC(=O)[C@H](C)c1c([C@]2(C)CCCC(C)(C)C2)ccc2c1C(=O)OC2</smiles>

$30 \quad \mathrm{R}_{1}=\mathrm{H}$

$\mathrm{R}_{2}=\mathrm{OMe}$

$31 \quad \mathrm{R}_{1}=\mathrm{OMe} \quad \mathrm{R}_{2}=\mathrm{H}$

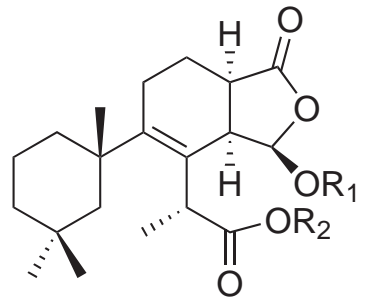

$43 \quad \mathrm{R}_{1}=\mathrm{Me} \quad \mathrm{R}_{2}=\mathrm{H}$

$44 \quad \mathrm{R}_{1}=\mathrm{H} \quad \mathrm{R}_{2}=\mathrm{Me}$

\subsection{Nitrogenous Terpenoids}

A review of the literature establishes that many marine nitrogenous terpenes including isocyanides, isothiocyanates, thiocyanates, dichloroimines and formamides have been reported where the origin of nitrogen was proposed to be from an inorganic source. ${ }^{59}$ There are also other known nitrogenous terpenes, such as steroidal compounds. ${ }^{23-29}$ The focus was narrowed to the more pertinent terpenes with nitrogens of proposed amino acid origin. 


\subsubsection{Nitrogenous Teprpenes of Proposed Amino Acid Origin}

Many examples of terpenes with nitrogens of proposed amino acid origin have been identified, including the nitrogenous spongian diterpenes discussed in Section 3.6.2, as well as some nitrogenous sesquiterpenoids, such as pyrodysinoic acid (46) isolated from the sponge Dysidea sp. ${ }^{60}$ and many sesterterpenoid examples. Molliorin A (47) appears to be the first marine example of a nitrogenous terpene with nitrogen of proposed amino acid origin to be isolated. Molliorin A (47), a nitrogenous scalarane sesterterpene, was reported from the sponge Cacospongia mollior in 1977 by Cafieri et al. ${ }^{61}$ The group continued to work on the same sponge and isolated four more nitrogenous terpenes molliorins B (48), C (49), D (50) and E (51) between 1977 and 1979. ${ }^{62-64}$ All the molliorins are thought to have nitrogens of amino acid origin (isoleucine, ornithine, valine, phenylalanine and glycine for molliorins A to E, respectively). Ornithine is an amino acid with two primary amine functionalities which is not involved in protein synthesis. It results from the action of the enzyme arginase on amino acid arginine and is a product of the urea cycle. ${ }^{65}$

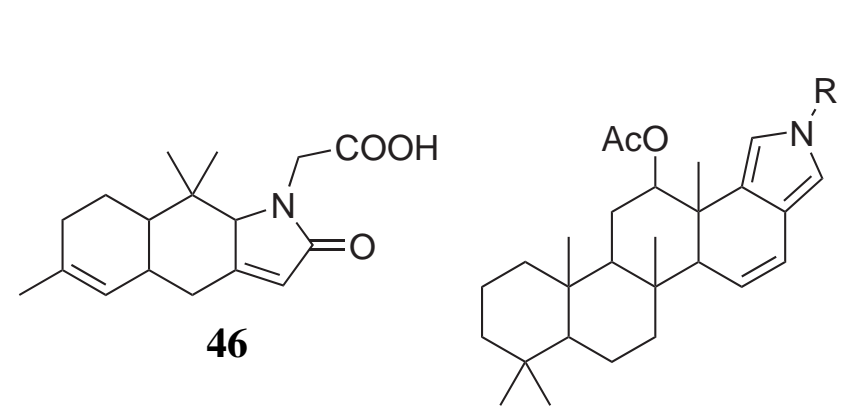

$47 \mathrm{R}=$

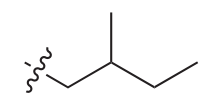

$49 \mathrm{R}=4$

$50 \mathrm{R}=$<smiles>[Te]CCc1ccccc1</smiles>

$51 \mathrm{R}=\quad 3 \cdot \mathrm{CH}_{3}$

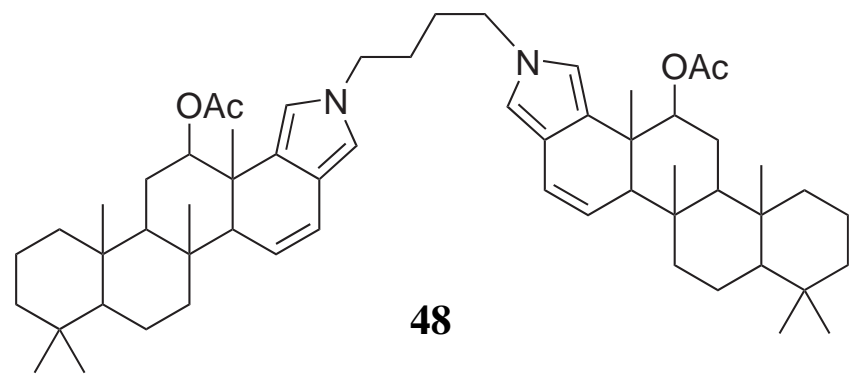

Sarcotragins A (52) and B (53), nitrogenous trisnorsesterterpenes, were isolated from the sponge Sarcotragus sp. by Shin et al. in $2001 .{ }^{66}$ At the time of isolation, the trisnorsesterterpene portion of the sacrotragins was, to their knowledge, an unprecedented structural 
group amongst sponge metabolites. ${ }^{66}$ In 2002, four more nitrogenous sesterterpenes (sarcotrines A (54), B (55), C (56) and D (57)) were isolated from Sarcotragus sp. by Liu et al. ${ }^{67}$ They suggested that it was possible the sarcotragins and sarcotrines shared the same precursor and that the sarcotragins were degradation products of the sarcotrines. ${ }^{67}$ They also observed degradation of $\mathbf{5 4 , 5 5}$ and $\mathbf{5 6}$ on standing to the C-21 epimers $\mathbf{5 8}$, 59 and 60, respectively. ${ }^{67}$ Another four nitrogenous sesterterpenes, sacrotrine E (61), isosarcotrine E (62), sarcotrine F (63) and isosarcotrine F (64), isolated from Sarcotragus sp. were reported by Liu et al. in the following year (2003). ${ }^{60}$

\subsubsection{Nitrogenous Spongian Diterpenoids}

Nitrogenous spongian diterpenes are rare, with only eight reported; the oxeatamides, the spongolactams and haumanamide (66). ${ }^{41,68,69}$ All examples have a lactam at ring D. The proposed source of the lactam nitrogen and alkyl side chain attached to the nitrogen is of amino acid origin. Pham et al. reported the isolation of the nitrogenous terpene haumanamide (66), from the sponge Spongia sp. in 1992. ${ }^{68}$ More recently, spongolactam A (67), B (68) and C (69) were isolated from Spongia sp. in $2007 .{ }^{69}$ Exhibiting the same terpene skeleton as haumanamide (66) the spongolactams have different alkyl side chains attached to the lactam nitrogen. Spongiolactams A (67) and B (68) are structural isomers differing only in the placement of the lactam carbonyl, similar to oxeatamide A (21) and iso-oxeatamide A (23). The spongolactams have shown promising activity as farensyl transferase inhibitors. ${ }^{69}$

\subsubsection{Proposed Biogenesis of Terpenes with Nitrogens of Proposed Amino Acid Origin}

In 1999, Sayed et al. reported the feeding of the natural product palinurin (70) (which had been previously isolated from the sponges Ircinia echinata and Ircinia variabillis) to the fungus Cunninghamella sp.. Palinurin (70), a furanosesterterpene similar to the sarcotins, was transformed by the fungus to the pyrrolosesterterpenes palinurines A (71) and B (72). 
<smiles>[R]N1CC=C(CCC/C(C)=C/C=C/[C@H](C)CC/C=C(/C)CC(O)C(=O)OC)C1=O</smiles><smiles>[R]N1CC=C(CCC/C(C)=C/C=C/[C@H](C)CC/C=C(/C)C[C@@H]2OC(=O)C(C)=C2O)C1=O</smiles><smiles>CCCCN1CC(CCC/C(C)=C/C=C/[C@H](C)CC/C=C(/C)C[C@@H]2OC(=O)C(C)=C2O)=CC1=O</smiles>

57
$52 \mathrm{R}=$<smiles>CCCc1ccccc1</smiles>

$53 \mathrm{R}=$

$54 \mathrm{R}=$<smiles>CCCC(C)C</smiles>

$55 \mathrm{R}=$

$56 \mathrm{R}=$<smiles>CCCCc1ccccc1</smiles>

$58 \mathrm{R}=$<smiles>CCCC(C)C</smiles><smiles>[R]N1CC=C(CCC/C(C)=C/C=C/[C@H](C)CC/C=C(/C)C[C@@H]2OC(=O)C(C)=C2O)C1=O</smiles>

$59 \mathrm{R}=$<smiles>CCCc1ccccc1</smiles>

$60 \mathrm{R}=$<smiles>CCCC(C)CC</smiles>

$61 \mathrm{R}=$ 聍 $\mathrm{CO}_{2} \mathrm{Na}$<smiles>CC1=C(O)[C@@H](C/C(C)=C\CC[C@H](C)/C=C/C=C(\C)CCCC2=CC(=O)N(CC(=O)O[Na])C2)OC1=O</smiles>

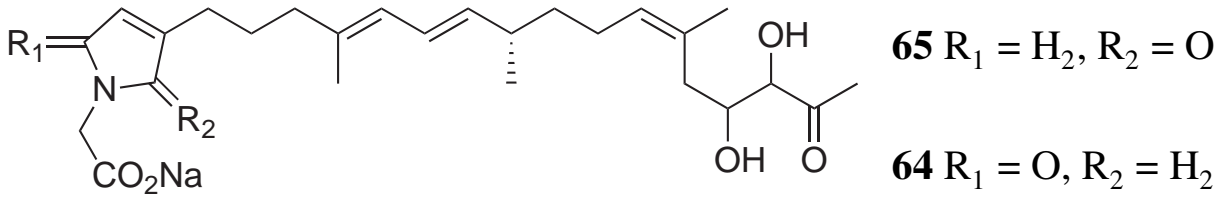




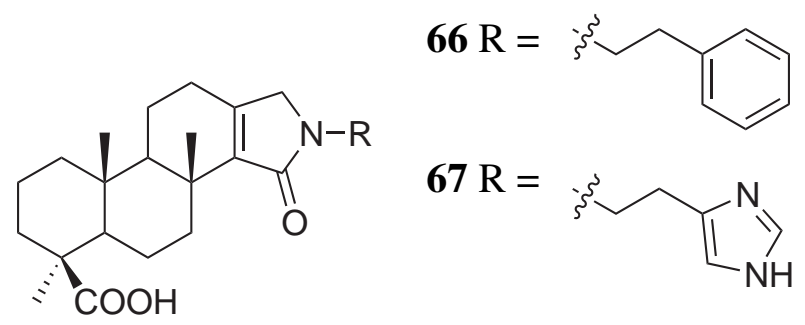

$69 \mathrm{R}=\xi^{3} \mathrm{COOH}$

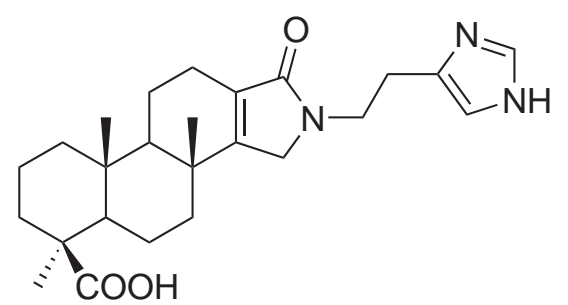

68

Their proposed biogenesis pathway for the $N$-substituted $\gamma$-lactam involves the furan of palinurin (70) reacting with a decarboxylated serine (Scheme 3.4). ${ }^{70}$

In the case of palinurin (70) the furan oxygen is adjacent to two accessible oxy-methine carbons. Both of the electron deficient methines are susceptible to the nucleophilic addition of amino acid derivatives leading to structural isomers of the lactam as seen in palinurine A (71) and B (72) and several other examples (Table 3.9).<smiles>CC(=CC=C[C@@H](C)CCC=C(C)CC1OC(=O)C(C)=C1O)CCCc1ccoc1</smiles>

70<smiles>CC(=CC=C[C@@H](C)CCC=C(C)CC1OC(=O)C(C)=C1O)CCCC1=CCN(CCO)C1=O</smiles><smiles>CC(=CC=C[C@@H](C)CCC=C(C)CC1OC(=O)C(C)=C1O)CCCC1=CC(=O)N(CCO)C1</smiles>

72

Pyrodysinoic acid (46), the sarcotragins, the sarcotrines, haumanamide (66), the spongolactams and the oxeatamides are all thought to arise from the reaction of a furan precursor and an amino acid derivative in a similar manner to that proposed for the reaction of 

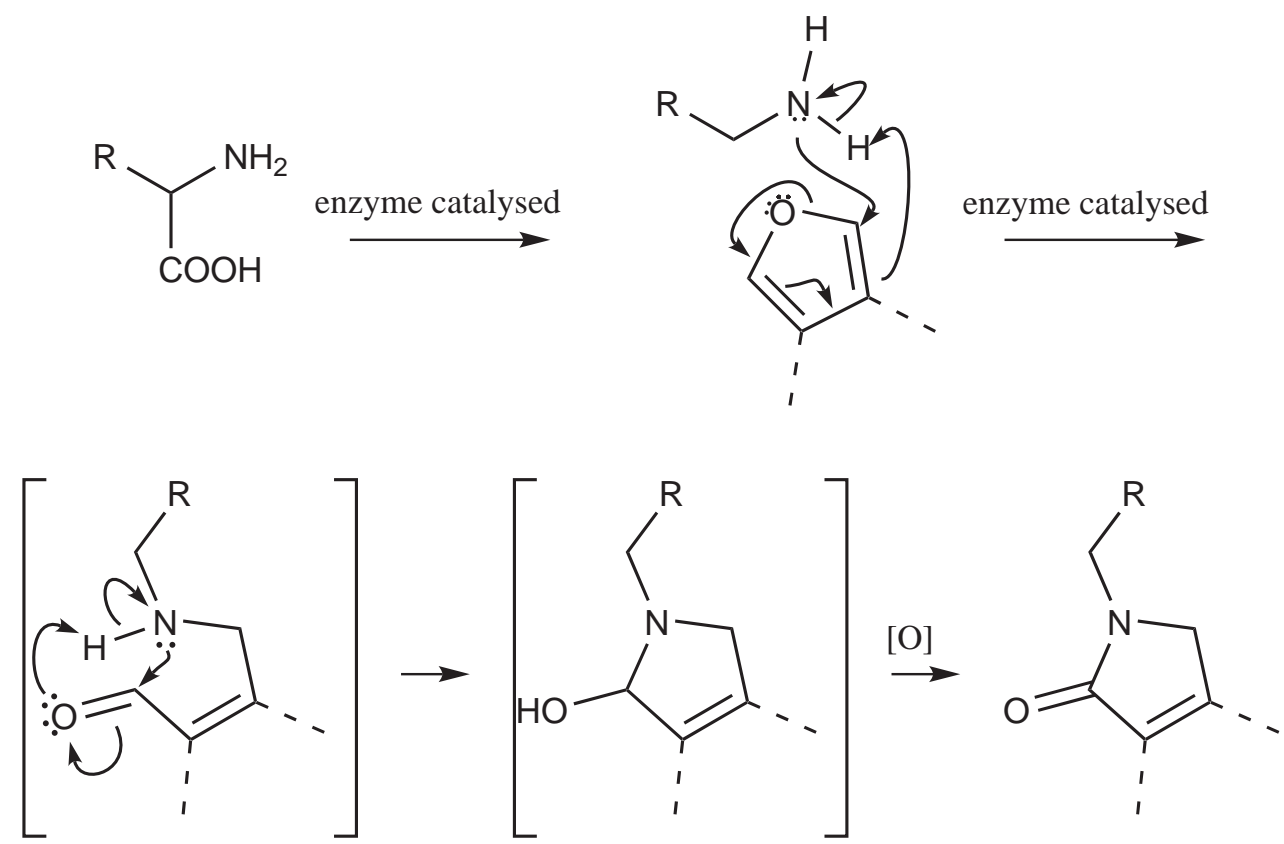

Scheme 3.4. Biogenesis of $N$-substituted lactams from furan precursors, proposed by El Sayed et al. ${ }^{70}$

palinurin (70) with decarboxylated serine (Scheme 3.4). ${ }^{70}$ For many of these compounds the proposed furan precursor is a known natural product. In the majority of cases, the amino acid derivate is decarboxylated with the notable exception of glycine. Enzyme mediated amino acid decarboxylation is a common phenomenon and specific carboxylyase enzymes (EC 4.1.1) have been identified for different amino acid residues. For example the enzyme responsible for the decarboxylation of phenylananine is aromaticL-amino acid carboxy-lyase (EC 4.1.1.28) whilst L-valine carboxy-lyase (EC 4.1.1.14) is known to decarboxylate valine and leucine. ${ }^{65}$

It is also possible that the biogenesis pathway of the $N$-substituted $\gamma$-lactams involves the initial oxidation of a furan precursor by ${ }^{1} \mathrm{O}_{2}$ as proposed in Scheme 3.5.

The proposed biogenesis of pyrodysinoic acid (46) involves the in vivo reaction of furodysinin $(\mathbf{7 3})^{71}$ and the amino acid glycine. Sarcotragin A (52) and B (53) are thought to arise from the reaction of sarcotin $\mathbf{J}(\mathbf{7 4})$ with decarboxylated phenylalanine and glycine respectively. Most of the sarcotrines with the exception of sarcotrine F (63) and isosarcotrine F (64) can be directly explained by the reaction of sarcotin A (75) or episarcotin A (76) with an amino acid derivate (refer to Table 3.9 for specific amino acid derivatives). As Episarcotin A (76) is the position 21 epimer of sarcotin A (75), it is 


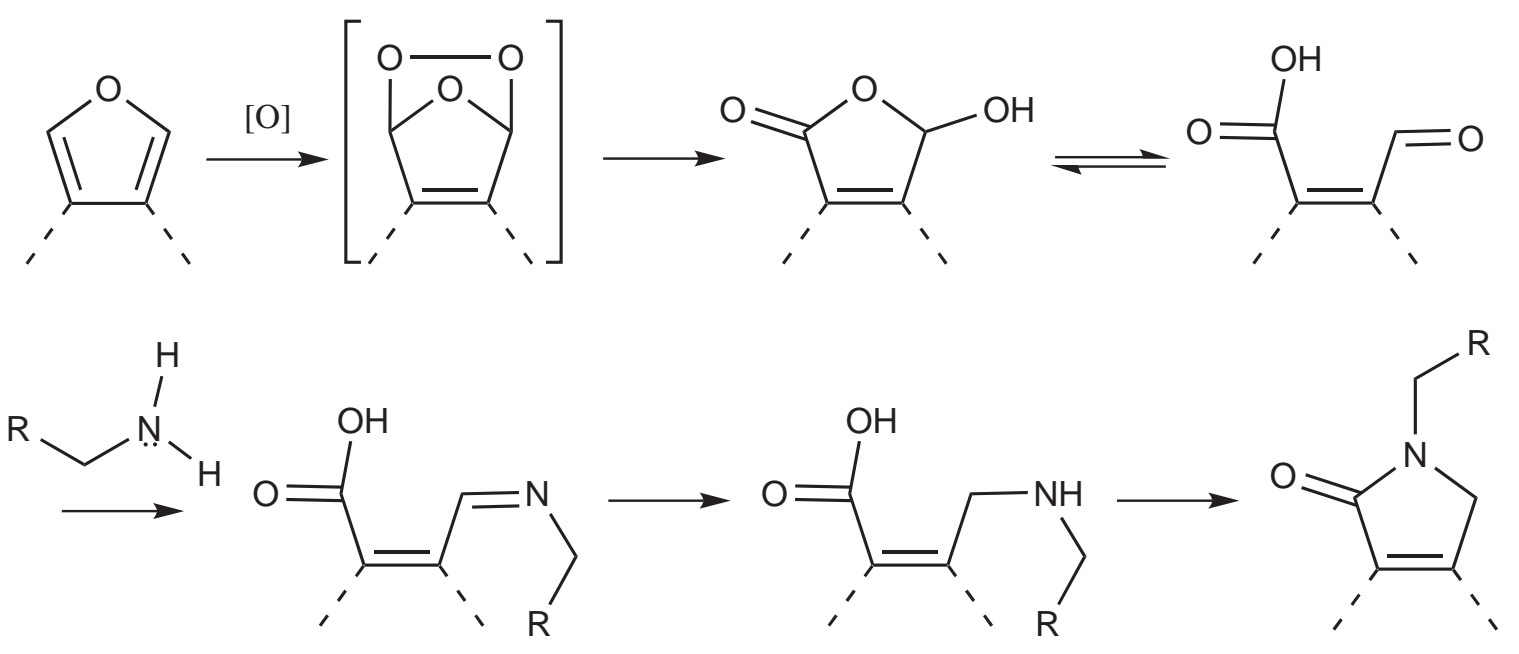

Scheme 3.5. Alternative biogenesis pathway for $N$-substituted lactams involving ${ }^{1} \mathrm{O}_{2}$ oxidation of furan precursors.

possible that $\mathbf{7 6}$ is a degradation product of $\mathbf{7 5}$ as degradation on standing of some of the sarcotrines to postion 21 epimers has been observed. ${ }^{67}$ Assuming that sarcotrine F (63) and isosarcotrine $\mathrm{F}(\mathbf{6 4})$ are also derived from a reaction between a furan precursor and an amino acid derivative, the logical furan precursor is compound $\mathbf{7 7 .}$

Pham et al. suggested the lactam nitrogen and the alkyl side chain of haumanamide (66) could be derived from $\beta$-phenylethylamine (decarboxylated phenylalanine). ${ }^{68}$ They also reported the isolation of furan spongia-13(16),14-dien-19-oic acid (78) from the same sponge extract as haumanamide (66). ${ }^{68}$ One can propose that the biogenesis of haumanmide (66) and spongiolactam A (67), B (68) and C (69) involves the reaction of spongia-13(16), 14-dien-19-oic acid (78) with various decarboxylated amino acid derivatives (refer to Table 3.9 for specific amino acid derivatives).

The pyrroloterpene molliorins (47-51) differ from the majority of nitrogenous terpenes mentioned which have lactam rings. This may indicate a slightly different biogenesis pathway. Cafieri et al. ${ }^{61}$ proposed that the biogenesis of molliorin A (47) involves the in vivo reaction of the known natural product scalaradial (79) ${ }^{72}$ with decarboxylated isoleucine. ${ }^{61}$ Scalaradial (79) does not posses a furan ring and instead has a dialdehyde moiety which explains the pyrrole formation rather than the lactam. The reaction of the dialdehydes of scalaradial (79) with amino acid derivatives is thought to account for the biogenesis of all of the molliorins (refer to Table 3.9 for specific amino acid derivatives). Molliorin B (48) is an unusual dimer that can be proposed to arise from the reaction of 
two molecules of $\mathbf{7 9}$ with decarboxylated ornithine, a diamine.

The oxeatamides possess a lactam at ring D indicating they may arise from the reaction of a furan precursor and an amino acid derivative. It is proposed that the hypothetical furan precursor is compound 80, an aplysulphurane skeleton with a carboxylic acid at position 6 and a furan at ring D. There are no known aplysulphuranes with a furan at ring $\mathrm{D}$, however amongst the spongian diterpenes as a whole, 25 of the 154 compounds in the 2006 literature review possess a ring D furan. ${ }^{21}$ The reaction of $\mathbf{8 0}$ with decarboxylated valine, phenylalanine, isoleucine and leucine, in the same manner as proposed for the synthesis of palinurine A (71) and B (72) (Scheme 3.4), would result in the formation of oxeatamides D (26), E (27), F (28) and G (29), respectively.<smiles>CC1=CC2Cc3ccoc3C(C)(C)C2CC1</smiles>

73<smiles>C[C@@]1(C(=O)O)CCC[C@@]2(C)C1CC[C@@]1(C)c3cocc3CC[C@@H]12</smiles>

78<smiles>CC1(C)CCCC2(C)C1CCC1(C)C2CC(OC2CC2)C2(C)C(C=O)C(C=O)=CCC12</smiles>

79<smiles>CC(C(=O)O)c1c(C2(C)CCCC(C)(C)C2)ccc2cocc12</smiles>

80<smiles>COC(=O)C(O)C/C(C)=C\CC[C@H](C)/C=C/C=C(\C)CCCc1ccoc1</smiles>

74<smiles>CC(=CC=C[C@@H](C)CCC=C(C)CC[C@H]1OC(=O)C(C)=C1O)CCCc1ccoc1</smiles>

75<smiles>CC(=CC=C[C@@H](C)CCC=C(C)C[C@@H]1OC(=O)C(C)=C1O)CCCc1ccoc1</smiles>

76<smiles>CC(=O)C(O)C(O)C/C(C)=C\CC[C@H](C)/C=C/C=C(\C)CCCc1ccoc1</smiles>

77

The origin of the nitrogenous moiety of oxeatamide $\mathrm{C}(\mathbf{2 5})$ is not immediately obvious. The other oxeatamides all contain nitrogens of proposed protogenic amino acid origin. Due to this precedence, 2,3-diaminopropanoic acid and ethylene diamine (the decarboxylated version of the amino acid) were considered as possible precursors of the nitrogenous portion of oxeatamide $\mathrm{C}(\mathbf{2 5})$. However, to the best of our knowledge, neither 


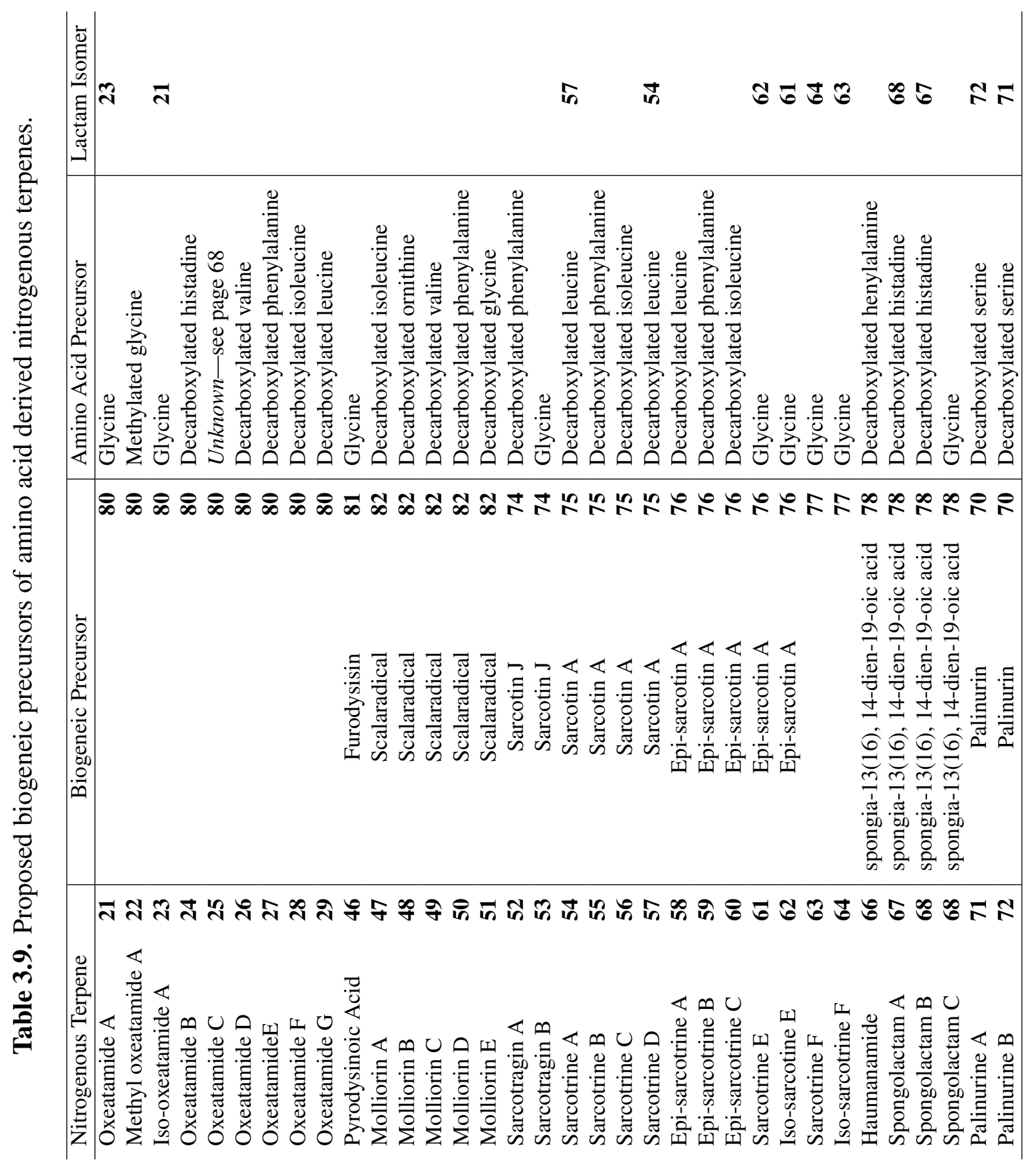


of these compounds are involved in any of the major metabolic pathways. Assuming the biogenesis of $\mathbf{2 5}$ is similar to that proposed for the other oxeatamides — the enzymatically controlled reaction of a furan precursor $\mathbf{8 0}$ with an amino acid derivative- we propose two possible biogenesis pathways for the formation of the lactam of $\mathbf{2 5}$ from the amino acids serine and glycine, respectively.

One of proposed biogenesis pathways for the ethylene diamine precursor involves the oxidation and subsequent transamination of decarboxylated serine. Decarboxylation of amino acids is, as previously stated, a relatively common enzmatically controlled phenomenon; the enzyme responsible for the decarboxylation of serine is phosphatidylserine decarboxylase (EC 4.1.1.65). ${ }^{65}$ The enzymatic oxidation of decarboxylated serine from an alcohol to an aldehyde would involve a dehydrogenase enzyme and the corresponding reduction of $\mathrm{NAD}^{+}$to $\mathrm{NADH}$. The aldehyde would then react with ammonia and be converted into an amine via imine formation followed by a reduction involving the corresponding oxidation of NADH to $\mathrm{NAD}^{+}$.

Alternatively, oxeatamide C (25) could derive from oxeatamide A (21) or a glycine derivative. This proposed biogenesis pathway involves the enzymatic reduction of the carboxylic acid functionality of either glycine or $\mathbf{2 1}$ to an aldehyde followed by transamination of the aldehyde to an amine (as described previously). The glycine derivative would then go on to react with the furan precursor 80 (method described previously) to form oxeatamide C (25).

Interestingly, no dimer of oxeatamide C (25) was isolated. Theoretically it would be possible for the terminal amine functionality of $\mathbf{2 5}$ to react with another furan precursor 80, in the same manner as that proposed for the biogenesis of the other oxeatamides, to form a dimer.

A schematic of the proposed biogenesis pathway for the known and new oxeatamides from a furan precursor 80, is depicted in Scheme 3.6. 


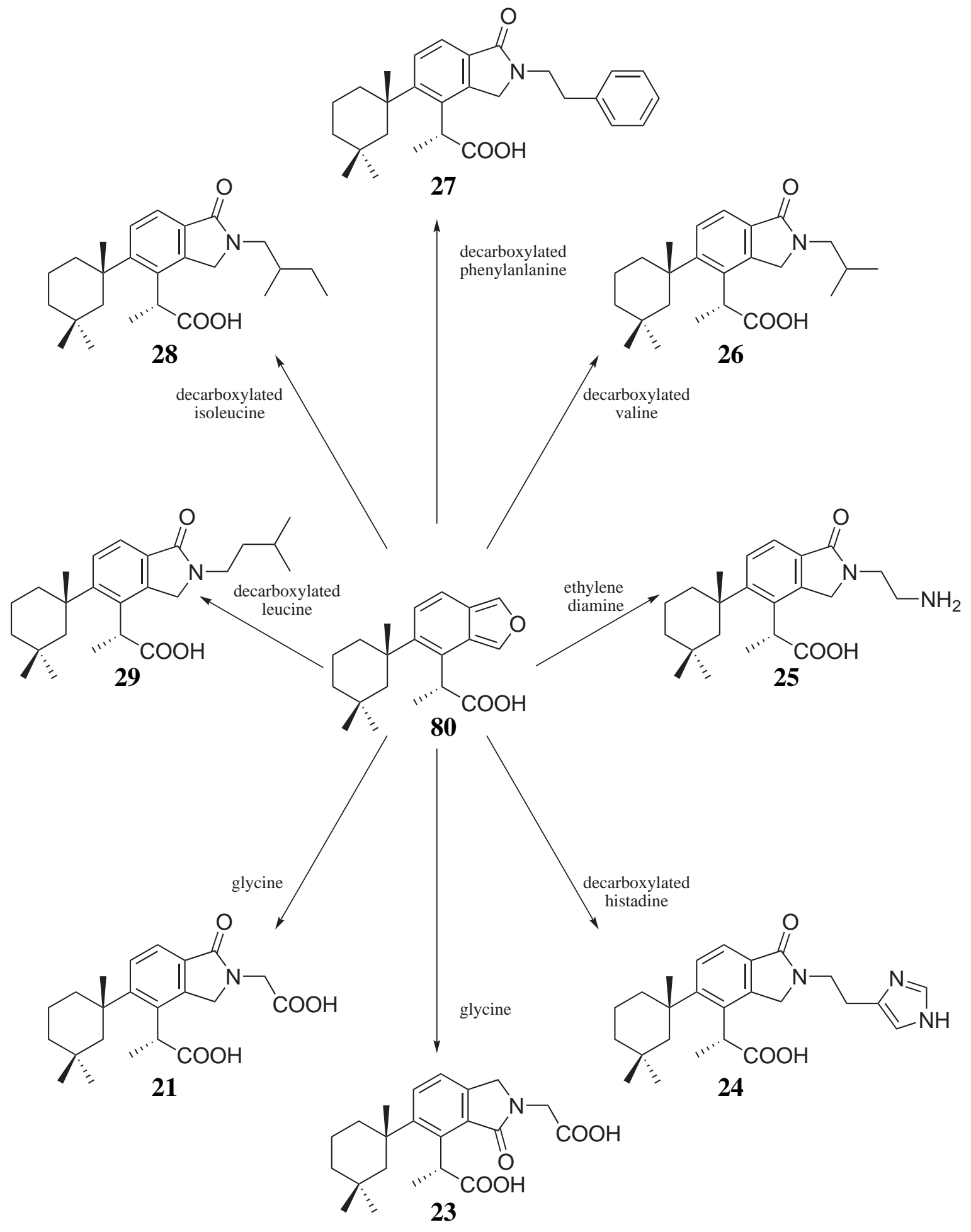

Scheme 3.6. Proposed biogenesis of the oxeatamides. 


\section{Chapter 4}

\section{Conclusion}

This spectroscopic guided study resulted in the isolation and structure elucidation of five new and five known rearranged spongian diterpenes of the aplysulphurane class from the New Zealand marine sponge Darwinella oxeata. Two of the known compounds isolated from $D$. oxeata had only previously been reported from the Antarctic marine sponge Dendrilla membranosa. The new compounds, oxeatamides C to G (25-29) share the same backbone and oxygenation pattern as the known oxeatamides, previously isolated from this sponge, and differ only in the lactam side chain. Like the known oxeatamides, the nitrogenous moiety is thought to be amino acid derived. Thus far six of the twenty protogenic amino acids have been identified as the likely precursors of the nitrogenous moiety of the oxeatamides, it is possible that there are more congeners yet to be isolated. The future isolation of the proposed furan precursor $\mathbf{8 0}$ would give further support for the proposed biogenesis pathway.

The origin of the diamine portion of oxeatamide C (25) is not immediately obvious. However, it is possible that it arises from a precursor or derivatisation of the amino acids glycine or serine. Theoretically, the terminal primary amine of $\mathbf{2 5}$ could react with a further furan precursor $\mathbf{8 0}$ forming a dimer, analogous to molliorin $\mathrm{B}(\mathbf{4 8})$, though this was not detected.

Oxeatamides C to G (25-29) were moderately cytotoxic towards HL-60 cell lines in a MTT assay. Due to the promising activity of the known oxeatamides, the new oxeatamides were also submitted for testing in antimycobacterial assays. Of particular interest will be their activity against mycobacteria. Any oxeatamide that exhibits interesting bioactivity can then compared to the observed activity of the other oxeatamides, essentially a small array of congeners. This would give insight into the structure-activity relationship and would provide a useful starting place for potential synthetic derivatives. 
In order to be useful as pharmaceutical leads the absolute configuration of the oxeatamides would need to be established. Due to the relatively small amount of oxeatamides isolated crystal growth was not possible. Thus the absolute configuration would need to be established through synthetic studies.

The success of both this study and that of Wojnar, ${ }^{41}$ would justify the investigation of the non-polar fractions of $D$. oxeata. Crude analysis of the ${ }^{1} \mathrm{H}$ NMR spectra of these fractions indicates the presence of structurally related compounds.

Four other New Zealand marine sponges were also briefly investigated, leading to the isolation of a known compound from Dictyodendrilla dendyi. The unidentified sponges MNP0996 and MNP1003 displayed promising results in the NMR based screening protocol and thus warrant further investigation by another researcher.

As in this study, a spectroscopic-guided method can result in the isolation of groups of structurally related new compounds that can be tested in screening libraries, that are unbiased by specific biological activity (as in bioassay guided studies). Such groups of congeners can provide significant insight into structure activity relationships, which normally would not be possible without synthetic derivatisation. 


\section{Chapter 5}

\section{Experimental}

\subsection{General}

NMR spectra were obtained using a Varian DirectDrive spectrometer fitted with a triple resonance $\mathrm{HCN}$ cryogenic probe, operating at $600 \mathrm{MHz}$ for the ${ }^{1} \mathrm{H}$ nucleus and $150 \mathrm{MHz}$ for the ${ }^{13} \mathrm{C}$ nucleus. Chemical shifts $(\delta \mathrm{ppm})$ were referenced to the residual solvent peak. ${ }^{73}$ Quantification of the samples was performed by ${ }^{1} \mathrm{H}$ NMR using an internal $\mathrm{CH}_{3} \mathrm{NO}_{2}$ standard $\left(100 \mu \mathrm{L}\right.$ in $\left.5 \mathrm{~mL} \mathrm{CDCl}_{3}\right)$, using the acquisition parameters described by West. ${ }^{36}$ High-resolution mass spectra were obtained using a Micromass Q-TOF Premier mass spectrometer. TLC analysis was performed on Machery-Nagel Alugram SIL G/UV $\mathrm{UV}_{254}$ normal-phase silica plates using a mobile phase of $5 \% \mathrm{MeOH} / \mathrm{CH}_{2} \mathrm{Cl}_{2}$ unless otherwise stated. TLC plates were visualized by fluorescence quenching under UV light or by dipping in a solution of $5 \% \mathrm{H}_{2} \mathrm{SO}_{4} / \mathrm{MeOH}$ followed by a solution of $0.1 \%$ vanillin/EtOH then application of heat.

Normal-phase column chromatography was performed using YMC Co. LTD 2,3-dihydroxypropoxypropyl derivatised silica gel (DIOL). Reversed-phase column chromatography was carried out using Supelco Diaion HP20 or HP20SS poly(styrene divinylbenzene) (PSDVB) resin. High-pressure liquid chromatography (HPLC) was performed on using a Ranin Dynamax solvent delivery module with $25 \mathrm{~mL}$ pump heads. UV detection for HPLC runs was obtained with a Varian Prostar 335 Diode Array detector. Solvents used for HPLC were of HPLC grade quality. All other solvents were glass distilled. Water was distilled and deionised using a Milli-Q ultrapure water system. Solvent mixtures are reported as \% vol/vol, unless otherwise stated.

The Marine Natural Products Group at VUW collected the Darwinella oxeata, Raspailia topsenti and Dictyodendrilla dendyi specimens whilst NIWA collected sponge specimens MNP0996 and MNP1003. All sponge specimens were stored at $-18{ }^{\circ} \mathrm{C}$ until extracted. 
A voucher sample of each specimen was taken and stored in $75 \% \mathrm{IPA} / \mathrm{H}_{2} \mathrm{O}$, at the School of Chemical and Physical Sciences at VUW.

\subsection{Investigation of Darwinella oxeata}

\subsubsection{Initial fractionation of Darwinella oxeata}

The Darwinella oxeata specimen was collected in November 2006, from Archway Bay, Cape Brett, Northland, New Zealand. Frozen sponge (535 g) was cut into small segments and extracted with $\mathrm{MeOH}(2 \times 2.5 \mathrm{~L})$ for $24 \mathrm{~h}$. The second then first extracts were passed through $400 \mathrm{~mL}$ of $\mathrm{HP} 20$ resin pre-equilibrated in $\mathrm{MeOH}$. The combined eluents were cyclic loaded ${ }^{*}$ onto the column. The column was washed with $\mathrm{H}_{2} \mathrm{O}(1.2 \mathrm{~L})$ and fractionated with $1.2 \mathrm{~L}$ portions of i) $20 \% \mathrm{Me}_{2} \mathrm{CO} / \mathrm{H}_{2} \mathrm{O}$ (fraction i), ii) $40 \% \mathrm{Me}_{2} \mathrm{CO} / \mathrm{H}_{2} \mathrm{O}$ (fraction ii), iii) $60 \% \mathrm{Me}_{2} \mathrm{CO} / \mathrm{H}_{2} \mathrm{O}$ (fraction iii), iv) $80 \% \mathrm{Me}_{2} \mathrm{CO} / \mathrm{H}_{2} \mathrm{O}$ (fraction iv) and v) $100 \% \mathrm{Me}_{2} \mathrm{CO}$ (fraction $\mathbf{v}$ ). Fractions $\mathbf{A}$ to $\mathbf{D}$ were each individually back loaded ${ }^{*}$ onto columns packed with $150 \mathrm{~mL} \mathrm{HP} 20$ pre-equilibrated in $\mathrm{H}_{2} \mathrm{O}$ for fractions $\mathbf{A}$ and $\mathbf{B}$ and pre-equilibrated in $\mathrm{MeOH}$ for fractions $\mathbf{C}$ and $\mathbf{D}$. The columns were then washed with $\mathrm{H}_{2} \mathrm{O}(450 \mathrm{~mL})$ and eluted with $\mathrm{Me}_{2} \mathrm{CO}(450 \mathrm{~mL})$. The eluents were then concentrated to dryness to give $78.7 \mathrm{mg}$ of fraction $\mathbf{A}, 163.4 \mathrm{mg}$ of fraction $\mathbf{B}, 247.2 \mathrm{mg}$ of fraction $\mathbf{C}$ and $891.5 \mathrm{mg}$ of fraction D. Fraction $\mathbf{E}$ was also concentrated to dryness (795.4 mg).

\subsubsection{Isolation of oxeatamides $A, B$ and $C$ and iso-oxeatamide $A$}

Fraction (i), from the initial fractionation of Darwinella oxeata (as detailed in Section 5.2.1), was dissolved in a minimum amount of $50 \% \mathrm{MeOH} / \mathrm{CH}_{2} \mathrm{Cl}_{2}$ and loaded on to $1 \mathrm{~mL}$ of DIOL and air-dried. The loaded DIOL was added to the top of a $24 \mathrm{~mL}$ DIOL column pre-equilibrated in $\mathrm{CH}_{2} \mathrm{Cl}_{2}$. The column was sequentially eluted with $75 \mathrm{~mL}$ fractions of i) $\mathrm{CH}_{2} \mathrm{Cl}_{2}$, ii) $1 \% \mathrm{MeOH} / \mathrm{CH}_{2} \mathrm{Cl}_{2}$, iii) $5 \% \mathrm{MeOH} / \mathrm{CH}_{2} \mathrm{Cl}_{2}$, iv) $10 \% \mathrm{MeOH} / \mathrm{CH}_{2} \mathrm{Cl}_{2}$

\footnotetext{
${ }^{*}$ For a detailed discussion of cyclic loading and back loading, please see Chapter 1, Section 1.4.1.
} 
(fraction A), v) $20 \% \mathrm{MeOH} / \mathrm{CH}_{2} \mathrm{Cl}_{2}$ (fraction B) and vi) $50 \% \mathrm{MeOH} / \mathrm{CH}_{2} \mathrm{Cl}_{2}$ (fraction C). The fractions were concentrated to dryness.

Approximately half of fraction (ii), from the initial fractionation of Darwinella oxeata (as detailed in Section 5.2.1) ( $~ 82 \mathrm{mg}$ ) was dissolved in a minimum of $\mathrm{CH}_{2} \mathrm{Cl}_{2}$ and loaded onto a $25 \mathrm{~mL}$ DIOL column pre-equilibrated in $\mathrm{CH}_{2} \mathrm{Cl}_{2}$. The column was sequentially eluted with $75 \mathrm{~mL}$ fractions of i) $\mathrm{CH}_{2} \mathrm{Cl}_{2}$, ii) $1 \% \mathrm{MeOH} / \mathrm{CH}_{2} \mathrm{Cl}_{2}$, iii) $2 \% \mathrm{MeOH} / \mathrm{CH}_{2} \mathrm{Cl}_{2}$, iv) $5 \% \mathrm{MeOH} / \mathrm{CH}_{2} \mathrm{Cl}_{2}$, v) $10 \% \mathrm{MeOH} / \mathrm{CH}_{2} \mathrm{Cl}_{2}$ (fraction D), vi) $20 \% \mathrm{MeOH} / \mathrm{CH}_{2} \mathrm{Cl}_{2}$ (fraction E) and vii) $50 \% \mathrm{MeOH} / \mathrm{CH}_{2} \mathrm{Cl}_{2}$. This protocol was repeated with the other half of fraction (ii).

Fraction A $(21.5 \mathrm{mg})$ and fraction $\mathbf{C}(17 \mathrm{mg})$ were combined and dissolved in $1 \mathrm{~mL}$ of $\mathrm{MeOH}$. Five $200 \mu \mathrm{L}$ samples were then injected onto a semi-preparative $(1 \mathrm{~cm} \times 25 \mathrm{~cm})$ Ranin Microb $\mathrm{C}_{18} \mathrm{HPLC}_{\mathrm{C}}$ column pre-equilibrated with 70\% MeOH/0.1 $\mathrm{M} \mathrm{HCOOH}_{(a q)}$, with a flow rate of $5 \mathrm{~mL} / \mathrm{min}$ and UV detection set to wavelengths $245 \mathrm{~nm}$ and $280 \mathrm{~nm}$. The column was then eluted isocratically with $70 \% \mathrm{MeOH} / 0.1 \mathrm{M} \mathrm{HCOOH}_{(a q)}$. The eluent between 19.5-23.5 minutes (fraction F) was collected. This fraction was back loaded onto $2 \mathrm{~mL}$ HP20SS column. The column was eluted with $6 \mathrm{~mL}$ of $\mathrm{MeOH}$ and then concentrated to dryness. ${ }^{1} \mathrm{H}$ NMR analysis showed fraction $\mathbf{F}$ contained oxeatamide A (21).

Fraction D (42 mg) was dissolved in $1.4 \mathrm{~mL}$ of $\mathrm{MeOH}$. Seven $200 \mu \mathrm{L}$ samples were then injected onto a semi-preparative $(1 \mathrm{~cm} \times 25 \mathrm{~cm}) \mathrm{C}_{18} \mathrm{HPLC}$ column pre-equilibrated with $70 \% \mathrm{MeOH} / 0.1 \mathrm{M} \mathrm{HCOOH}_{(a q)}$, with a flow rate of $5 \mathrm{~mL} / \mathrm{min}$ and $\mathrm{UV}$ detection set to wavelengths $245 \mathrm{~nm}$ and $280 \mathrm{~nm}$. The column was then eluted with 70\% $\mathrm{MeOH} / 0.1 \mathrm{M}$ $\mathrm{HCOOH}_{(a q)}$. Three fractions eluting between 4.5-8.5 minutes (fraction G), 20.8-23.5 minutes (fraction $\mathbf{H}$ ) and 24.5-26.5 (fraction $\mathbf{I}$ ) were collected. These fractions ( $\mathbf{G}, \mathbf{H}$ and I) were each back loaded onto $2 \mathrm{~mL}$ HP20SS columns. The columns were each eluted with $6 \mathrm{~mL}$ of $\mathrm{MeOH}$ and then concentrated to dryness. ${ }^{1} \mathrm{H}$ NMR analysis showed that fraction $\mathbf{G}$ contained impure oxeatamide B (24), fraction $\mathbf{H}$ contained oxeatamide A (21) and fraction I contained $2.3 \mathrm{mg}$ of impure iso-oxeatamide A (23).

Fraction B (21.2 mg) and fraction $\mathbf{E}(34.5 \mathrm{mg})$ were combined and dissolved in $1 \mathrm{~mL}$ of 
$\mathrm{MeOH}$. Five $200 \mu \mathrm{L}$ samples were then injected onto a semi-preparative $(1 \mathrm{~cm} \times 25 \mathrm{~cm})$ $\mathrm{C}_{18} \mathrm{HPLC}$ column pre-equilibrated with $70 \% \mathrm{MeOH} / 0.1 \mathrm{M} \mathrm{HCOOH}_{(a q)}$, with a flow rate of $5 \mathrm{~mL} / \mathrm{min}$ and UV detection set to wavelengths $245 \mathrm{~nm}$ and $280 \mathrm{~nm}$. The column was then eluted with $70 \% \mathrm{MeOH} / 0.1 \mathrm{M} \mathrm{HCOOH}_{(a q)}$. The fractions eluted between 7.8-15.4 minutes (fraction $\mathbf{J}$ ) and 20.2-23.8 minutes (fraction $\mathbf{K}$ ) were collected. Fractions $\mathbf{J}$ and K were each back loaded onto $2 \mathrm{~mL}$ HP20SS columns. The columns were each eluted with $6 \mathrm{~mL}$ of $\mathrm{MeOH}$ and then concentrated to dryness. ${ }^{1} \mathrm{H}$ NMR analysis showed that fraction $\mathbf{J}$ contained $0.5 \mathrm{mg}$ of oxeatamide $\mathbf{C}(\mathbf{2 5})$ and fraction $\mathbf{K}$ contained oxeatamide A (21).

Fraction G (5.9 mg) was dissolved in $200 \mu \mathrm{L}$ of $\mathrm{MeOH}$. The sample was then injected onto a semi-preparative $(1 \mathrm{~cm} \times 25 \mathrm{~cm}) \mathrm{C}_{18}$ HPLC column pre-equilibrated with $60 \%$ $\mathrm{MeOH} / 0.1 \mathrm{M} \mathrm{HCOOH}_{(a q)}$, with a flow rate of $5 \mathrm{~mL} / \mathrm{min}$ and $\mathrm{UV}$ detection set to wavelengths $245 \mathrm{~nm}$ and $280 \mathrm{~nm}$. The column was then eluted with 60\% MeOH/0.1 $\mathrm{M} \mathrm{HCOOH}_{a q}$. The fraction eluted between 10.1-14.8 minutes (fraction L) was collected. Fraction $\mathbf{L}$ was back loaded onto a $2 \mathrm{~mL}$ HP20SS column. The column was eluted with $6 \mathrm{~mL}$ of $\mathrm{MeOH}$ and then concentrated to dryness. ${ }^{1} \mathrm{H} \mathrm{NMR}$ analysis showed that fraction L contained $3.1 \mathrm{mg}$ oxeatamide B (24).

Fraction I (5.1 mg) was dissolved in $240 \mu \mathrm{L}$ of $\mathrm{MeOH}$. Three $80 \mu \mathrm{L}$ samples were then injected onto an analytical $(0.46 \mathrm{~cm} \times 25 \mathrm{~cm})$ Phenomenex $\mathrm{C}_{18}$ HPLC column preequilibrated with $80 \% \mathrm{MeOH} / 0.1 \mathrm{M} \mathrm{HCOOH}_{(a q)}$, with a flow rate of $1 \mathrm{~mL} / \mathrm{min}$ and UV detection set to wavelengths $245 \mathrm{~nm}$ and $280 \mathrm{~nm}$. The column was then eluted isocratically with $80 \% \mathrm{MeOH} / 0.1 \mathrm{M} \mathrm{HCOOH}_{(a q)}$. The fraction eluted between 8.2-9.7 minutes (fraction M) was collected. This fraction was backloaded onto a $2 \mathrm{~mL}$ HP20SS column. The column was eluted with $6 \mathrm{~mL}$ of $\mathrm{MeOH}$ and then concentrated to dryness. ${ }^{1} \mathrm{H}$ NMR analysis showed fraction M contained $2.18 \mathrm{mg}$ of iso-oxeatamide A (23).

Fractions $\mathbf{F}, \mathbf{H}$ and $\mathbf{K}$ were combined to yield $34.2 \mathrm{mg}$ of oxeatamide A (21). 
Oxeatamide A (21)

Amphorphous white solid; all spectroscopic data as previously published. ${ }^{41}$

\section{Iso-oxeatamide A (23)}

Amphorphous white solid; all spectroscopic data as previously published. ${ }^{41}$

\section{Oxeatamide B (24)}

Amphorphous white solid; all spectroscopic data as previously published. ${ }^{41}$

\section{Oxeatamide C (25)}

Amphorphous white solid; $[\alpha]_{D}^{20}-60.3^{\circ} \mathrm{C}(c 0.15, \mathrm{MeOH})$; NMR data see Table 3.8; HRESIMS, observed $m / z$ z95.2318 $[\mathrm{M}+\mathrm{Na}]^{+}, \mathrm{C}_{22} \mathrm{H}_{32} \mathrm{~N}_{2} \mathrm{O}_{3} \mathrm{Na}$ requires 395.2316, $\Delta 0.5$ ppm.

\subsubsection{Isolation of oxeatamides $\mathrm{D}, \mathrm{E}, \mathrm{F}$ and $\mathrm{G}$}

Approximately one-third of fraction (iii) fraction, from the initial fractionation of Darwinella oxeata (as detailed in Section 5.2.1) ( $~ 80 \mathrm{mg}$ ), was dissolved in the minimum of $\mathrm{CH}_{2} \mathrm{Cl}_{2}$ and loaded onto a $22 \mathrm{~mL}$ DIOL column pre-equilibrated in $\mathrm{CH}_{2} \mathrm{Cl}_{2}$. The column was sequentially eluted with $70 \mathrm{~mL}$ fractions of i) $\mathrm{CH}_{2} \mathrm{Cl}_{2}$ (fraction $\mathbf{A}$ ), ii) $1 \%$ $\mathrm{MeOH} / \mathrm{CH}_{2} \mathrm{Cl}_{2}$ (fraction B), iii) $2 \% \mathrm{MeOH} / \mathrm{CH}_{2} \mathrm{Cl}_{2}$, iv) $5 \% \mathrm{MeOH} / \mathrm{CH}_{2} \mathrm{Cl}_{2}$, v) $10 \%$ $\mathrm{MeOH} / \mathrm{CH}_{2} \mathrm{Cl}_{2}$, vi) $20 \% \mathrm{MeOH} / \mathrm{CH}_{2} \mathrm{Cl}_{2}$ and vii) $50 \% \mathrm{MeOH} / \mathrm{CH}_{2} \mathrm{Cl}_{2}$. This protocol was repeated with the other two-thirds of fraction (iii).

Fraction $\mathrm{A}(\sim 40 \mathrm{mg})$ was dissolved in minimum of $\mathrm{CH}_{2} \mathrm{Cl}_{2}$ and loaded onto a $15 \mathrm{~mL}$ DIOL column pre-equilibrated in $\mathrm{CH}_{2} \mathrm{Cl}_{2}$. The column was sequentially eluted with 
$90 \mathrm{~mL}$ fractions of i) $\mathrm{CH}_{2} \mathrm{Cl}_{2}$ (fractions 1-30) and ii) $1 \% \mathrm{MeOH} / \mathrm{CH}_{2} \mathrm{Cl}_{2}$ (fractions 31 60 ), followed by a $45 \mathrm{~mL}$ fraction of iii) $50 \% \mathrm{MeOH} / \mathrm{CH}_{2} \mathrm{Cl}_{2}$. The fractions were analysed by TLC and fractions 13-39 were combined to give fraction $\mathbf{C}$ and fractions 40-42 were combined to give fraction $\mathbf{D}$.

Fraction $\mathbf{B}$ (14.1 mg) was dissolved in a minimum of $\mathrm{CH}_{2} \mathrm{Cl}_{2}$ and loaded onto a $10 \mathrm{~mL}$ DIOL column pre-equilibrated in $\mathrm{CH}_{2} \mathrm{Cl}_{2}$. The column was sequentially eluted with $60 \mathrm{~mL}$ fractions of i) $\mathrm{CH}_{2} \mathrm{Cl}_{2}$ (fractions 1-21) and ii) $1 \% \mathrm{MeOH} / \mathrm{CH}_{2} \mathrm{Cl}_{2}$ (fractions 2240 ), followed by a $30 \mathrm{~mL}$ fraction of iii) $50 \% \mathrm{MeOH} / \mathrm{CH}_{2} \mathrm{Cl}_{2}$. The fractions were analysed by TLC and fractions $25-29$ were combined to give fraction $\mathbf{E}$.

Fractions D (3.7 mg) and $\mathbf{E}$ were combined and dissolved in $650 \mu \mathrm{L}$ of $\mathrm{MeOH}$. Thirteen $50 \mu \mathrm{L}$ samples were then injected onto an analytical $(0.46 \mathrm{~cm} \times 25 \mathrm{~cm}) \mathrm{C}_{18}$ HPLC column pre-equilibrated with $80 \% \mathrm{MeOH} / 0.1 \mathrm{M} \mathrm{HCOOH}_{(a q)}$, with a flow rate of $1 \mathrm{~mL} / \mathrm{min}$ and UV detection set to wavelengths $245 \mathrm{~nm}$ and $280 \mathrm{~nm}$. The column was then eluted with $80 \% \mathrm{MeOH} / 0.1 \mathrm{M} \mathrm{HCOOH}_{(a q)}$. The fractions eluted between 17.2-19.1 minutes (fraction F), 20.0-22.4 minutes (fraction G), 22.5-24.3 minutes (fraction H) and 24.326.7 (fraction I) were collected. These fractions (F, G, H and I) were back loaded onto $2 \mathrm{~mL}$ HP20SS columns. The columns were each eluted with $6 \mathrm{~mL}$ of $\mathrm{MeOH}$ and then concentrated to dryness. ${ }^{1} \mathrm{H}$ NMR analysis showed that fraction $\mathbf{F}$ contained $0.5 \mathrm{mg}$ of oxeatamide D (26), fraction $\mathbf{G}$ contained $1 \mathrm{mg}$ of oxeatamide E (27), fraction $\mathbf{H}$ contained $0.8 \mathrm{mg}$ of oxeatamide $\mathrm{F}(\mathbf{2 8})$ and fraction I contained $0.6 \mathrm{mg}$ of oxeatamide $\mathrm{G}(\mathbf{2 9})$.

Fraction $\mathbf{C}(\sim 10 \mathrm{mg})$ was dissolved in $200 \mu \mathrm{L}$ of $\mathrm{MeOH}$. Four $50 \mu \mathrm{L}$ samples were then injected onto an analytical $(0.46 \mathrm{~cm} \times 25 \mathrm{~cm}) \mathrm{C}_{18}$ HPLC column pre-equilibrated with $\left.80 \% \mathrm{MeOH} / 0.1 \mathrm{M} \mathrm{HCOOH}_{(} a q\right)$, with a flow rate of $1 \mathrm{~mL} / \mathrm{min}$ and $\mathrm{UV}$ detection set to wavelengths $220 \mathrm{~nm}$ and $245 \mathrm{~nm}$. The column was then eluted isocratically with $80 \%$ $\mathrm{MeOH} / 0.1 \mathrm{M} \mathrm{HCOOH}_{(a q)}$. The fractions eluted between 16.8-18.9 minutes (fraction $\mathbf{J}$ ), 19.8-23.3 minutes (fraction $\mathbf{K}$ ), 23.3-25.5 minutes (fraction $\mathbf{L}$ ), 25.5-27.1 (fraction $\mathbf{M}$ ) and 27.1-28.5 (fraction $\mathbf{N}$ ) were collected. These fractions (J, K, L, M and $\mathbf{N}$ ) were each backloaded onto $2 \mathrm{~mL}$ HP20SS columns. The eluents were again diluted two-fold and passed back through their original columns. The columns were each eluted with $6 \mathrm{~mL}$ 
of $\mathrm{MeOH}$ and then concentrated to dryness. ${ }^{1} \mathrm{H}$ NMR analysis showed that fraction $\mathbf{J}$ contained membranolide C (30), fraction $\mathbf{K}$ contained membranolide D (31), fraction $\mathbf{L}$ oxeatamide $\mathrm{E}$ (27), fraction $\mathbf{M}$ contained oxeatamide $\mathrm{F}(\mathbf{2 8})$ and fraction $\mathbf{N}$ contained of oxeatamide $\mathrm{G}$ (29).

Oxeatamide D (26)

Amphorphous white solid; $[\alpha]_{D}^{20}-59.2^{\circ} \mathrm{C}(c$ 0.2, MeOH); NMR data see Table 3.3; HRESIMS, observed $\mathrm{m} / \mathrm{z} 408.2520[\mathrm{M}+\mathrm{Na}]^{+}, \mathrm{C}_{24} \mathrm{H}_{35} \mathrm{NO}_{3} \mathrm{Na}$ requires 408.2515, $\Delta 1.2 \mathrm{ppm}$.

\section{Oxeatamide E (27)}

Amphorphous white solid; $[\alpha]_{D}^{20}-60.1^{\circ} \mathrm{C}(c \quad 0.17, \mathrm{MeOH})$; NMR data see Table 3.5; HRESIMS, observed $\mathrm{m} / \mathrm{z} 456.2518[\mathrm{M}+\mathrm{Na}]^{+}, \mathrm{C}_{28} \mathrm{H}_{35} \mathrm{NO}_{3} \mathrm{Na}$ requires 456.2515, $\Delta 0.7 \mathrm{ppm}$.

\section{Oxeatamide F (28)}

Amphorphous white solid; $[\alpha]_{D}^{20}-59.9^{\circ} \mathrm{C}(c \quad 0.19, \mathrm{MeOH})$; NMR data see Table 3.6; HRESIMS, observed $\mathrm{m} / \mathrm{z} 422.2669[\mathrm{M}+\mathrm{Na}]^{+}, \mathrm{C}_{25} \mathrm{H}_{37} \mathrm{NO}_{3} \mathrm{Na}$ requires 422.2671, $\Delta 0.5 \mathrm{ppm}$.

\section{Oxeatamide G (29)}

Amphorphous white solid; $[\alpha]_{D}^{20}-60.1^{\circ} \mathrm{C}(c \quad 0.2, \mathrm{MeOH}) ; \mathrm{NMR}$ data see Table 3.7; HRESIMS, observed $\mathrm{m} / \mathrm{z} 422.2670[\mathrm{M}+\mathrm{Na}]^{+}, \mathrm{C}_{25} \mathrm{H}_{37} \mathrm{NO}_{3} \mathrm{Na}$ requires 422.2671, $\Delta 0.2 \mathrm{ppm}$. 
Membranolide C (30)

Amphorphous white solid; all spectroscopic data as previously published. ${ }^{52}$

Membranolide D (31)

Amphorphous white solid; all spectroscopic data as previously published. ${ }^{52}$

\subsubsection{Methylation of oxeatamide G}

To approximately $120 \mu \mathrm{g}$ of oxeatamide $\mathrm{G}$ (29) in $500 \mu \mathrm{L}$ of dry $\mathrm{MeOH}, 2.0 \mathrm{M}$ TMSCHN $_{2}$ in dry diethyl ether $(5 \mu \mathrm{L}, 10 \mu \mathrm{mol})$ was added. The reaction was left under nitrogen at room temperature for $1 \mathrm{~h}$ then quenched with $2 \%$ acetic acid and left for $1 \mathrm{~h}$. The resulting mixture was then back loaded onto a $2 \mathrm{~mL}$ HP20SS column. The column was then washed with $10 \mathrm{~mL}$ of $\mathrm{H}_{2} \mathrm{O}$ and eluted with $10 \mathrm{~mL} 80 \% \mathrm{Me}_{2} \mathrm{CO} / \mathrm{H}_{2} \mathrm{O}$ followed by $10 \mathrm{~mL}$ of $\mathrm{Me}_{2} \mathrm{CO}$. The $\mathrm{Me}_{2} \mathrm{CO}$ fraction contained $0.1 \mathrm{mg}$ the methyl ester oxeatamide G (33).

Methyl ester oxeatamide G (33)

Amphorphous white solid; HRESIMS, observed $\mathrm{m} / \mathrm{z} 414.3005[\mathrm{M}+\mathrm{H}]^{+}, \mathrm{C}_{26} \mathrm{H}_{40} \mathrm{NO}_{3}$ requires $414.3008, \Delta 0.3 \mathrm{ppm}$.

\subsection{Investigation of Dictyodendrilla dendyi}

Dictyodendrilla dendyi was collected on February 2005 from Piercy Island, Cape Brett, Northland, New Zealand. The frozen sponge (301 g) was cut into small segments and extracted with $\mathrm{MeOH}(2 \times 1.2 \mathrm{~L})$ for $24 \mathrm{~h}$. The second then first extracts were passed through $250 \mathrm{~mL}$ of HP20 resin pre-equilibrated in $\mathrm{MeOH}$. The combined eluents 
were cyclic loaded onto the column. The column was washed with $\mathrm{H}_{2} \mathrm{O}(750 \mathrm{~mL})$ and fractionated with $750 \mathrm{~mL}$ portions of i) $20 \% \mathrm{Me}_{2} \mathrm{CO} / \mathrm{H}_{2} \mathrm{O}$ (fraction A), ii) $40 \%$ $\mathrm{Me}_{2} \mathrm{CO} / \mathrm{H}_{2} \mathrm{O}$ (fraction B), iii) $60 \% \mathrm{Me}_{2} \mathrm{CO} / \mathrm{H}_{2} \mathrm{O}$ (fraction C), iv) $80 \% \mathrm{Me}_{2} \mathrm{CO} / \mathrm{H}_{2} \mathrm{O}$ (fraction D) and v) $100 \% \mathrm{Me}_{2} \mathrm{CO}$. The cyclic loading eluent was retained as fraction E. Fractions A to $\mathbf{D}$ were each back loaded onto columns packed with $80 \mathrm{~mL}$ HP20; preequilibrated in $\mathrm{H}_{2} \mathrm{O}$ for fractions $\mathbf{A}$ and $\mathbf{B}$ and pre-equilibrated in $\mathrm{MeOH}$ for fractions $\mathbf{C}$ and D. The columns were then washed with $\mathrm{H}_{2} \mathrm{O}(450 \mathrm{~mL})$ and eluted with $\mathrm{Me}_{2} \mathrm{CO}$ (450 $\mathrm{mL}$ ). The eluents were then concentrated to dryness to give $113.4 \mathrm{mg}$ of fraction $\mathbf{A}, 803.8$ $\mathrm{mg}$ of fraction $\mathbf{B}, 493.7 \mathrm{mg}$ of fraction $\mathbf{C}$ and $527.6 \mathrm{mg}$ of fraction $\mathbf{D}$.

The cyclic loading eluent, fraction $\mathbf{E}$, was saturated with $\mathrm{NaCl}$ and passed through a column packed with $80 \mathrm{~mL}$ HP20 pre-equilibrated in $\mathrm{H}_{2} \mathrm{O}$. The column was then washed with $\mathrm{H}_{2} \mathrm{O}(450 \mathrm{~mL})$ and eluted with $\mathrm{Me}_{2} \mathrm{CO}(450 \mathrm{~mL})$ and the eluent concentrated to dryness. This fraction was then loaded onto $100 \mathrm{~mL}$ column of Sephadex G10 and eluted with $\mathrm{H}_{2} \mathrm{O}$ into test tubes. All test tubes were concentrated to dryness and all that contained black residue were combined giving fraction $\mathbf{F}$. Approximately half of fraction $\mathbf{F}$, was dissolved in $2 \mathrm{~mL}$ of $50 \% \mathrm{MeOH} / \mathrm{CH}_{2} \mathrm{Cl}_{2}$ and loaded on to $4 \mathrm{~mL}$ of DIOL pre-equilibrated in $\mathrm{CH}_{2} \mathrm{Cl}_{2}$, the eluent was diluted with $2 \mathrm{~mL} \mathrm{CH}_{2} \mathrm{Cl}_{2}$ and passed back through the column, the eluent was diluted with $4 \mathrm{~mL} \mathrm{CH}_{2} \mathrm{Cl}_{2}$ and passed back through the column, the eluent was diluted with $8 \mathrm{~mL} \mathrm{CH}_{2} \mathrm{Cl}_{2}$ and passed back through the column finally the eluent was diluted with $16 \mathrm{~mL} \mathrm{CH}_{2} \mathrm{Cl}_{2}$ and passed back through the column. The loaded DIOL column was sequentially eluted with $12 \mathrm{~mL}$ fractions of i) $\left.\mathrm{CH}_{2} \mathrm{Cl}_{2}, \mathrm{ii}\right) 5 \% \mathrm{MeOH} / \mathrm{CH}_{2} \mathrm{Cl}_{2}$, iii) $10 \% \mathrm{MeOH} / \mathrm{CH}_{2} \mathrm{Cl}_{2}$, iv) $20 \% \mathrm{MeOH} / \mathrm{CH}_{2} \mathrm{Cl}_{2}$, v) $30 \% \mathrm{MeOH} / \mathrm{CH}_{2} \mathrm{Cl}_{2}$ (fraction G), vi) $40 \% \mathrm{MeOH} / \mathrm{CH}_{2} \mathrm{Cl}_{2}$ and vii) $50 \% \mathrm{MeOH} / \mathrm{CH}_{2} \mathrm{Cl}_{2}$. Fraction $\mathbf{G}$ was found to contain $5.3 \mathrm{mg}$ of lamellarin $\theta$ 4",4"' - disulfate (14).

\section{Lamellarin $\theta$ 4",4"'- disulfate (14)}

Yellow-brown oil; all spectroscopic data as previously published. ${ }^{40}$ 


\subsection{Investigation of Raspailia topsenti}

Raspailia topsenti was collected in January 2002 from Great Barrier Island, North Island, New Zealand. The frozen sponge (210 g) was cut into small segments and extracted with $\mathrm{MeOH}(2 \times 800 \mathrm{~mL})$ for $24 \mathrm{~h}$. The second then first extracts were passed through $150 \mathrm{~mL}$ of HP20 resin pre-equilibrated in MeOH. The combined eluents were cyclic loaded onto the column. The column was washed with $\mathrm{H}_{2} \mathrm{O}(450 \mathrm{~mL})$ and fractionated with $450 \mathrm{~mL}$ portions of i) $40 \% \mathrm{Me}_{2} \mathrm{CO} / \mathrm{H}_{2} \mathrm{O}$ (fractionA), ii) $60 \% \mathrm{Me}_{2} \mathrm{CO} / \mathrm{H}_{2} \mathrm{O}$ (fraction B), iii) $80 \%$ $\mathrm{Me}_{2} \mathrm{CO} / \mathrm{H}_{2} \mathrm{O}$ (fraction $\mathbf{C}$ ) and iv) $100 \% \mathrm{Me}_{2} \mathrm{CO}$. Fractions $\mathbf{A}$ to $\mathbf{C}$ were each back loaded onto columns packed with $80 \mathrm{~mL}$ HP20 resin; pre-equilibrated in $\mathrm{H}_{2} \mathrm{O}$ for fraction $\mathbf{A}$ and pre-equilibrated in $\mathrm{MeOH}$ for fractions $\mathbf{B}$ and $\mathbf{C}$. The columns were then washed with $\mathrm{H}_{2} \mathrm{O}(250 \mathrm{~mL})$ and eluted with $\mathrm{Me}_{2} \mathrm{CO}(250 \mathrm{~mL})$. The eluents were then concentrated to dryness to give $135.4 \mathrm{mg}$ of fraction A, $292.2 \mathrm{mg}$ of fraction $\mathbf{B}$ and $430.3 \mathrm{mg}$ of fraction C.

\subsection{Investigation of MNP1003}

Unidentified sponge, MNP1003, was collected by NIWA in April 2000 from D’Urville Island, Marlborough Sounds, New Zealand. The frozen sponge (203 g) was cut into small segments and extracted with $\mathrm{MeOH}(2 \times 1 \mathrm{~L})$ for $24 \mathrm{~h}$. The second then first extracts were passed through $80 \mathrm{~mL}$ of $\mathrm{HP} 20$ resin pre-equilibrated in $\mathrm{MeOH}$. The combined eluents were cyclic loaded onto the column. The column was washed with $\mathrm{H}_{2} \mathrm{O}(250$ $\mathrm{mL}$ ) and fractionated with $250 \mathrm{~mL}$ portions of i) $20 \% \mathrm{Me}_{2} \mathrm{CO} / \mathrm{H}_{2} \mathrm{O}$ (fraction A), ii) $40 \% \mathrm{Me}_{2} \mathrm{CO} / \mathrm{H}_{2} \mathrm{O}$ (fraction B), iii) $60 \% \mathrm{Me}_{2} \mathrm{CO} / \mathrm{H}_{2} \mathrm{O}$ (fraction C), iv) $80 \% \mathrm{Me}_{2} \mathrm{CO} / \mathrm{H}_{2} \mathrm{O}$ (fraction D) and v) $100 \% \mathrm{Me}_{2} \mathrm{CO}$. Fractions $\mathbf{A}$ to $\mathbf{D}$ were each back loaded onto columns packed with $40 \mathrm{~mL}$ HP20 pre-equilibrated in $\mathrm{H}_{2} \mathrm{O}$ for fractions $\mathbf{A}$ and $\mathbf{B}$ and pre-equilibrated in $\mathrm{MeOH}$ for fractions $\mathbf{C}$ and $\mathrm{D}$. The columns were then washed with $\mathrm{H}_{2} \mathrm{O}(120 \mathrm{~mL})$ and eluted with $\mathrm{Me}_{2} \mathrm{CO}(120 \mathrm{~mL})$. The eluents were then concentrated to dryness to give $92.3 \mathrm{mg}$ of fraction $\mathbf{A}, 14.8 \mathrm{mg}$ of fraction $\mathbf{B}, 36.6 \mathrm{mg}$ of fraction $\mathbf{C}$ and $220 \mathrm{mg}$ of fraction $\mathbf{D}$. 


\subsection{Investigation of MNP0996}

Unidentified sponge, MNP0996, was collected by NIWA in April 2000 from D’Urville Island, Marlborough Sounds, New Zealand. The frozen sponge (403 g) was cut into small segments and extracted with $\mathrm{MeOH}(2 \times 2 \mathrm{~L})$ for $24 \mathrm{~h}$. The second then first extracts were passed through $150 \mathrm{~mL}$ of $\mathrm{HP} 20$ resin pre-equilibrated in $\mathrm{MeOH}$. The combined eluents were cyclic loaded onto the column. The column was washed with $\mathrm{H}_{2} \mathrm{O}(450$ $\mathrm{mL}$ ) and fractionated with $450 \mathrm{~mL}$ portions of i) $20 \% \mathrm{Me}_{2} \mathrm{CO} / \mathrm{H}_{2} \mathrm{O}$ (fraction A), ii) $40 \% \mathrm{Me}_{2} \mathrm{CO} / \mathrm{H}_{2} \mathrm{O}$ (fraction B), iii) $60 \% \mathrm{Me}_{2} \mathrm{CO} / \mathrm{H}_{2} \mathrm{O}$ (fraction C), iv) $80 \% \mathrm{Me}_{2} \mathrm{CO} / \mathrm{H}_{2} \mathrm{O}$ (fraction D) and v) $100 \% \mathrm{Me}_{2} \mathrm{CO}$ (fraction $\mathbf{E}$ ). Fractions $\mathbf{A}$ to $\mathbf{D}$ were each back loaded onto columns packed with $80 \mathrm{~mL}$ HP20 pre-equilibrated in $\mathrm{H}_{2} \mathrm{O}$ for fractions $\mathbf{A}$ and $\mathbf{B}$ and pre-equilibrated in $\mathrm{MeOH}$ for fractions $\mathbf{C}$ and $\mathbf{D}$. The columns were then washed with $\mathrm{H}_{2} \mathrm{O}(250 \mathrm{~mL})$ and eluted with $\mathrm{Me}_{2} \mathrm{CO}(250 \mathrm{~mL})$. The eluents were then concentrated to dryness to give $13.4 \mathrm{mg}$ of fraction $\mathbf{A}, 22.8 \mathrm{mg}$ of fraction $\mathbf{B}, 94.5 \mathrm{mg}$ of fraction $\mathbf{C}$ and $597.7 \mathrm{mg}$ of fraction D. Fraction $\mathbf{E}$ was also concentrated to dryness yielding $998 \mathrm{mg}$. 


\section{Appendix A}

\section{Existing Sponge Screening Protocol ${ }^{*}$}

\section{Preparation}

\section{Equipment Needed (per Screen)}

- 1 x Screen column loaded with $80 \mathrm{~mL}$ of HP20 equilibrated in distilled $\mathrm{MeOH}$

- 1 x Backloading column loaded with $40 \mathrm{~mL}$ of $\mathrm{HP} 20$ equilibrated in distilled $\mathrm{MeOH}$

\section{NMR Standard}

Prepare a standard of 1,3,5-tribromobenzene in $\mathrm{CDCl}_{3}$ by dissolving $78.9 \mathrm{mg}$ of 1,3,5tribromobenzene in $5 \mathrm{~mL}$ of $\mathrm{CDCl}_{3}$.

\section{Procedure}

1. Voucher Sample Preparation

- Take a voucher specimen of ca. $10 \mathrm{~g}$ of sponge material ensuring that both the ectoderm and the endoderm are represented.

- Label and store the voucher sample in 75\% IPA in $\mathrm{H}_{2} \mathrm{O}$.

2. Extraction

- Extract ca. $100 \mathrm{~g}$ of sponge material in $400 \mathrm{~mL}$ of distilled $\mathrm{MeOH}$ overnight.

- Filter the first extract and set aside. Re-extract the sponge material (and any filter paper/celite as necessary) in $400 \mathrm{~mL}$ of distilled $\mathrm{MeOH}$ overnight.

*Last updated: $13 / 11 / 06$ 
- Filter the second extract.

- Keep all sponge material (and any filter paper/celite as necessary) until the screen is complete at which time it may be discarded.

3. Cyclic Loading

- Pass the second extract through the screen column with a flow rate of ca. $10 \mathrm{~mL} / \mathrm{min}$.

- Pass the first extract through the screen column with a flow rate of ca. $10 \mathrm{~mL} / \mathrm{min}$. Combine the eluent with that of the second extract.

- Dilute the combined eluents with $800 \mathrm{~mL}$ of distilled $\mathrm{H}_{2} \mathrm{O}$. Pass the diluted eluents back through the screen column at a flow rate of ca. $10 \mathrm{~mL} / \mathrm{min}$.

- Dilute the eluent with $1.6 \mathrm{~L}$ of distilled $\mathrm{H}_{2} \mathrm{O}$. Pass the diluted eluent back through the screen column at a flow rate of ca. $10 \mathrm{~mL} / \mathrm{min}$.

- The eluent should be kept until the screen is complete at which time it may be discarded.

4. Elution

- Elute the screen column with $250 \mathrm{~mL}$ of distilled $\mathrm{H}_{2} \mathrm{O}$ at a flow rate of ca. $10 \mathrm{~mL} / \mathrm{min}$. The $\mathrm{H}_{2} \mathrm{O}$ eluent can be discarded immediately.

- Elute the screen column with $250 \mathrm{~mL}$ of $30 \%$ distilled $\mathrm{Me}_{2} \mathrm{CO}$ in distilled $\mathrm{H}_{2} \mathrm{O}\left(75 \mathrm{~mL} \mathrm{Me}_{2} \mathrm{CO}\right.$ to $\left.175 \mathrm{~mL} \mathrm{H}_{2} \mathrm{O}\right)$ at a flow rate of ca. $10 \mathrm{~mL} / \mathrm{min}$.

- Elute the screen column with $250 \mathrm{~mL}$ of $75 \%$ distilled $\mathrm{Me}_{2} \mathrm{CO}$ in distilled $\mathrm{H}_{2} \mathrm{O}\left(187.5 \mathrm{~mL} \mathrm{Me} \mathrm{CO}_{2}\right.$ to $\left.62.5 \mathrm{~mL} \mathrm{H}_{2} \mathrm{O}\right)$ at a flow rate of ca. $10 \mathrm{~mL} / \mathrm{min}$.

- Elute the screen column with $250 \mathrm{~mL}$ of distilled $\mathrm{Me}_{2} \mathrm{CO}$ at a flow rate of ca. $10 \mathrm{~mL} / \mathrm{min}$.

5. Backloading the $75 \%$ Acetone Fraction

- Dilute the $75 \% \mathrm{Me}_{2} \mathrm{CO}$ fraction with $250 \mathrm{~mL}$ of distilled $\mathrm{H}_{2} \mathrm{O}$. Pass the diluted eluent through the backloading column at a flow rate of ca. $8 \mathrm{~mL} / \mathrm{min}$.

- Dilute the eluent with $500 \mathrm{~mL}$ of distilled $\mathrm{H}_{2} \mathrm{O}$. Pass the diluted eluent back through the backloading column at a flow rate of ca. $8 \mathrm{~mL} / \mathrm{min}$. 
- The eluent should be kept until the screen is complete at which time it may be discarded.

- Elute the backloading column with $150 \mathrm{~mL}$ of distilled $\mathrm{Me}_{2} \mathrm{CO}$.

6. Processing the $75 \%$ Acetone Fraction

- Evaporate the $\mathrm{Me}_{2} \mathrm{CO}$ eluent of the backloading column to dryness and transfer to a pre-weighed sample vial. Evaporate to dryness and record the mass.

- Sub-sample approximately $30 \mathrm{mg}$ of material for NMR analysis if necessary.

- Prepare an NMR sample in ca. $700 \mu \mathrm{L}$ of $\mathrm{CD}_{3} \mathrm{OD}$ in a $5 \mathrm{~mm}$ NMR tube.

- Add $10 \mu \mathrm{L}$ of the 1,3,5-tribromobenzene standard (representing $507 \mathrm{nmol}$ of 1,3,5-tribromobenzene) to the NMR tube.

7. NMR Analysis of the $75 \%$ Acetone Fraction

- Run a ${ }^{1} \mathrm{H}$ spectrum of the sample on the $600 \mathrm{MHz}$ instrument using the standard Screen $1 \mathrm{H}$ parameter set. (Experiment time: ca. 4 min)

- Make a note "Standard Added" in the sample text.

- Run a COSY spectrum of the sample using the standard ScreenCOSY parameter set. (Experiment time: ca. $20 \mathrm{~min}$ )

- Run an HSQC spectrum of the sample using the standard ScreenHSQC parameter set. (Experiment time: ca. $4 \mathrm{~h}$ )

- Process appropriately and export HSQC phasefile.

- Add HSQC phasefile to HSQC mask.

- Apply HSQC mask to HSQC phasefile.

8. Assigning Hit Values to the Screen

- Threshold set at 3\%.

- Signal strength

- An arbitrary value indicating how the strength of the interesting peaks. 
- Weak - 1. Medium - 2. Strong - 3 (remember to consider the subsampling factor if necessary).

- Number of interesting peaks

- Indicates how many red peaks in the HSQC. Something exhibiting more than 20 non-masked peaks will score a 10.

- Uniqueness of interesting peaks

- An arbitrary value indicating whether non-masked peaks represent something interesting (1-10).

- Available mass

- The total mass of the available sponge material (including that used for the screen) in $\mathrm{kg}$ is multiplied by 10 and rounded to the nearest integer. If more than $1 \mathrm{~kg}$ of sponge material is available the score is 10 .

- Recollectability

- Collected locally -3 . Collected from Northland -2 . Other -1 .

- Sum all 5 hit values. A score of 20 would be considered average.

9. Backloading the $30 \%$ Acetone Fraction

- Dilute the $30 \% \mathrm{Me}_{2} \mathrm{CO}$ fraction with $250 \mathrm{~mL}$ of distilled $\mathrm{H}_{2} \mathrm{O}$. Pass the diluted eluent through the backloading column at a flow rate of ca. $8 \mathrm{~mL} / \mathrm{min}$.

- Dilute the eluent with $500 \mathrm{~mL}$ of distilled $\mathrm{H}_{2} \mathrm{O}$. Pass the diluted eluent back through the backloading column at a flow rate of ca. $8 \mathrm{~mL} / \mathrm{min}$.

- The eluent should be kept until the screen is complete at which time it may be discarded.

- Elute the backloading column with $150 \mathrm{~mL}$ of distilled $\mathrm{MeOH}$.

10. Processing the $30 \%$ Acetone Fraction

- Evaporate the $\mathrm{MeOH}$ eluent of the backloading column to dryness and transfer to a pre-weighed sample vial. Evaporate to dryness and record the mass.

- Sub-sample approximately $30 \mathrm{mg}$ of material for NMR analysis if necessary. 
- Prepare an NMR sample in ca. $700 \mu \mathrm{L}$ of $\mathrm{CD}_{3} \mathrm{OD}$ in a $5 \mathrm{~mm}$ NMR tube.

11. NMR Analysis of the $30 \%$ Acetone Fraction

- Run a ${ }^{1} \mathrm{H}$ spectrum of the sample on the $600 \mathrm{MHz}$ instrument using the standard Screen1H parameter set. (Experiment time: ca. 4 min)

12. Processing the $100 \%$ Acetone Fraction

- Evaporate the $\mathrm{Me}_{2} \mathrm{CO}$ eluent of the screen column to dryness and transfer to a pre-weighed sample vial. Evaporate to dryness and the record mass.

- Sub-sample approximately $30 \mathrm{mg}$ of material for NMR analysis if necessary.

- Prepare an NMR sample in ca. $700 \mu \mathrm{L}$ of $\mathrm{CDCl}_{3}$ in a $5 \mathrm{~mm}$ NMR tube.

13. NMR Analysis of the $100 \%$ Acetone Fraction

- Run a ${ }^{1} \mathrm{H}$ spectrum of the sample on the $600 \mathrm{MHz}$ instrument using the standard Screen1H parameter set. (Experiment time: ca. 4 min) 


\section{Standard NMR Parameter Sets for Screening}

\section{Screen1H (Standard Pulse-acquire)}

$\begin{array}{lll}\text { Acquisition: } & \text { acquisition delay } & 10 \mathrm{~ms} \\ \text { nutation angle } & 60^{\circ} \\ \text { acquisition time } & 4 \mathrm{~s}(38462 \text { complex points }) \\ \text { steady-state scans } & \text { none } \\ \text { number of transients } & 64 \\ \text { temperature } & 20{ }^{\circ} \mathrm{C} \\ \text { spectral width } & 14 \mathrm{ppm} \text { to }-2 \mathrm{ppm} \\ \text { total time } & \text { ca. } 4 \text { min } \\ \text { fourier number } & 65536 \text { complex points } \\ \text { Processing: } & \text { neighting } & \text { none }\end{array}$

\section{ScreenCOSY (Absolute Value Gradient COSY)}

$\begin{array}{lll}\text { Acquisition: } & \text { acquisition delay } & 2 \mathrm{~s} \\ & \text { gradient strength } & 10 \mathrm{G} \mathrm{cm}^{-1} \\ & \text { gradient duration } & 1 \mathrm{~ms} \\ & \text { gradient stabilisation delay } & 500 \mu \mathrm{s} \\ & \text { number of increments } & 512 \\ & \text { acquisition time } & 213 \mathrm{~ms}(1153 \text { complex points }) \\ & \text { steady state scans } & 16 \\ & \text { number of transients } & 1 \\ & \text { temperature } & 20{ }^{\circ} \mathrm{C} \\ & \text { spectral width }\left(\mathrm{F}_{2} \& \mathrm{~F}_{1}\right) & 9 \mathrm{ppm} \text { to } 0 \text { ppm } \\ & \text { total time } & \text { ca. } 20 \text { min } \\ \text { fourier number }\left(\mathrm{F}_{2} \& \mathrm{~F}_{1}\right) & 2048 \text { complex points } \\ \text { Processing: } & \text { sinebell }\end{array}$




\section{ScreenHSQC (Adiabatic Gradient-enhanced HSQC)}

\begin{tabular}{|c|c|c|}
\hline \multirow[t]{21}{*}{ Acquisition: } & steady-state gradient strength & $13 \mathrm{G} \mathrm{cm}^{-1}$ \\
\hline & steady-state gradient duration & $2 \mathrm{~ms}$ \\
\hline & acquisition delay & $1.5 \mathrm{~s}$ \\
\hline & TANGO gradient strength & $10 \mathrm{Gcm}^{-1}$ \\
\hline & TANGO gradient duration & $2 \mathrm{~ms}$ \\
\hline & adiabatic sweep pulse bandwidth & $300 \mathrm{ppm}$ \\
\hline & encoding gradient strength & $10 \mathrm{Gcm}^{-1}$ \\
\hline & encoding gradient time & $4 \mathrm{~ms}$ \\
\hline & decoding gradient strength & $-6 \mathrm{Gcm}^{-1}$ \\
\hline & decoding gradient time & $2.4 \mathrm{~ms}$ \\
\hline & number of increments & 512 \\
\hline & acquisition time & $213 \mathrm{~ms}$ (1153 complex points) \\
\hline & broadband ${ }^{13} \mathrm{C}$ decoupling shape & WURST40 \\
\hline & broadband ${ }^{13} \mathrm{C}$ decoupling bandwidth & $200 \mathrm{ppm}$ \\
\hline & steady state scans & 64 \\
\hline & number of transients & 8 \\
\hline & temperature & $20^{\circ} \mathrm{C}$ \\
\hline & spectral width in $\mathrm{F}_{2}$ & $9 \mathrm{ppm}$ to $0 \mathrm{ppm}$ \\
\hline & spectral width in $\mathrm{F}_{1}$ & $160 \mathrm{ppm}$ to $0 \mathrm{ppm}$ \\
\hline & ${ }^{1} J_{\mathrm{CH}}$ selection & $140 \mathrm{~Hz}$ \\
\hline & total time & ca. $4 \mathrm{~h}$ \\
\hline \multirow[t]{3}{*}{ Processing: } & fourier number in $\mathrm{F}_{2}$ & 2048 complex points \\
\hline & fourier number in $F_{1}$ & 1024 complex points \\
\hline & weighting $\left(\mathrm{F}_{2} \& \mathrm{~F}_{1}\right)$ & gaussian \\
\hline
\end{tabular}


Appendix B

\section{Oxeatamide D}

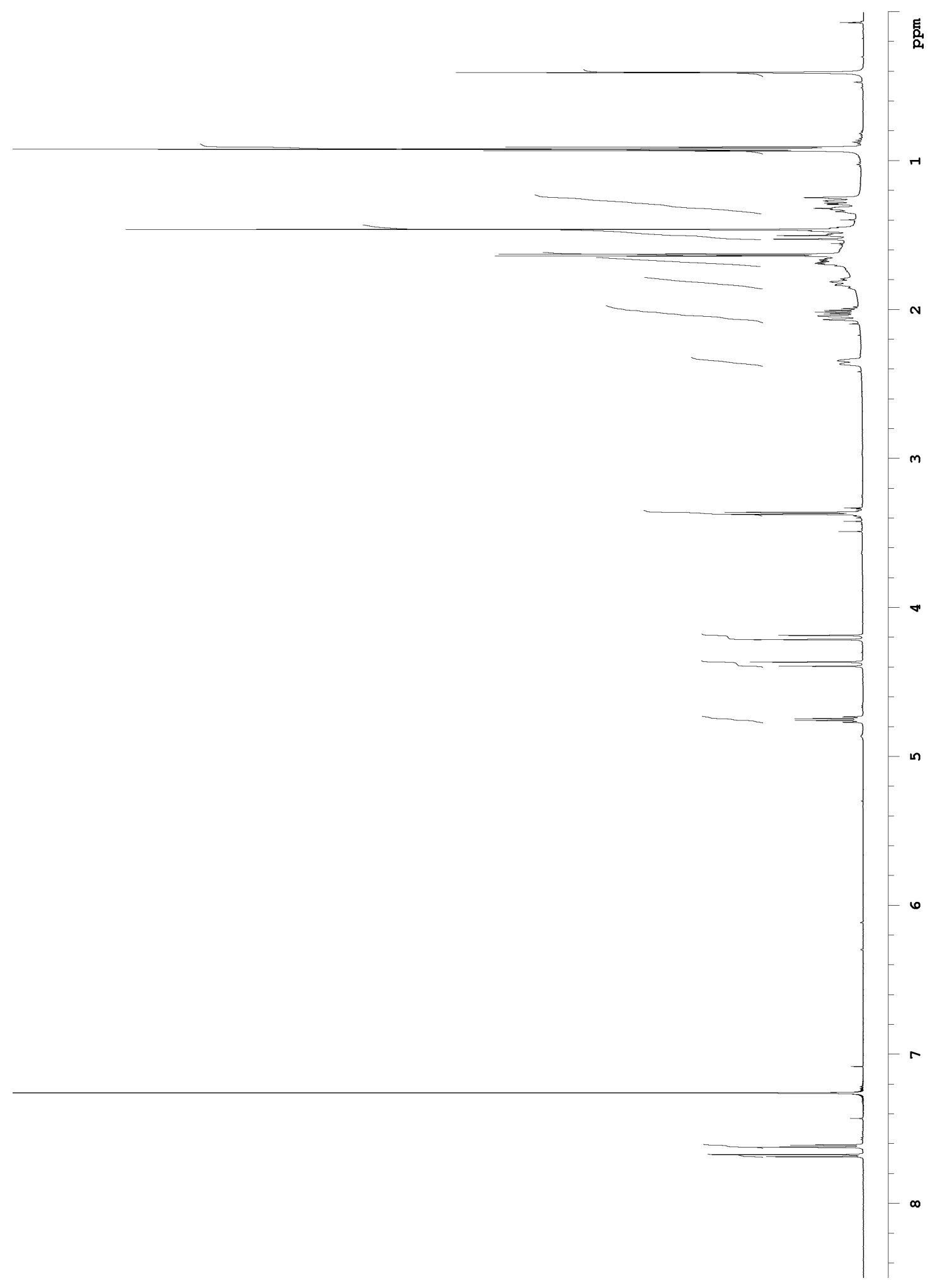

${ }^{1} \mathrm{H}$ NMR spectrum of oxeatamide $\mathrm{D}(\mathbf{2 6})\left(600 \mathrm{MHz}, \mathrm{CDCl}_{3}\right)$ 


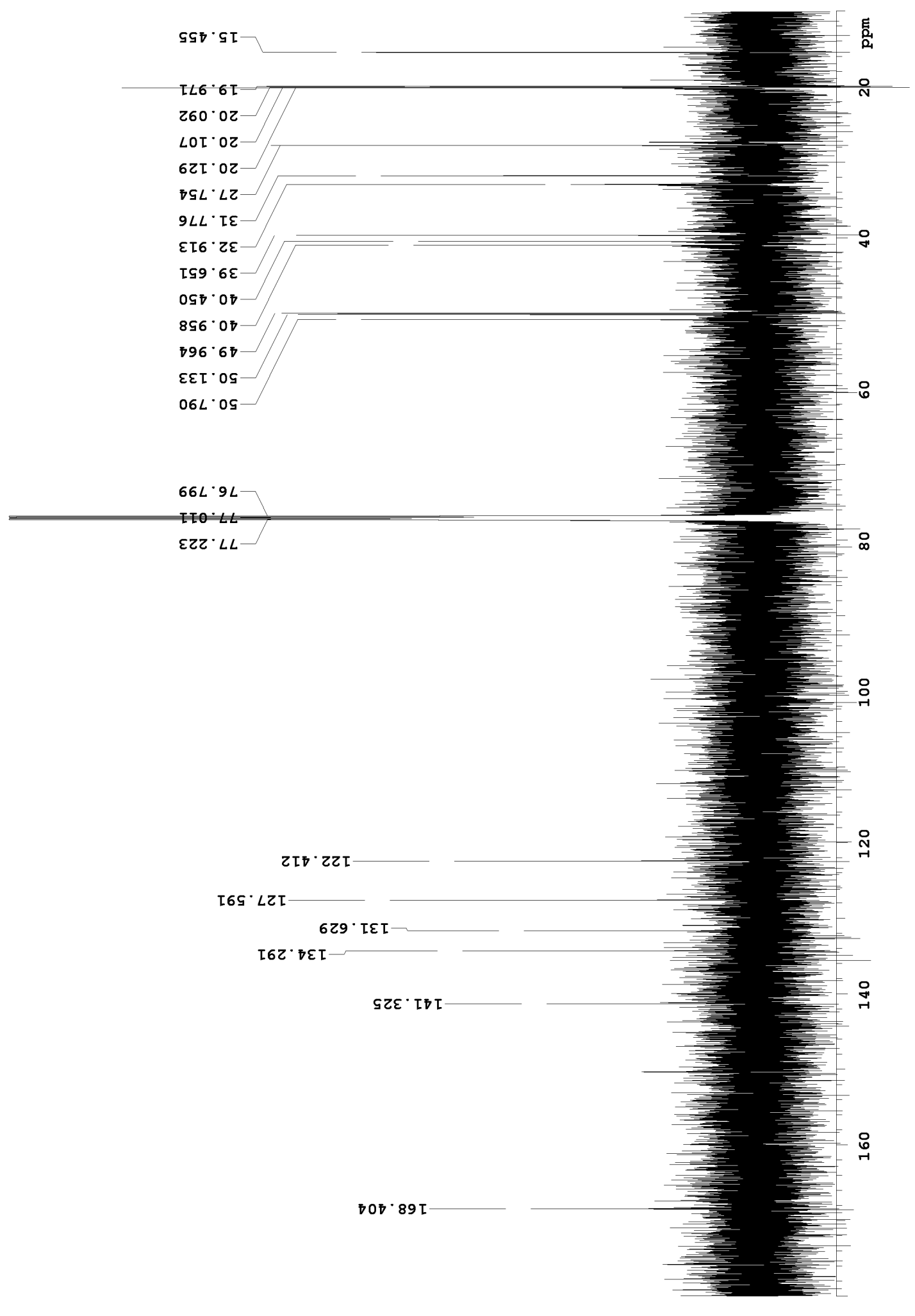

${ }^{13} \mathrm{C}$ NMR spectrum of oxeatamide D (26) $\left(150 \mathrm{MHz}, \mathrm{CDCl}_{3}\right)$ 


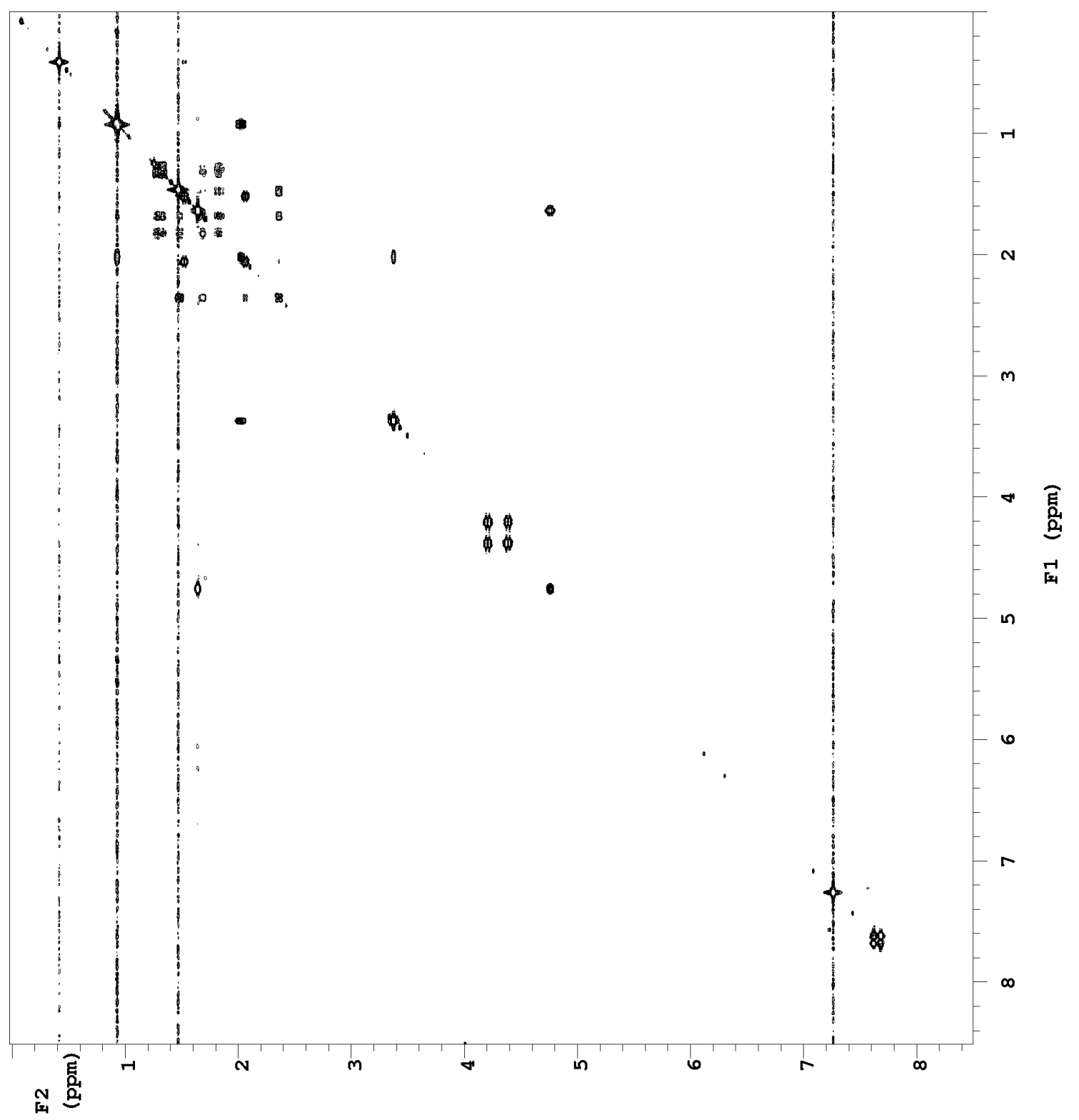

COSY NMR spectrum of oxeatamide D (26) $\left(600 \mathrm{MHz}, \mathrm{CDCl}_{3}\right)$ 


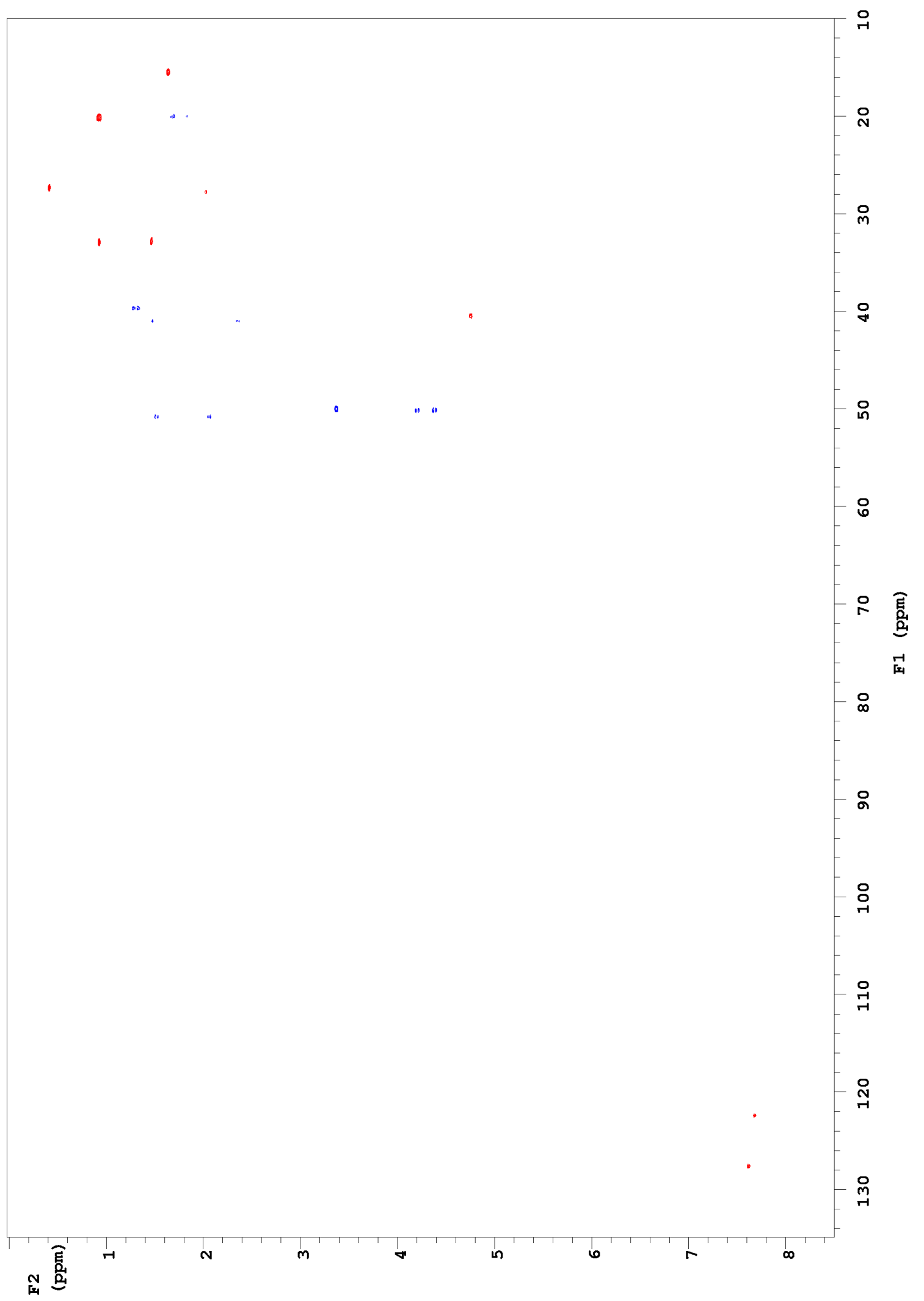

HSQC NMR spectrum of oxeatamide D (26) $\left(600 \mathrm{MHz}, \mathrm{CDCl}_{3}\right)$ 


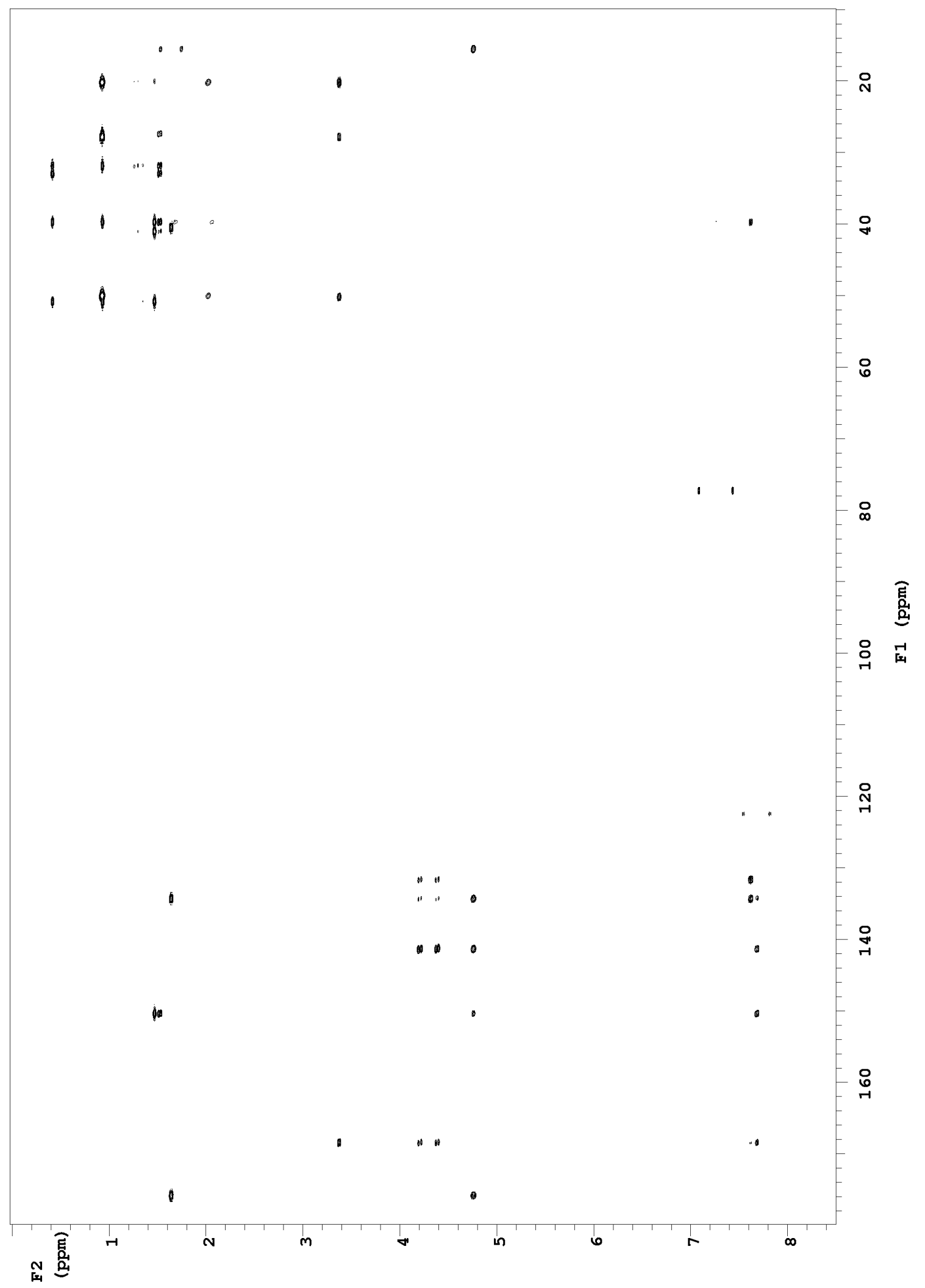

HMBC NMR spectrum of oxeatamide D (26) $\left(600 \mathrm{MHz}, \mathrm{CDCl}_{3}\right)$ 
Appendix C

Oxeatamide E

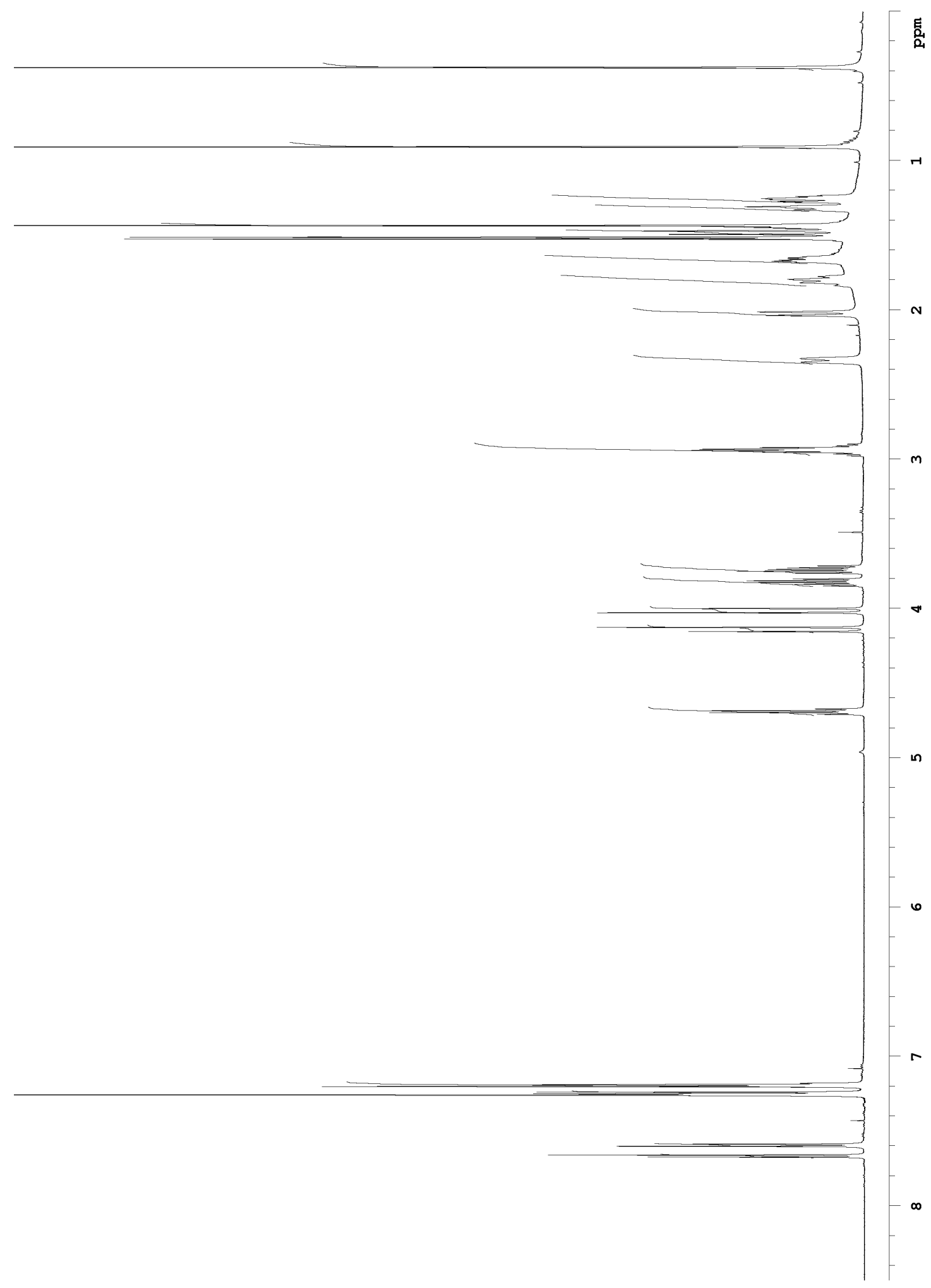

${ }^{1} \mathrm{H}$ NMR spectrum of oxeatamide E (27) $\left(600 \mathrm{MHz}, \mathrm{CDCl}_{3}\right)$ 


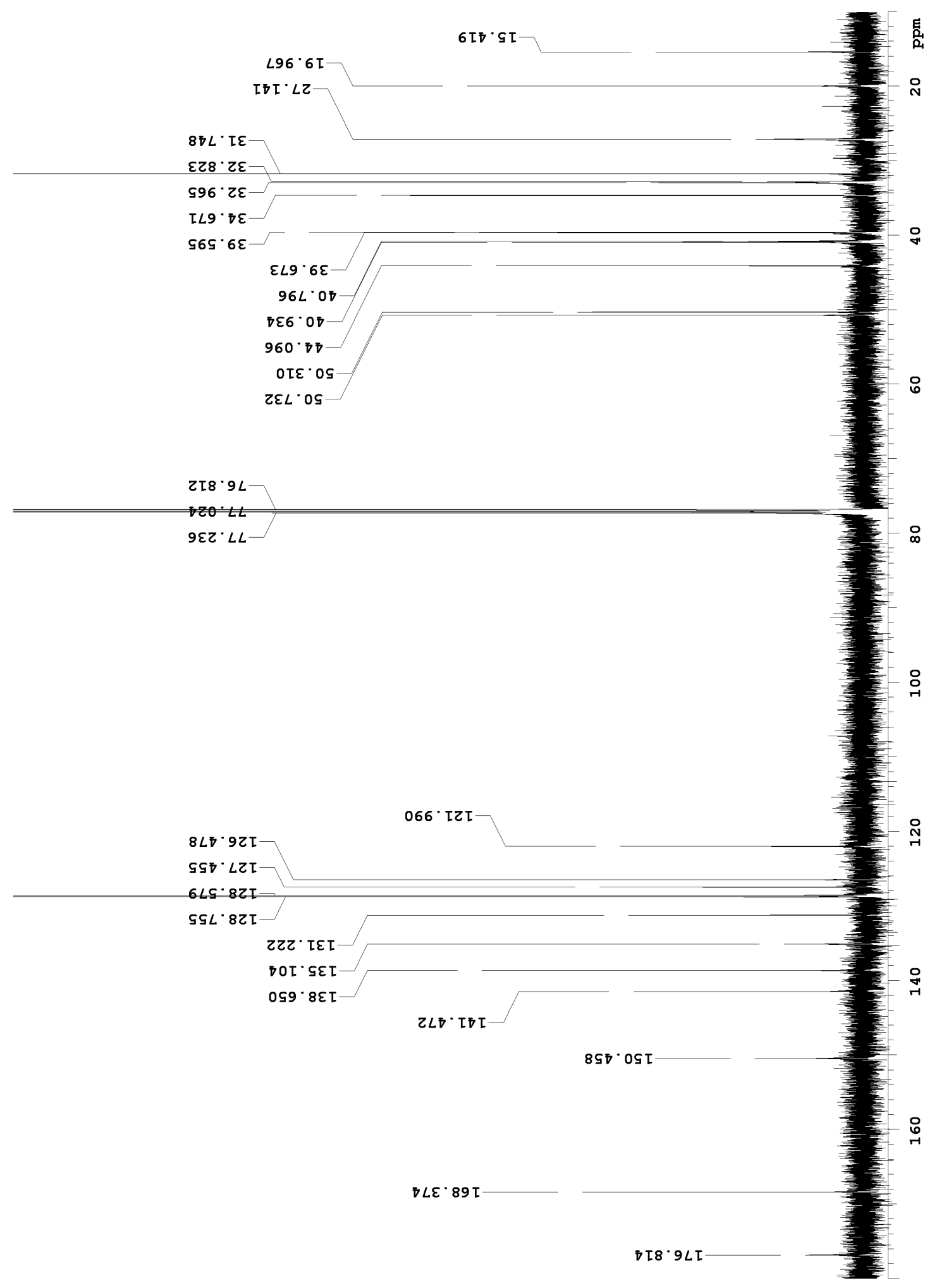

${ }^{13} \mathrm{C}$ NMR spectrum of oxeatamide $\mathrm{E}(\mathbf{2 7})\left(150 \mathrm{MHz}, \mathrm{CDCl}_{3}\right)$ 


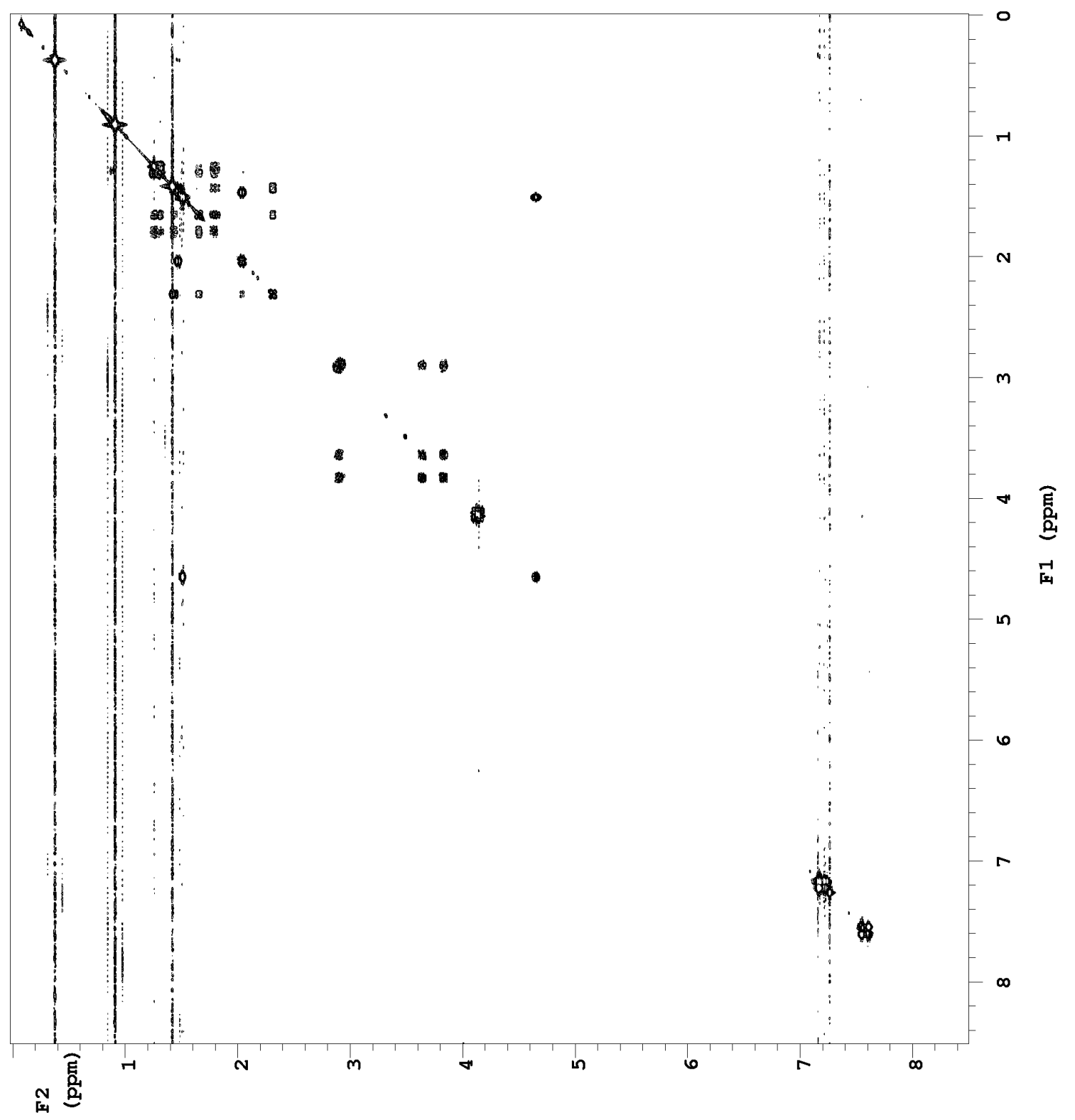

COSY NMR spectrum of oxeatamide E (27) $\left(600 \mathrm{MHz}, \mathrm{CDCl}_{3}\right)$ 


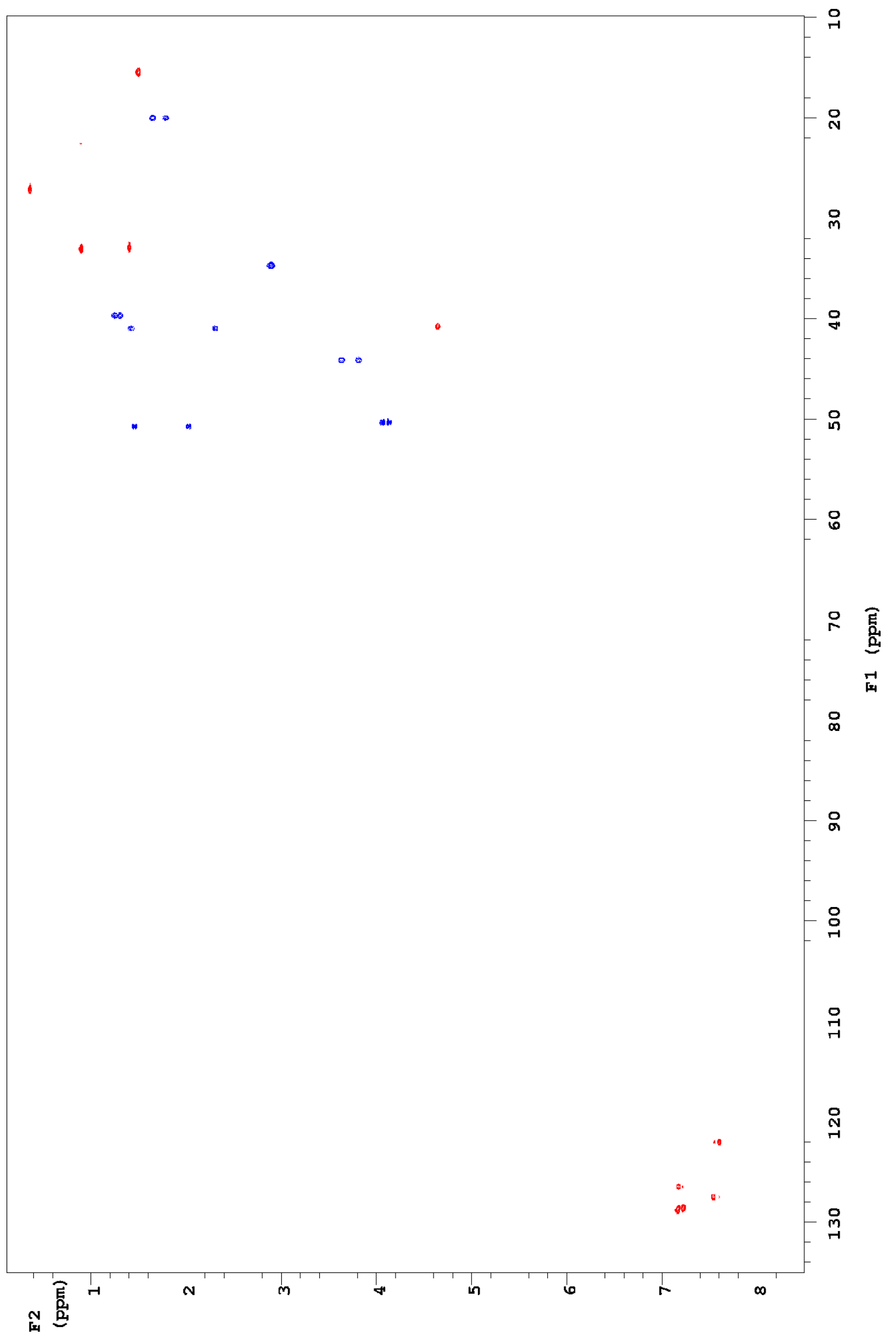

HSQC NMR spectrum of oxeatamide E (27) $\left(600 \mathrm{MHz}, \mathrm{CDCl}_{3}\right)$ 


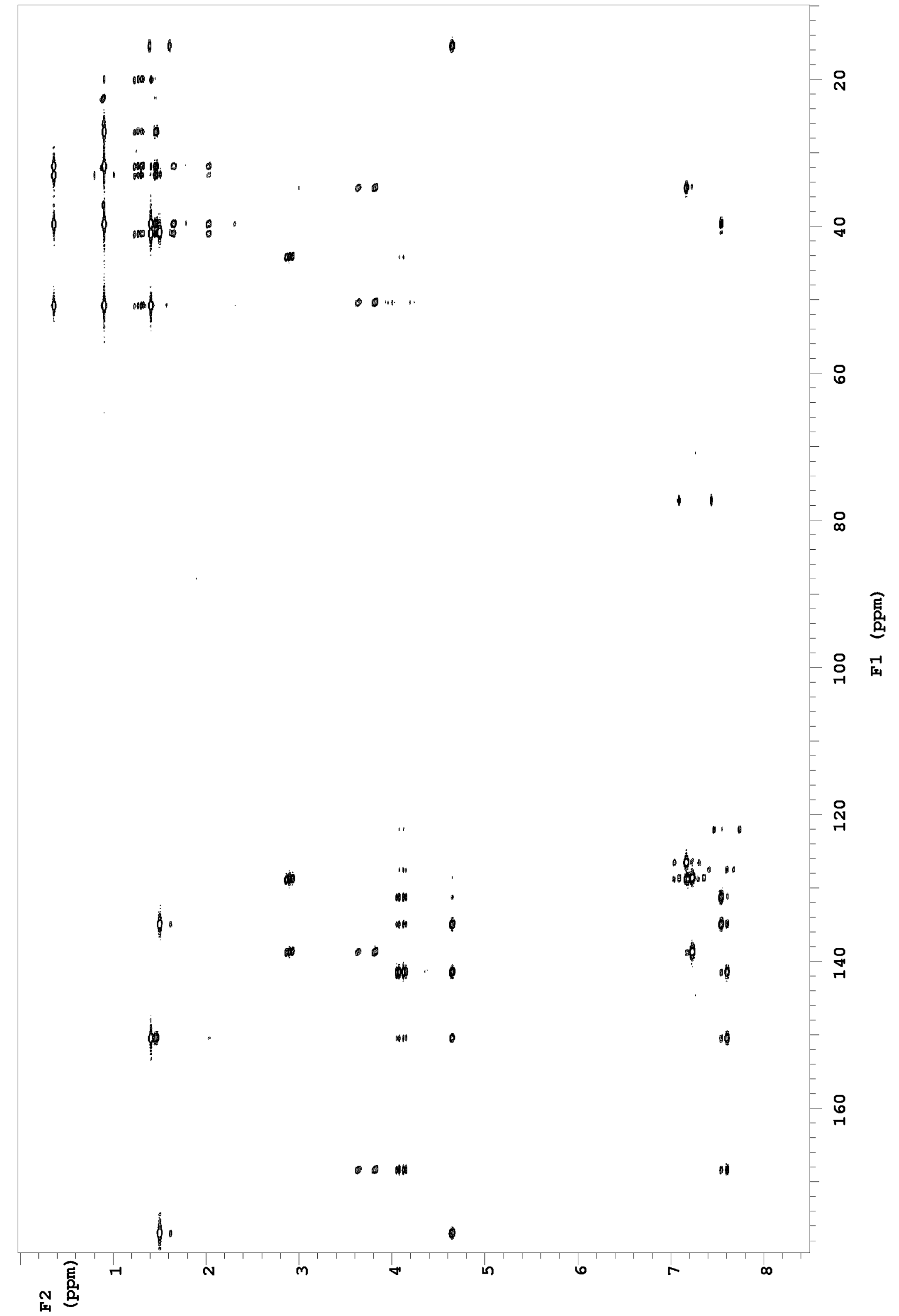

HMBC NMR spectrum of oxeatamide E (27) $\left(600 \mathrm{MHz}, \mathrm{CDCl}_{3}\right)$ 
Appendix D

Oxeatamide F

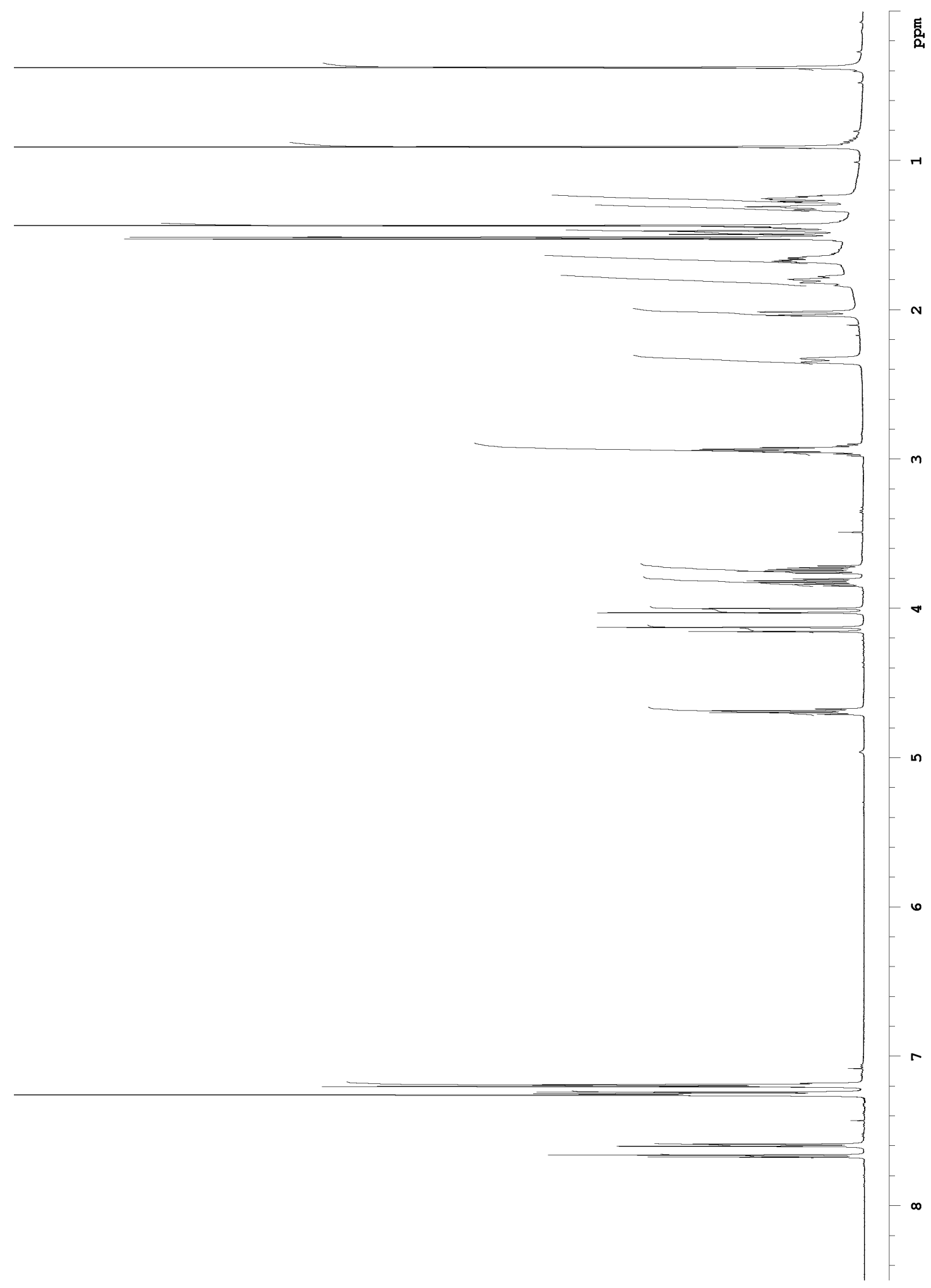

${ }^{1} \mathrm{H}$ NMR spectrum of oxeatamide F $(\mathbf{2 8})\left(600 \mathrm{MHz}, \mathrm{CDCl}_{3}\right)$ 


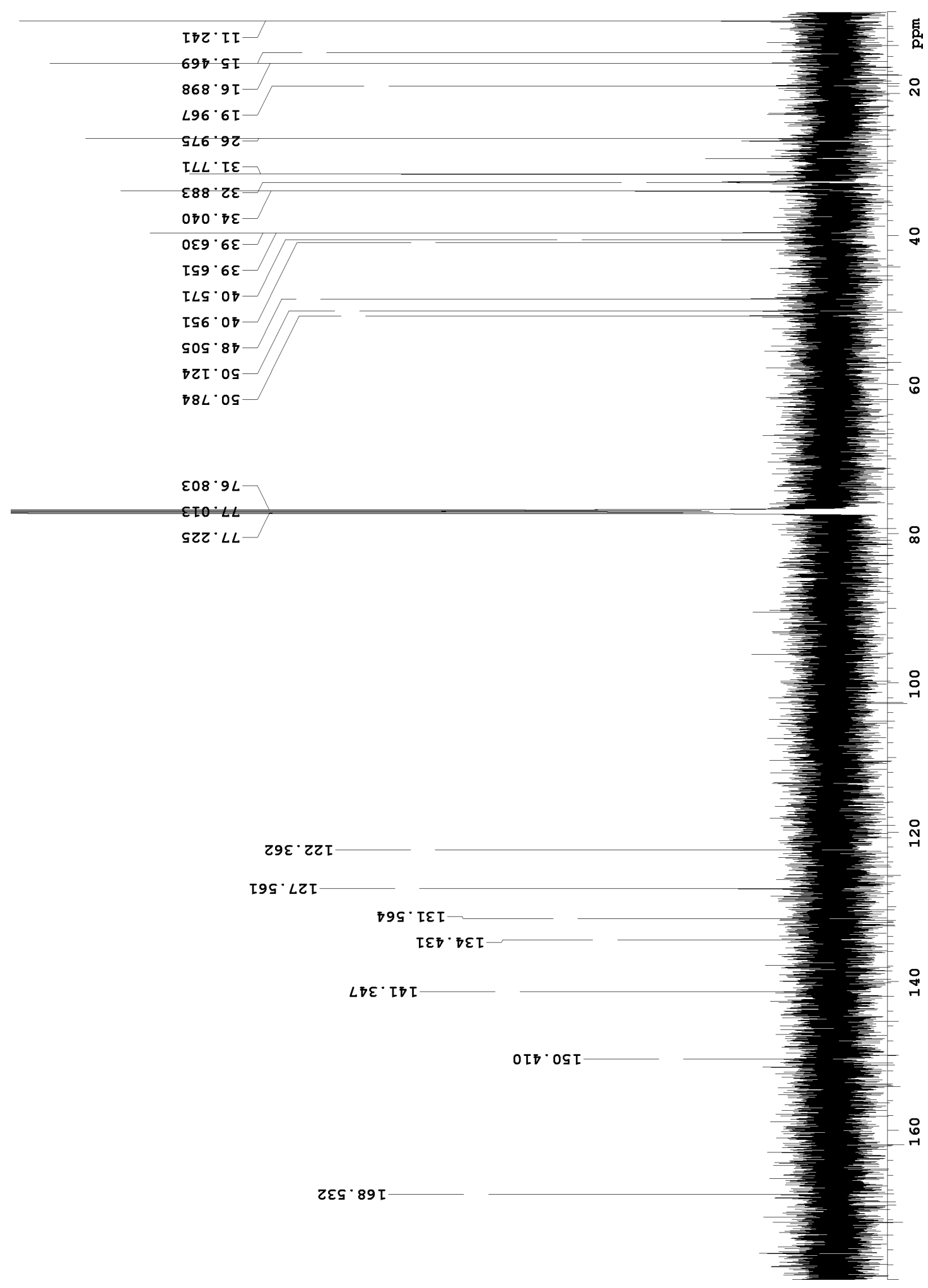

${ }^{13} \mathrm{C}$ NMR spectrum of oxeatamide $\mathrm{F}(\mathbf{2 8})\left(150 \mathrm{MHz}, \mathrm{CDCl}_{3}\right)$ 


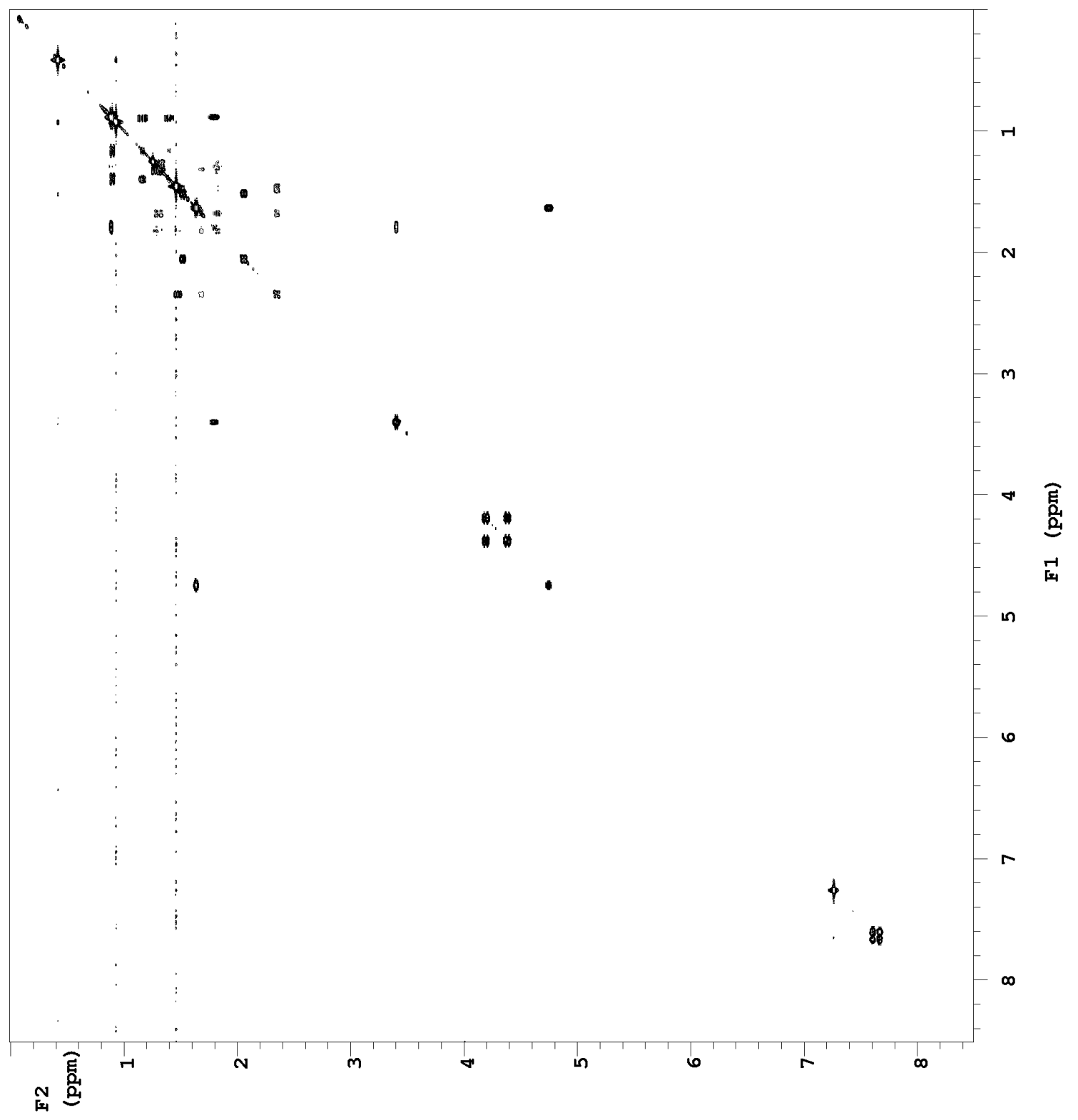

COSY NMR spectrum of oxeatamide F (28) $\left(600 \mathrm{MHz}, \mathrm{CDCl}_{3}\right)$ 


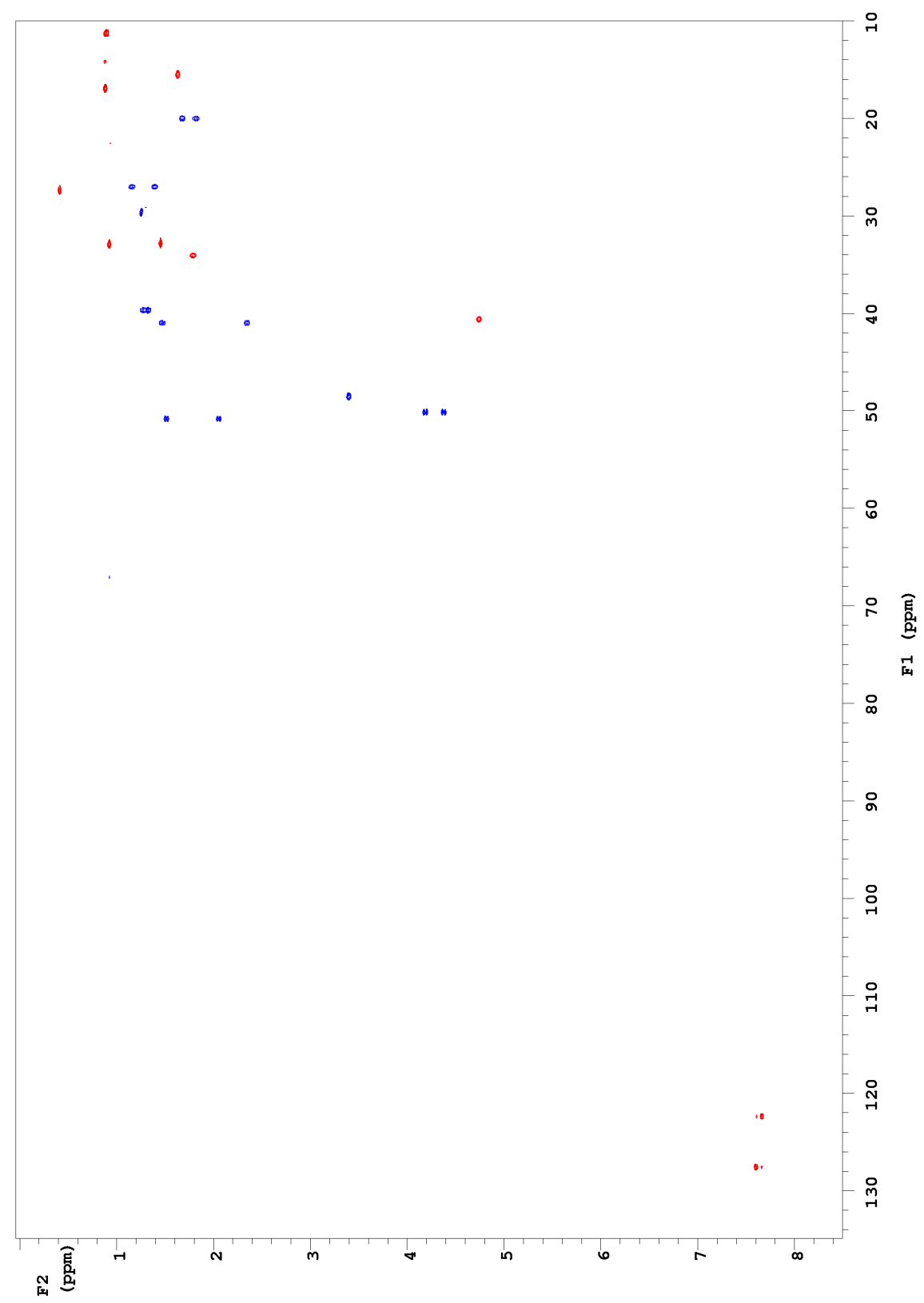

HSQC NMR spectrum of oxeatamide F (28) $\left(600 \mathrm{MHz}, \mathrm{CDCl}_{3}\right)$ 


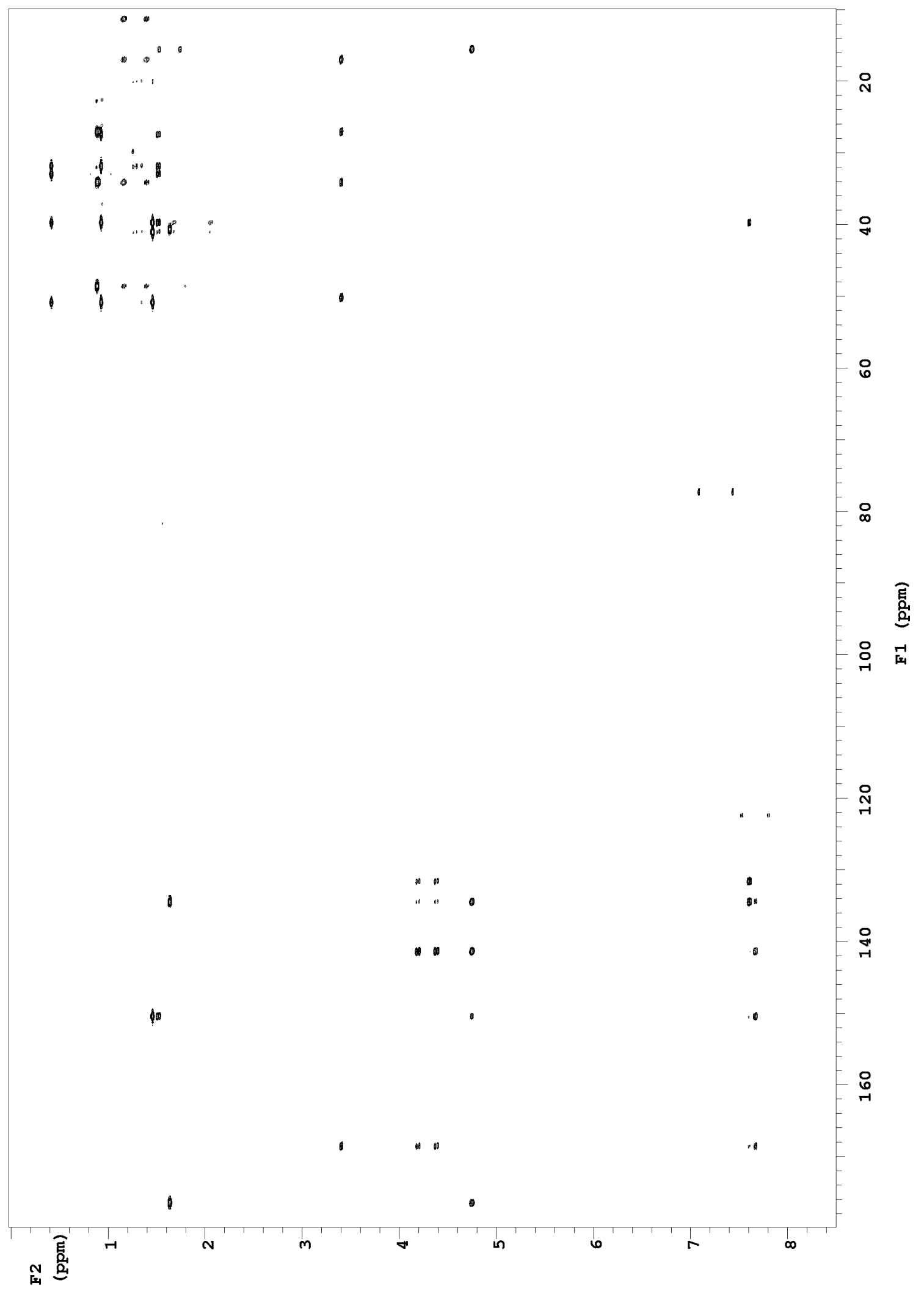

HMBC NMR spectrum of oxeatamide F (28) $\left(600 \mathrm{MHz}, \mathrm{CDCl}_{3}\right)$ 
Appendix E

\section{Oxeatamide G}

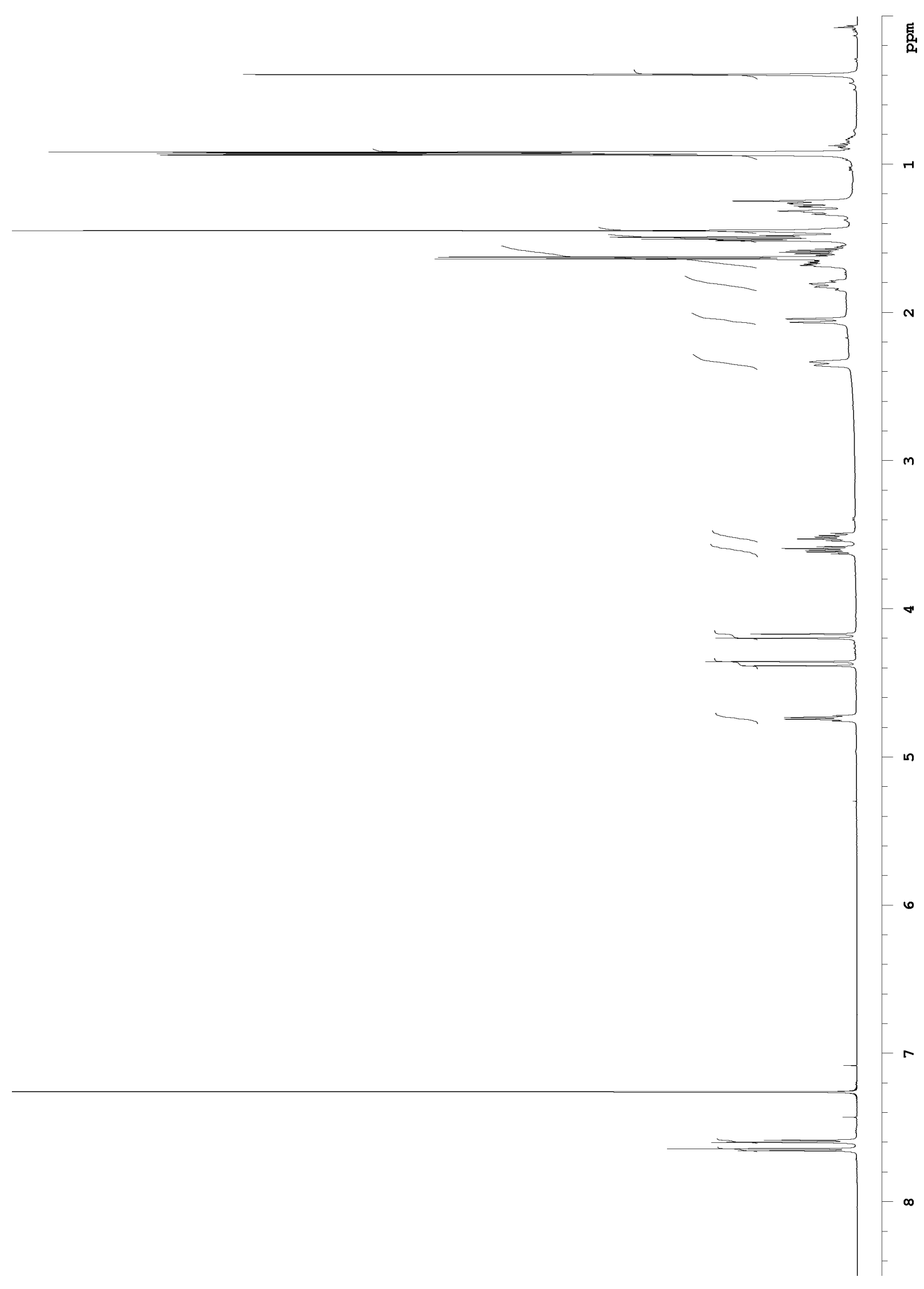

${ }^{1} \mathrm{H}$ NMR spectrum of oxeatamide G (29) $\left(600 \mathrm{MHz}, \mathrm{CDCl}_{3}\right.$ ) 


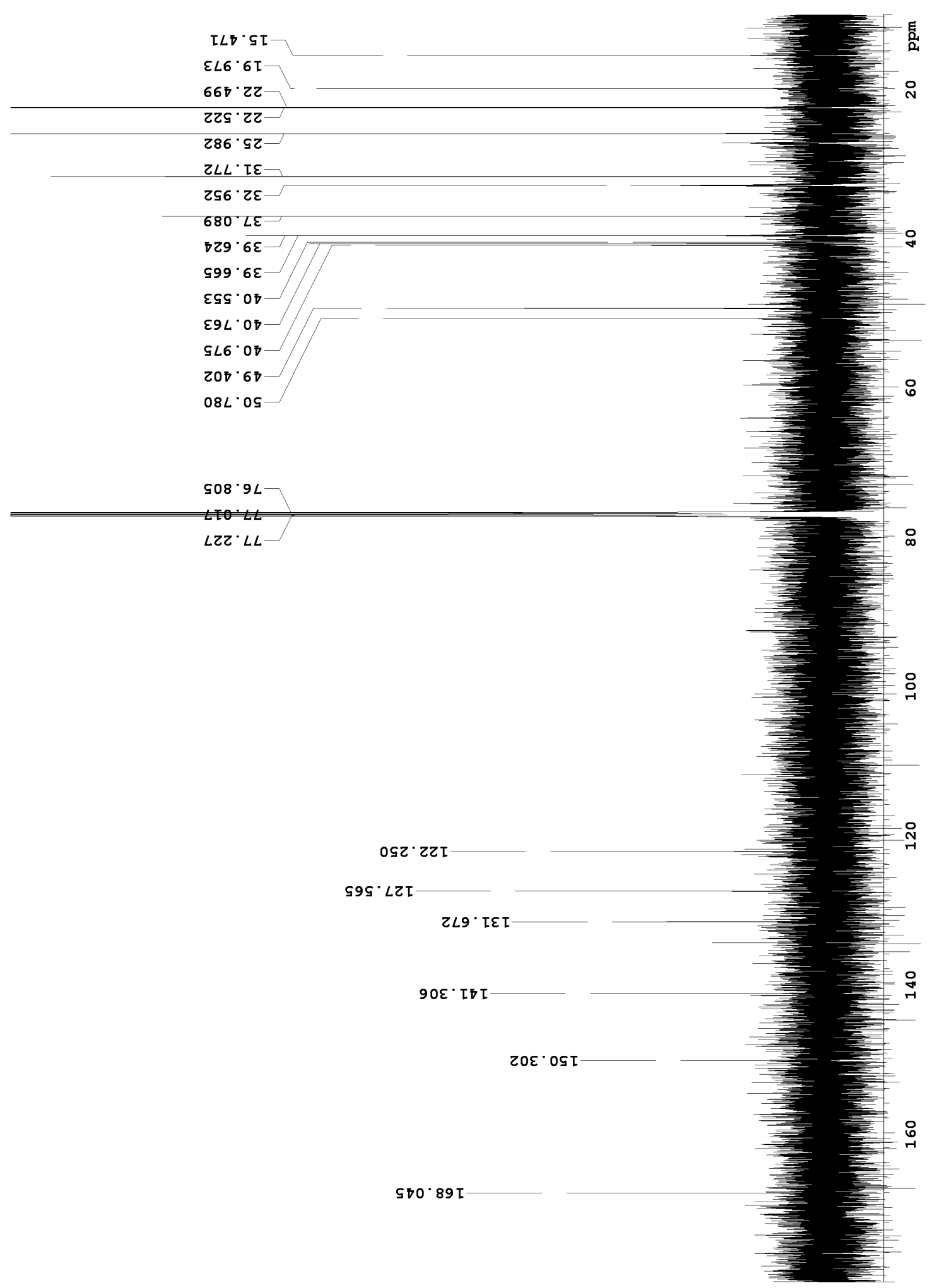

${ }^{13} \mathrm{C}$ NMR spectrum of oxeatamide $\mathrm{G}(\mathbf{2 9})\left(150 \mathrm{MHz}, \mathrm{CDCl}_{3}\right)$ 


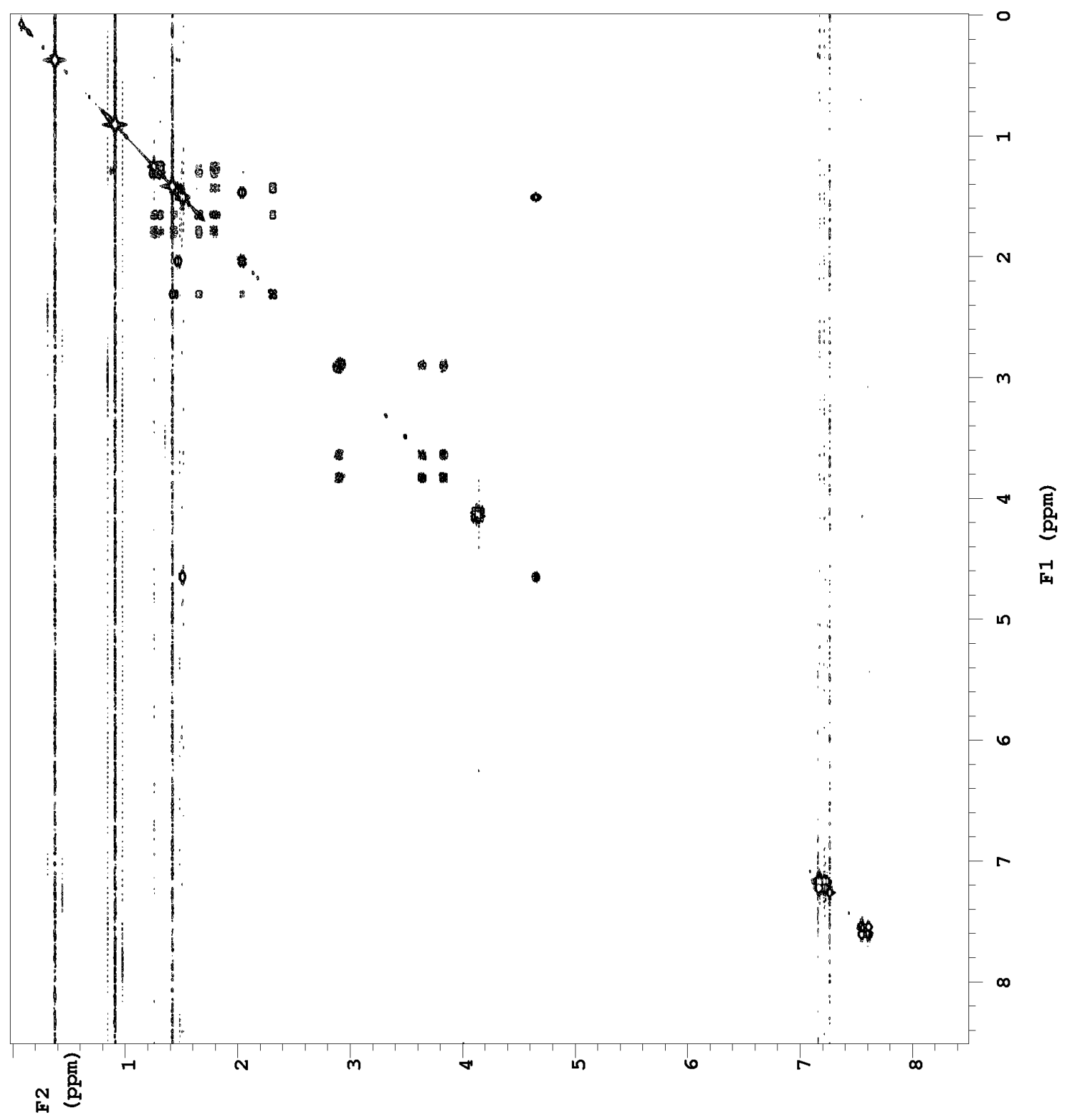

COSY NMR spectrum of oxeatamide $\mathrm{G}(29)\left(600 \mathrm{MHz}, \mathrm{CDCl}_{3}\right)$ 


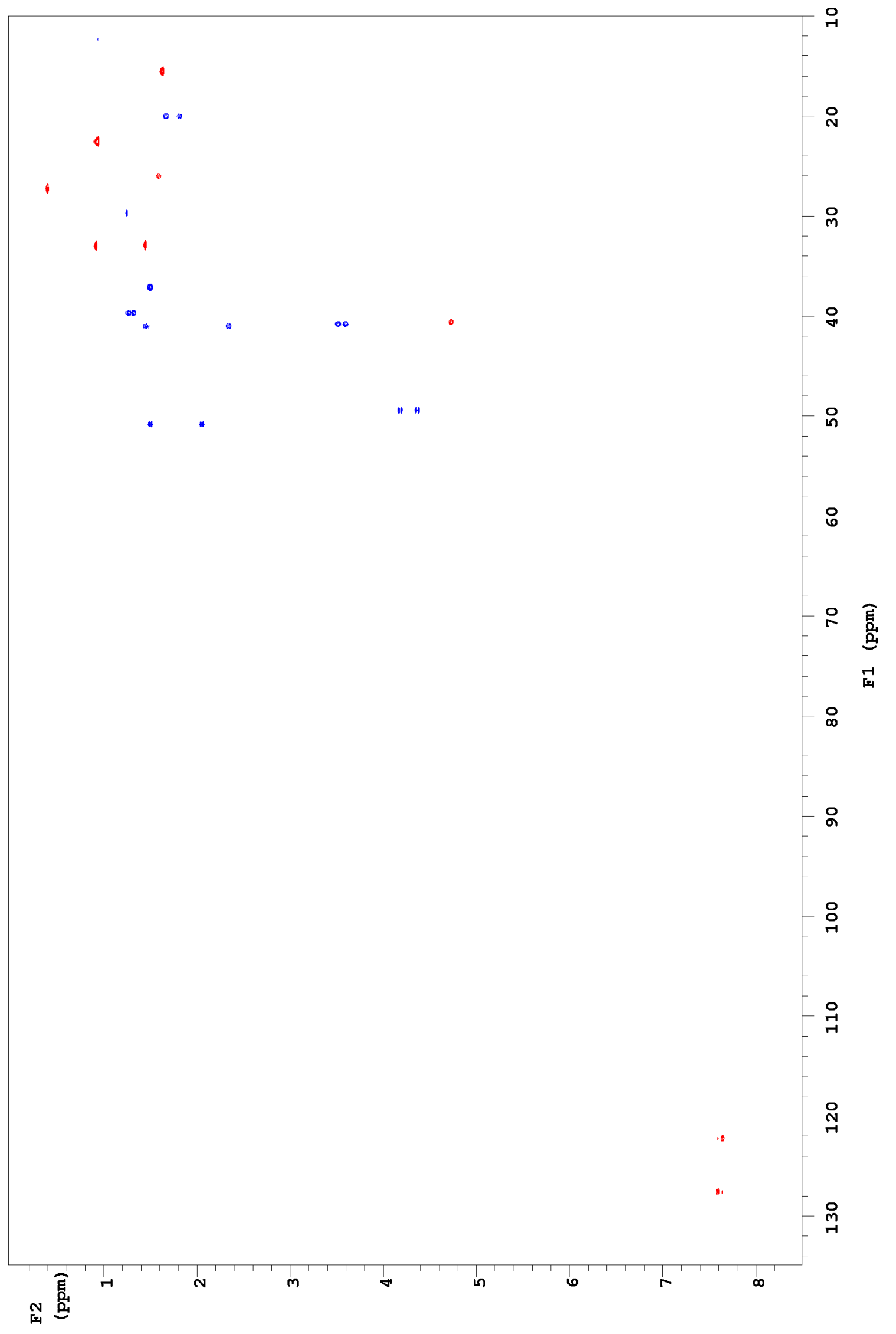

HSQC NMR spectrum of oxeatamide G (29) $\left(600 \mathrm{MHz}, \mathrm{CDCl}_{3}\right.$ ) 


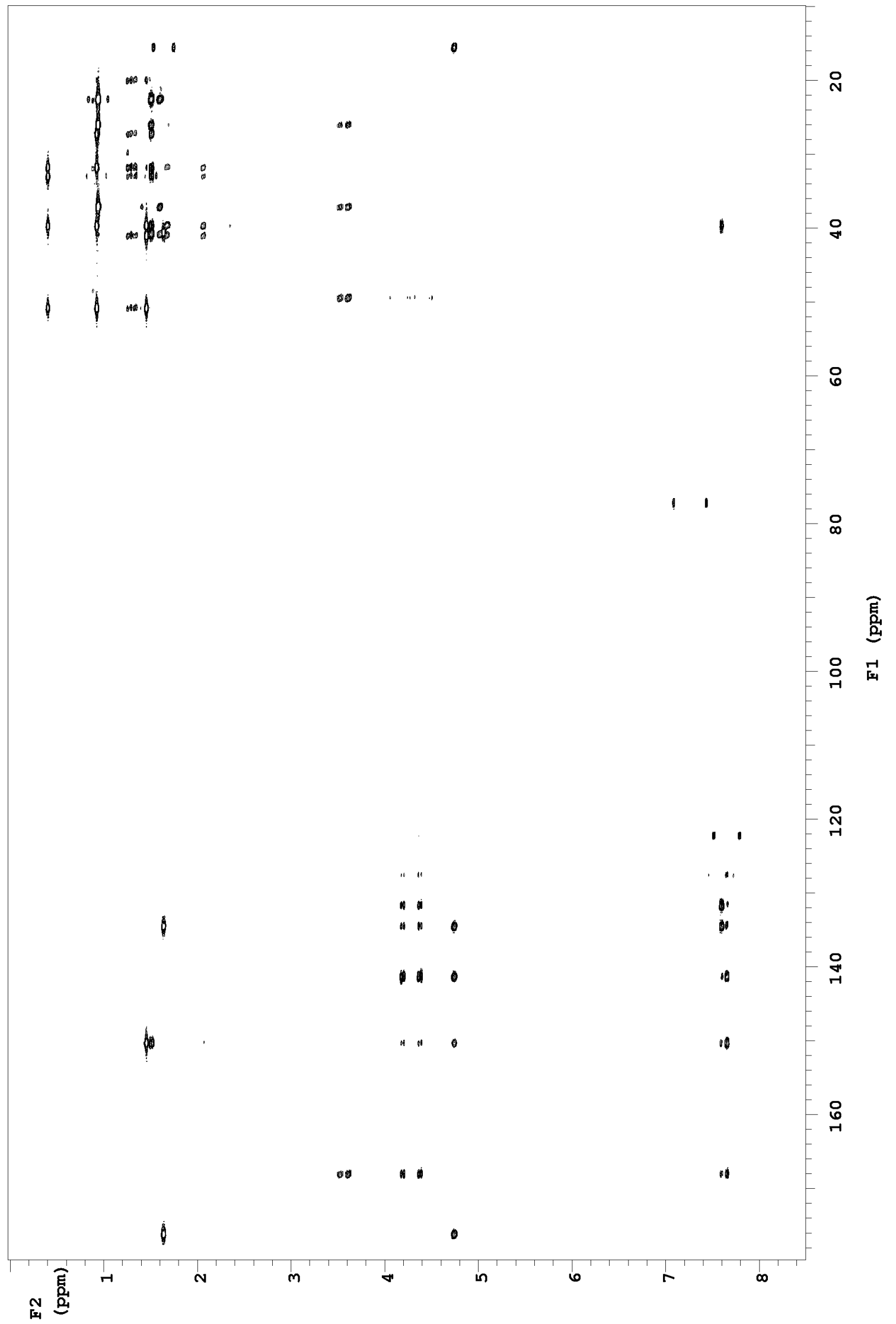

HMBC NMR spectrum of oxeatamide G (29) (600 MHz, $\mathrm{CDCl}_{3}$ ) 
Appendix F

\section{Oxeatamide C}

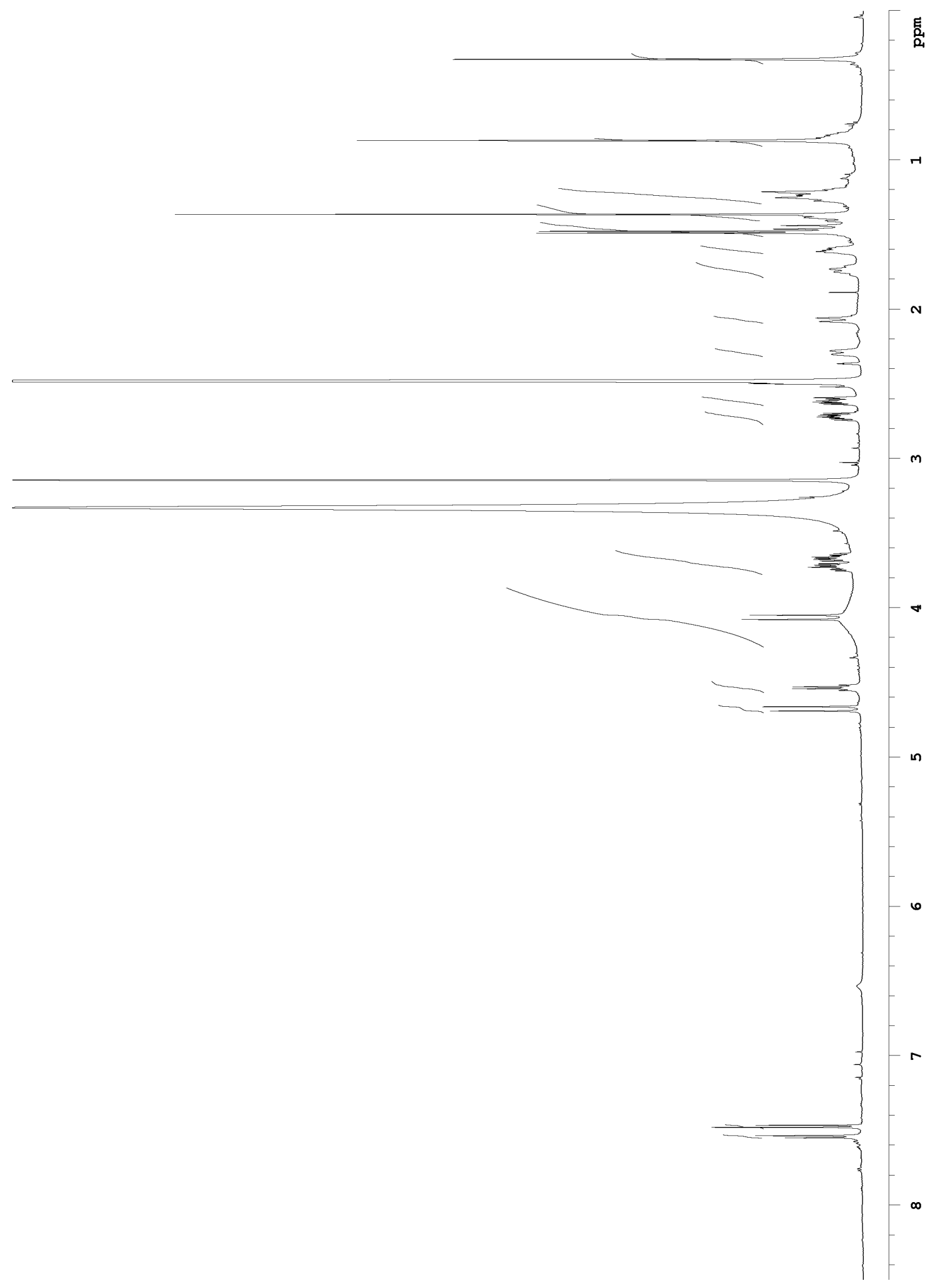

${ }^{1} \mathrm{H}$ NMR spectrum of oxeatamide C (25) $\left(600 \mathrm{MHz}, d_{6}\right.$-DMSO) 


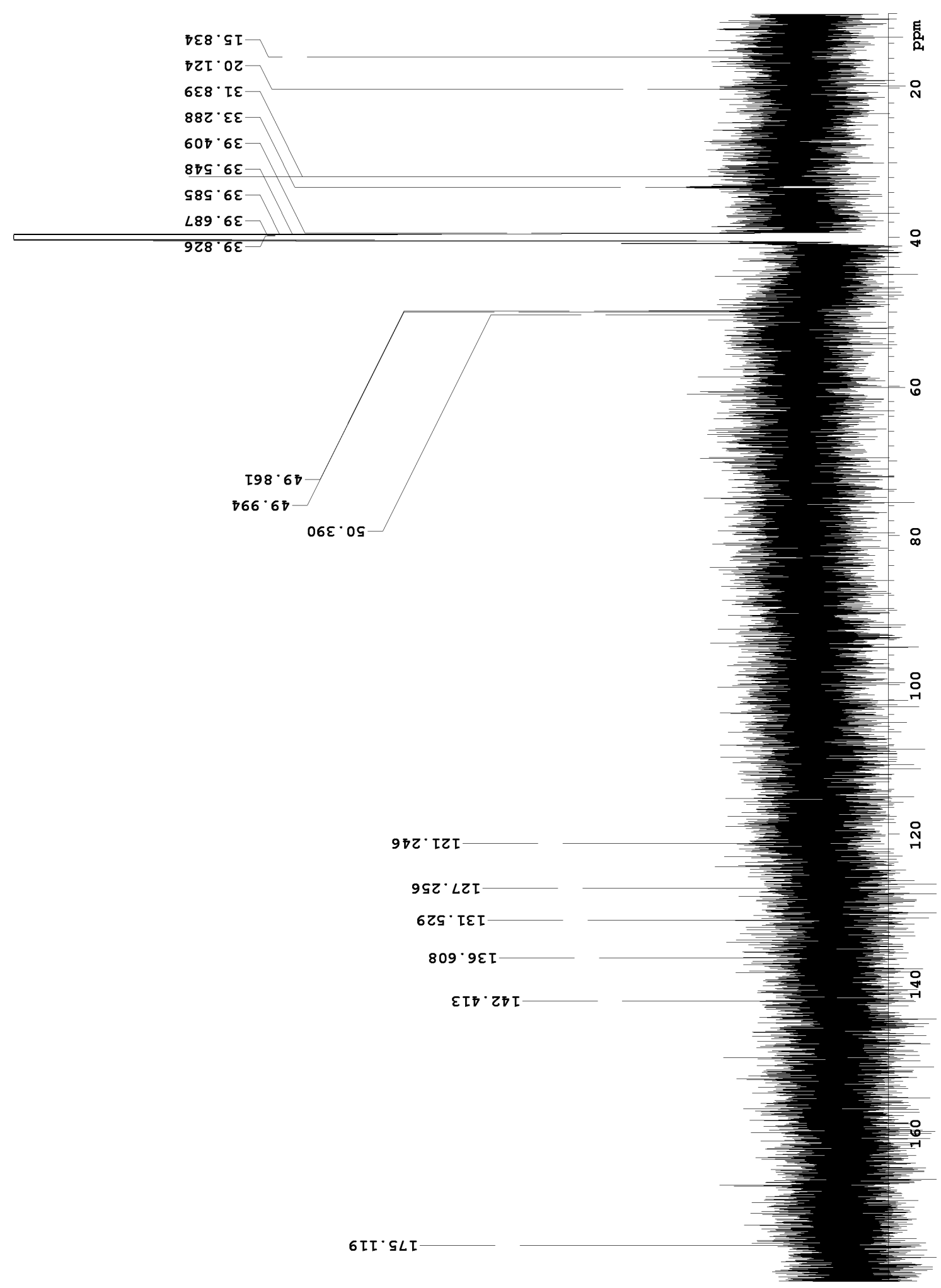

${ }^{13} \mathrm{C}$ NMR spectrum of oxeatamide $\mathrm{C}(\mathbf{2 5})\left(150 \mathrm{MHz}, d_{6}\right.$-DMSO) 


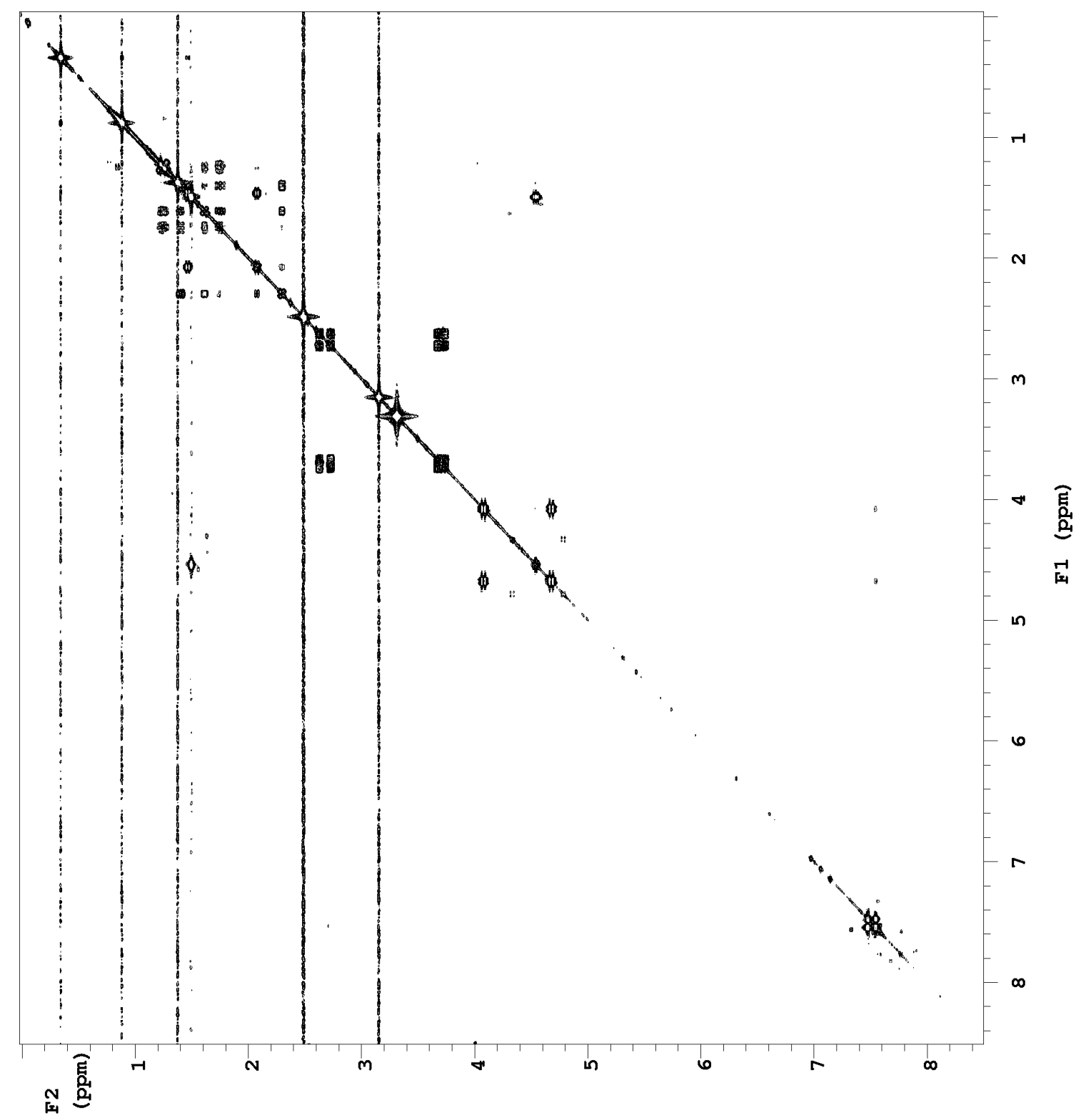

COSY NMR spectrum of oxeatamide C (25) $\left(600 \mathrm{MHz}, d_{6}\right.$-DMSO) 


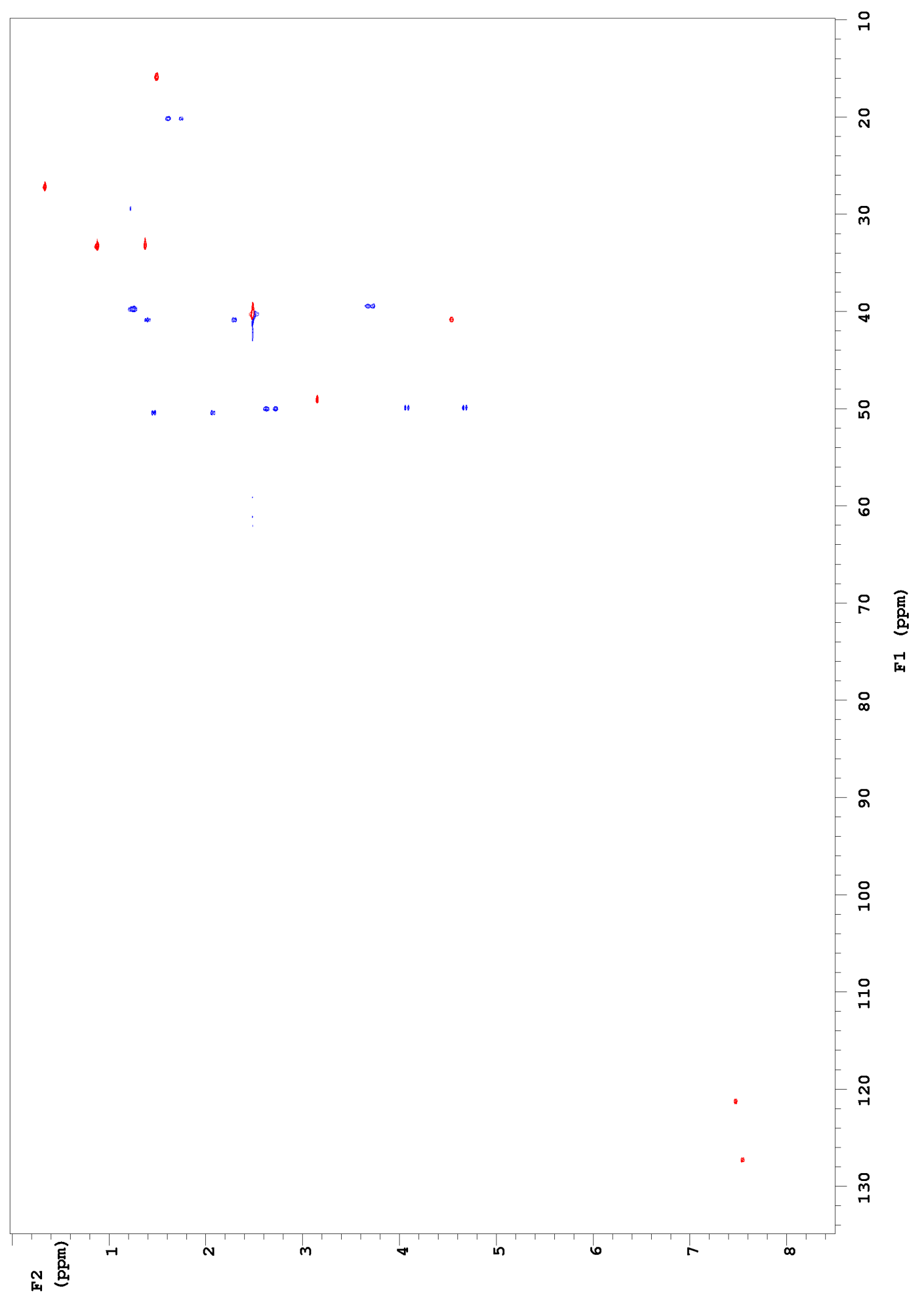

HSQC NMR spectrum of oxeatamide C (25) (600 MHz, $d_{6}$-DMSO) 


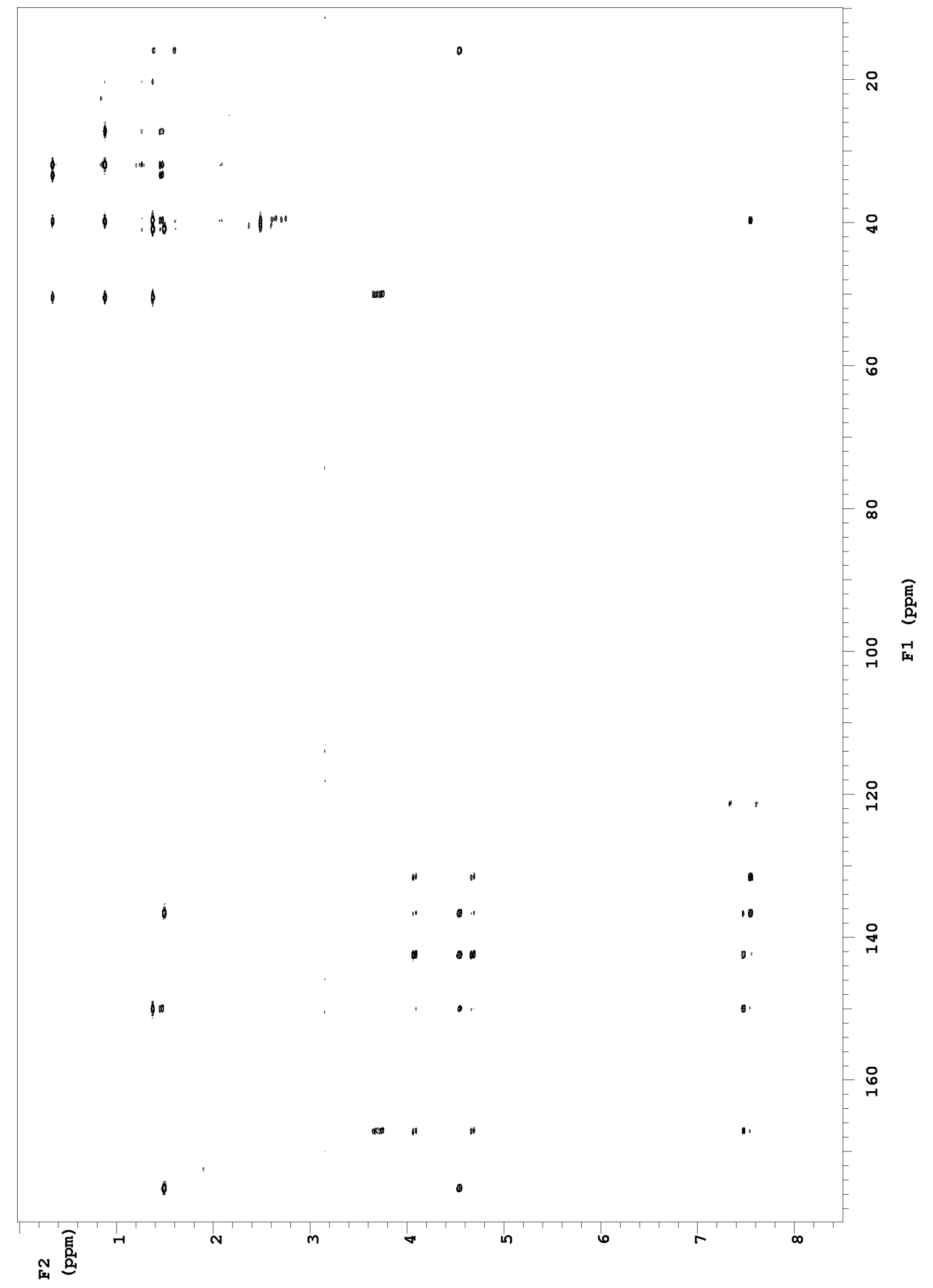

HMBC NMR spectrum of oxeatamide C (25) $\left(600 \mathrm{MHz}, d_{6}\right.$-DMSO) 


\section{References}

1. Drug Discovery from Nature; Grabley, S., Thiericke, R., Eds.; Springer- Verlag: Berlin, 1999.

2. Lambert, W. G. JNES 1989, 48, 215-221.

3. Newman, D. J.; Cragg, G. M. J. Nat. Prod. 2007, 70, 461-477.

4. Rouhi, A. M. Chem. Eng. Sci. 2003, 81, 77-91.

5. Newman, D. J.; Cragg, G. M.; Snader, K. M. J. Nat. Prod. 2003, 66, 1022-1037.

6. Feher, M.; Schmidt, J. M. J. Chem. Inf. Comput. Sci. 2003, 43, 218-227.

7. Newman, D. J.; Cragg, G. M. Curr. Med. Chem. 2004, 11, 1693-1713.

8. Jha, R. K.; Xu, Z.-R. Marine Drugs 2004, 2, 123-146.

9. Costantino, V.; Fattorusso, E.; Menna, M.; Taglialatela-Scafati, O. Curr. Med. Chem. 2004, 11, 1671-1692.

10. Bergmann, W.; Feeney, R. J. J. Org. Chem. 1951, 16, 981-987.

11. Bergmann, W.; Burke, D. C. J. Org. Chem. 1955, 20, 1501-1507.

12. Marine Biotechnology; Attaway, D. H., Zaborsky, O. R., Eds.; Plenum Press: New York, 1993; Vol. 1.

13. Scheuer, P. J. J. Nat. Prod. 1995, 58, 335-343.

14. Olivera, B. M.; Gray, W. R.; Zeikus, R.; McIntosh, J. M.; Varga, J.; Rivier, J.; de Santos, V.; Cruz, L. J. Science 1985, 230, 1338-1343.

15. Miljanich, G. P. Curr. Med. Chem. 2004, 11, 3029-3049.

16. Kijjoa, A.; Sawangwong, P. Mar. Drugs 2004, 2, 73-82.

17. Banerjee, S.; Wang, Z.; Mohammad, M.; Sarkar, F. H.; Mohammad, R. M. J. Nat. Prod. 2008, 71, 492-496.

18. Bergquist, P. R. Sponges, 1st ed.; Hutchinson \& Co.: London, 1978.

19. Systema Porifera : A guide to the classification of sponges; Hooper, J. N. A., van Soest, R. W. M., Willenz, P., Eds.; Kluwer Academic/Plenum Publishers: New York, 2002.

20. Thakur, N. L.; Mller, W. E. G. Curr. Sci. 2004, 86, 1506-1512.

21. Keyzers, R. A.; Northcote, P. T.; Davies-Coleman, M. T. Nat. Prod. Rep. 2006, 23, 321334.

22. Proksch, P. Toxicon 1994, 32, 639-655.

23. Faulkner, D. J. Nat. Prod. Rep. 2001, 18, 1-49.

24. Faulkner, D. J. Nat. Prod. Rep. 2002, 19, 1-48. 
25. Blunt, J. W.; Copp, B. R.; Munro, M. H. G.; Northcote, P. T.; Prinsep, M. R. Nat. Prod. Rep. 2003, 20, 1-48.

26. Blunt, J. W.; Copp, B. R.; Munro, M. H. G.; Northcote, P. T.; Prinsep, M. R. Nat. Prod. Rep. 2004, 21, 1-49.

27. Blunt, J. W.; Copp, B. R.; Munro, M. H. G.; Northcote, P. T.; Prinsep, M. R. Nat. Prod. Rep. 2005, 22, 15-61.

28. Blunt, J. W.; Copp, B. R.; Munro, M. H. G.; Northcote, P. T.; Prinsep, M. R. Nat. Prod. Rep. 2006, 23, 26-78.

29. Blunt, J. W.; Copp, B. R.; Hu, W. P.; Munro, M. H. G.; Northcote, P. T.; Prinsep, M. R. Nat. Prod. Rep. 2007, 24, 31-86.

30. Faulkner, J.; Unson, M. D.; Bewley, C. A. Pure Appl. Chem. 1994, 66, 1983-1990.

31. Faulkner, D. J.; Bewley, C. A. Angew. Chem. Int. Ed. 1998, 37, $2162-2178$.

32. Butler, M. S. Nat. Prod. Rep. 2005, 22, 162-195.

33. Northcote, P. T. Victoria University of Wellington, New Zealand. Personal communication, 2008.

34. West, L. M.; Northcote, P. T.; Battershill, C. N. J. Org. Chem. 2000, 65, 445-449.

35. Shining a spotlight on the biodiversity of New Zealands marine ecoregion; Arnold, A., Ed.; WWF-New Zealand: Wellington, 2004.

36. West, L. M. The Isolation of Secondary Metabolites from New Zealand Marine Sponges, Ph.D. thesis, Victoria University of Wellington, 2001.

37. Lipinski, C. A.; Lombardo, F.; Dominy, B. W.; Feeney, P. J. Adv. Drug Deliv. Rev. 1997, 23, 3-25.

38. Exarchou, V.; Krucker, M.; van Beek, T. A.; Vervoort, J.; Gerothanassis, I. P.; Albert, K. Magn. Reson. Chem. 2005, 43, 681-687.

39. Keyzers, R. A. The Isolation of Biologically Active Secondary Metabolites from New Zealand Marine Organisms, Ph.D. thesis, Victoria University of Wellington, 2003.

40. Ryan, J. M. Novel Secondary Metabolites from New Zealand Marine Sponges, Ph.D. thesis, Victoria University of Wellington, 2007.

41. Wojnar, J. M. Isolation of Novel Secondary Metabolites from New Zealand Marine Organisms, Ph.D. thesis, Victoria University of Wellington, 2008.

42. Williamson, R. T.; Chapin, E. L.; Carr, A. W.; Gilbert, J. R.; Graupner, P. R.; Lewer, P.; McKamey, P.; Carney, J. R.; Gerwick, W. H. Org. Lett. 2000, 2, 289-292.

43. Tsuda, M.; Yasuda, T.; Fukushi, E.; Kawabata, J.; Sekiguchi, M.; Fromont, J.; Kobayashi, J. Org. Lett. 2006, 8, 4235-4238.

44. Schroeder, F. C.; Gibson, D. M.; Churchill, A. C. L.; Sojikul, P.; Wursthorn, E. J.; Krasnoff, S. B.; Clardy, J. Angew. Chem. Int. Ed. 2007, 119, 919-922. 
45. Moraes, G. The Isolation and Structure Elucidation of Novel, Anti-inflammatory Secondary Metabolites from New Zealand Marine Invertebrates, Ph.D. thesis, Victoria University of Wellington, 2006.

46. Dowle, K. The Investigation of New and Known Secondary Metabolites from the New Zealand Marine Sponge Raspailia topsenti, Honours project, Victoria University of Wellington, 2006.

47. Bergquist, P. R. The marine fauna of New Zealand: Porifera: Demospongiae: Part 5. Dendroceratida and Halisarcida; National Institute of Water and Atmospheric Research: Wellington, 1996.

48. Karuso, P.; Skelton, B. W.; Taylor, W. C.; White, A. H. Aust. J. Chem. 1984, 37, 1081-1093.

49. Karuso, P.; Bergquist, P. R.; Cambie, R. C.; Buckleton, J. S.; Clark, G. R.; Rickard, C. E. F. Aust. J. Chem. 1986, 49, 1643-1653.

50. Karuso, P.; Bergquist, P. R.; Buckleton, J. S.; Cambie, R. C.; Clark, G. R.; Rickard, C. E. F. Tetrahedron Lett. 1986, 27, 2177-2178.

51. Diaz-Marrero, A. R.; Dorta, E.; Cueto, M.; San-Martn, A.; Dariasa, J. Tetrahedron 2004, 60, 10731078.

52. Ankisetty, S.; Amsler, C. D.; McClintock, J. B.; Baker, B. J. J. Nat. Prod. 2004, 67, 1172-1174.

53. Silverstein, R. M.; Webster, F. X. Spectrometric Identification of Organic Compounds, 6th ed.; John Wiley \& Sons, Inc., 1998.

54. Jones, M. Organic Chemistry; W. W. Norton \& Company, Inc.: New York, 2000.

55. Molinski, T. F.; Faulkner, D. J. J. Org. Chem. 1987, 52, 296-298.

56. Chan, A. Victoria University of Wellington, New Zealand. Personal communication, 2007.

57. Keyzers, R. A.; Northcote, P. T.; Zubkov, O. A. Eur. J. Org. Chem. 2004, 419-425.

58. Tischler, M.; Andersen, R. J.; Choudhary, M. I.; Clardy, J. J. Org. Chem. 1991, 56, $42-47$.

59. Garson, M. J.; Simpson, J. S. Nat. Prod. Rep. 2004, 21, 164-179.

60. Liu, Y.; Mansoor, T. A.; Hong, J.; Lee, C.-O.; Sim, C. J.; Im, K. S.; Kim, N. D.; Jung, J. H. J. Nat. Prod. 2003, 66, 1415-1456.

61. Cafieri, F.; de Napoli, L.; Fattorusso, E.; Santacroce, C.; Sica, D. Tetrahedron Lett. 1977, 5, 477-480.

62. Cafieri, F.; de Napoli, L.; Fattorusso, E.; Santacroce, C. Experientia 1977, 33, 994995.

63. Cafieri, F.; de Napoli, L.; Iengo, A.; Santacroce, C. Experientia 1978, 34, 300-301.

64. Cafieri, F.; de Napoli, L.; Iengo, A.; Santacroce, C. Experientia 1979, 35, 157-158. 
65. Voet, D.; Voet, J. G. Biochemistry, 3rd ed.; John Wiley \& sons: New York, 2004; Vol. 1.

66. Shin, J.; Rho, J.-R.; Seo, Y.; Lee, H.-S.; Cho, K. W.; Sim, C. J. Tetrahedron Lett. 2001, 42, 3005-3007.

67. Liu, Y.; Hong, J.; Lee, C.-O.; Im, K. S.; Kim, N. D.; Choi, J. S.; Jung, J. H. J. Nat. Prod. 2002, 65, 1307-1314.

68. Pham, A. T.; Carney, J. R.; Yoshida, W. Y.; Scheuer, P. J. Tetrahedron Lett. 1992, 33, 1147-1148.

69. Mori, D.; Kimura, Y.; Kitamura, S.; Sakagami, Y.; Yoshioka, Y.; Shintani, T.; Okamoto, T.; Ojika, M. J. Org. Chem. 2007, 72, 7190-7198.

70. El Sayed, K. A.; Mayer, A. M. S.; Kelly, M.; Hamann, M. T. J. Org. Chem. 1999, 64, 9258-9260.

71. Kazlauskas, R.; Murphy, P. T.; Wells, R. J.; Daly, J. J.; Schonholzer, P. Tetrahedron Lett. 1978, 49, 4951-4954.

72. Cimino, G.; de Stefano, S.; Minale, L. Experientia 1975, 30, 846-847.

73. Gottlieb, H. E.; Kotlyar, V.; Nudelman, A. J. Org. Chem. 1997, 62, 7512-7515. 


\begin{abstract}
During the course of this research five New Zealand marine sponges were investigated. Detailed examination of one of the species, Darwinella oxeata, has resulted in the isolation of ten compounds whose structures were elucidated using a variety of spectroscopic techniques and a simple derivatisation reaction. These compounds were identified as rearranged spongian diterpenes with the aplysulphurane backbone. Five of these compounds have been previously reported, though two of them were originally isolated from another marine sponge, Dendrilla membranosa. The five new compounds, oxeatamides $\mathrm{C}$ to $\mathrm{G}(\mathbf{2 5 - 2 9})$, were found to have the same diterpene portion as the oxeatamides already isolated from this sponge. They do, however, differ in the $\gamma$-lactam side chain, which is proposed to be of amino acid origin. The new oxeatamides showed moderate levels of cytotoxicity against the HL-60 cell line in MTT assays.
\end{abstract}<smiles>C[C@H](C(=O)O)c1c([C@@]2(C)CCCC(C)(C)C2)ccc2c1CN(CCN)C2=O</smiles>

25<smiles>CC(C)CN1Cc2c(ccc([C@@]3(C)CCCC(C)(C)C3)c2[C@H](C)C(=O)O)C1=O</smiles>

26<smiles>C[C@H](C(=O)O)c1c(C2(C)CCCC(C)(C)C2)ccc2c1CN(CCc1ccccc1)C2=O</smiles>

27<smiles>CCC(C)CN1Cc2c(ccc([C@]3(C)CCCC(C)(C)C3)c2[C@H](C)C(=O)O)C1=O</smiles>

28<smiles>CC(C)CCN1Cc2c(ccc([C@]3(C)CCCC(C)(C)C3)c2[C@H](C)C(=O)O)C1=O</smiles>

29 